\title{
Codificação e compressão iterativa de sinais biomédicos
}

\author{
Luiz Fernando Oliveira Corte Real
}

\author{
DisSERTAÇÃo APRESENTADA \\ $\mathrm{AO}$ \\ Instituto De MATEMÁtica E EstatísticA \\ DA \\ Universidade De SÃo PaUlo \\ PARA \\ OBTENÇÃO DO TÍTULO \\ $\mathrm{DE}$ \\ Mestre EM CiÊnCIAS \\ Programa: Ciência da Computação \\ Orientador: Prof. Dr. Marcel Parolin Jackowski
}

São Paulo, abril de 2013 


\section{Codificação e compressão iterativa de sinais biomédicos}

Esta versão da dissertação/tese contém as correções e alterações sugeridas pela Comissão Julgadora durante a defesa da versão original do trabalho, realizada em 08/03/2013. Uma cópia da versão original está disponível no Instituto de Matemática e Estatística da Universidade de São Paulo.

Comissão Julgadora:

- Prof. Dr. Marcel Parolin Jackowski (orientador) - IME-USP

- Prof. Dr. Marco Antonio Gutierrez - FMUSP

- Prof. Dr. Roberto Hirata Júnior - IME-USP 


\section{Agradecimentos}

Em primeiro lugar, agradeço a Deus pela oportunidade de chegar até aqui.

Agradeço aos meus pais pelo grande apoio aos meus estudos desde pequeno e pela educação que me deram. É graças a ela que este trabalho ficou pronto.

Agradeço imensamente ao meu orientador pela amizade, pela paciência e pelos conselhos desde a iniciação científica.

Por fim, não poderia deixar de agradecer aos meus amigos pela força, pelos momentos de descontração e pela ajuda, com ideias e com revisão. 


\section{Resumo}

REAL, L. F. O. C. Codificação e compressão iterativa de sinais biomédicos. 2013. 103 f. Dissertação (Mestrado) - Instituto de Matemática e Estatística, Universidade de São Paulo, São Paulo, 2013.

Em Biomedicina, a deteç̧ão e a quantificação de anormalidades presentes num sinal são desejáveis. Uma estratégia de codificação baseada em extração de características, tais como picos ou frequências, pode não capturar todas as irregularidades. Assim, uma representação baseada em funções de base definidas com conhecimento a priori do sinal pode ser mais precisa para aplicações biomédicas.

A escolha das funções base depende da natureza fisiológica do sinal e de suas peculiaridades. Sinais de eletrocardiograma (ECG) e eletroencefalograma (EEG) exibem características bem definidas. ECG, por exemplo, é um sinal elétrico composto de uma forma de onda específica (P, QRS e T). Se as características de um sinal a ser sintetizado são bem compreendidas, é possível derivar uma assinatura para o sinal. Uma codificação apropriada permite a extração de parâmetros relevantes para sua análise, tais como anormalidades num ciclo cardíaco representadas por uma alteração no sinal de ECG, ou então uma excitação das ondas cerebrais representada por uma modificação no sinal de EEG.

O objetivo deste projeto é introduzir uma nova técnica de codificação de sinais, que representa um sinal pela soma de funções sigmoides para aproximar iterativamente o sinal medido, com foco em aplicações biomédicas. Funções sigmoides tendem a reproduzir bem as grandes variações presentes em sinais biomédicos, daí a escolha de usá-las na codificação deste tipo de sinal. Serão explorados o nível de compressão dos dados, bem como a taxa de convergência. A técnica desenvolvida será comparada com técnicas convencionais de codificação e sua robustez será avaliada.

Uma estratégia de codificação ótima pode trazer benefícios não só para a compressão, mas também na criação de assinaturas de sinais representando tanto condições fisiológicas normais como patológicas.

Palavras-chave: Codificação de Sinais, Classificação de Sinais, Processamento de Sinais, Compressão, Sinais Biomédicos, ECG, EEG 


\section{Abstract}

REAL, L. F. O. C. R. Iterative encoding and compression of biomedical signals. 2013. 103 f. Dissertação (Mestrado) - Instituto de Matemática e Estatística, Universidade de São Paulo, São Paulo, 2013.

In Biomedicine, detection and quantification of abnormalities present in a signal are desired. An encoding strategy based on feature extraction, such as peaks or frequencies, may not capture all irregularities. Thus, a function-based representation, constructed using a priori knowledge of signal characteristics, may be more accurate for biomedical applications.

The choice of the basis function depends on the physiological nature of the signal and its specific features. Electrocardiogram (ECG) and electroencephalogram (EEG) signals exhibit well-defined characteristics. ECG, for instance, is an electrical signal composed of specific waveform (P, QRS, and $\mathrm{T}$ ). If the characteristics of a signal to be synthesized are well understood, it's possible to derive a signal signature. An appropriate encoding allows the extraction of parameters relevant for its analysis, such as, abnormalities in a cardiac cycle represented by an alteration in the ECG signal, or an excitation of the brain waves represented by a modification of the EEG.

The objective of this project is to introduce a novel signal encoding technique that represents a signal by a sum of sigmoidal functions to iteratively approximate the measured signal, targeted at biomedical applications. Sigmoidal functions tend to reproduce well large variations in biomedical signals, hence their use for coding this type of signal. We explore the data compression level as well as the convergence rate. We also compare it to conventional encoding techniques and assess the robustness of this model.

An optimal encoding strategy may bring not only benefits in compression, but also in the creation of signatures for signals representing both physiological and pathological conditions.

Keywords: Signal Encoding, Signal Classification, Signal Processing, Compression, Biomedical Signals, ECG, EEG 


\section{Sumário}

$\begin{array}{ll}\text { Lista de Abreviaturas } & \text { ix }\end{array}$

Lista de Figuras $\quad$ xi

1 Introdução $\quad 1$

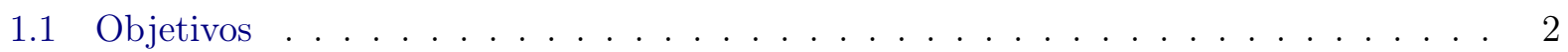

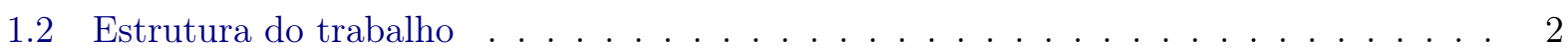

2 Trabalhos relacionados $\quad 3$

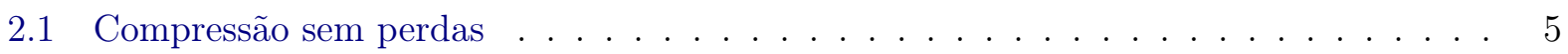

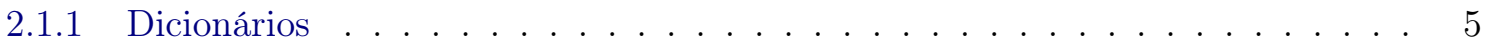

2.1 .2 Codificação run-length . . . . . . . . . . . . . . . . . . . . 6

2.1 .3 Codificação diferencial . . . . . . . . . . . . . . . . . . . . 6

2.2 Compressão com perdas . . . . . . . . . . . . . . . . . . . . . . 6

2.2 .1 Quantização . . . . . . . . . . . . . . . . . . . 6

2.2.2 Compressão por transformadas . . . . . . . . . . . . . . . . . . . 7

2.3 Técnicas para sinais específicos . . . . . . . . . . . . . . . . . . 13

2.3 .1 Compressão direta . . . . . . . . . . . . . . . . . . . . . . . 13

2.3.2 Compressão por transformadas . . . . . . . . . . . . . . . . . . 16

2.3.3 Compressão por extração de parâmetros . . . . . . . . . . . . . . . . . . . 17

2.4 Resumo . . . . . . . . . . . . . . . . . . . . . . . . . . . 19

3 Metodologia desenvolvida $\quad 21$

3.1 Uma primeira abordagem . . . . . . . . . . . . . . . . . . . . . . . . 21

3.1 .1 Algoritmos . . . . . . . . . . . . . . . . . . . 24

3.2 Otimização para compressão . . . . . . . . . . . . . . . . . . . . . 27

3.2 .1 Armazenamento . . . . . . . . . . . . . . . . . . . 28

3.2 .2 Algoritmos . . . . . . . . . . . . . . . . . . . . . . . 32

3.3 Implementação . . . . . . . . . . . . . . . . . . . . . . . . . . . 33

3.4 Aplicação para imagens . . . . . . . . . . . . . . . . . . . . . . . 34

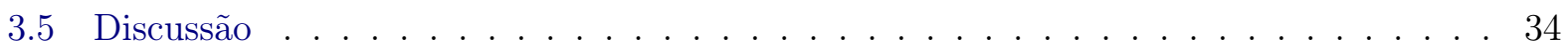

3.6 Avaliação . . . . . . . . . . . . . . . . . . . . . . . . . . 35

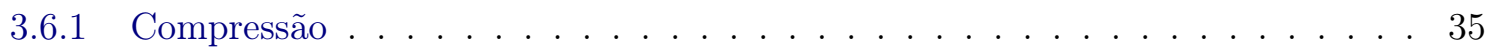

3.6 .2 Análise . . . . . . . . . . . . . . . . . . . . . . 40

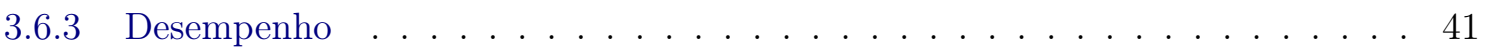


viii SUMÁRIO

4 Resultados $\quad 43$

4.1 Compressão . . . . . . . . . . . . . . . . . . . . . . . . . 43

4.2 Qualidade do sinal comprimido . . . . . . . . . . . . . . . . . 43

4.3 Imagens . . . . . . . . . . . . . . . . . . . . . . . 59

4.4 Análise . . . . . . . . . . . . . . . . . . . . . . . 75

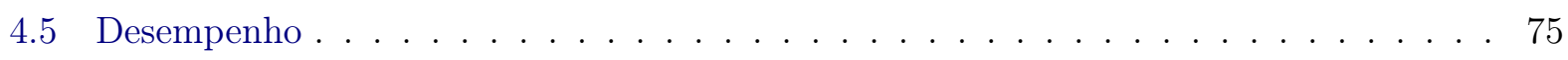

4.6 Comentários . . . . . . . . . . . . . . . . . . . . . . . . 75

5 Conclusão $\quad 83$

$\begin{array}{ll}\text { Referências Bibliográficas } & 85\end{array}$ 


\title{
Lista de Abreviaturas
}

\author{
CR Taxa de compressão (do inglês compression ratio) \\ CT Tomografia computadorizada (do inglês Computed Tomography) \\ DCT Transformada discreta de cossenos (do inglês Discrete Cosine Transform) \\ DPCM Codificação diferencial da modulação por código de pulsos (do inglês Differential \\ pulse-code modulation) \\ ECG Eletrocardiograma \\ EEG Eletroencefalograma \\ EMG Eletromiografia \\ FFT Transformada rápida de Fourier (do inglês Fast Fourier Transform) \\ PET Tomografia por emissão de pósitrons (do inglês Positron Emission Tomography) \\ SNR Razão sinal-ruído (do inglês Signal-to-Noise Ratio)
}




\section{Lista de Figuras}

2.1 Onda triangular e redundância $\ldots \ldots \ldots \ldots \ldots \ldots$

2.2 Exemplo de imagem PGM . . . . . . . . . . . . . . . . . . . . . 4

2.3 Sinal típico de ECG . . . . . . . . . . . . . . . . . . . . . 13

2.4 Sinal de ECG e o resultado de sua compressão pelo algoritmo AZTEC. . . . . . . . . 15

2.5 Compressão de um sinal de ECG com wavelets . . . . . . . . . . . . . . . . 17

3.1 Aproximação de um sinal de ECG por sessenta sigmoides . . . . . . . . . . . . . . 22

3.2 Explicação visual da tolerância a erros . . . . . . . . . . . . . . . . . . . . . . . 24

3.3 Com a alteração proposta, cada segmento monotônico da primeira iteração passa a ser processado independentemente na segunda iteração. . . . . . . . . . . . . . . . 29

3.4 Sinal de exemplo para codificação . . . . . . . . . . . . . . . . . . . . 30

3.5 Pontos selecionados na primeira iteração por ambos os algoritmos para o sinal da

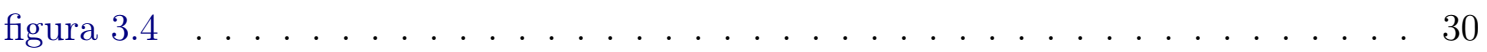

3.6 Pontos selecionados na segunda iteração por ambos os algoritmos para o sinal da

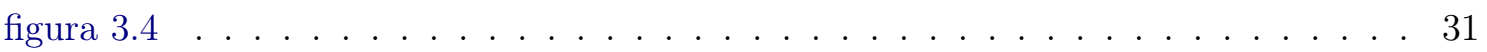

3.7 Codificação do número da iteração de um ponto em diferentes números de bits . . . . 32

3.8 Linearizações utilizadas para codificar imagens . . . . . . . . . . . . . . . . . 34

3.9 Alguns dos sinais utilizados para testar os algoritmos estudados . . . . . . . . . . 38

3.10 Imagens utilizadas nos testes comparativos de desempenho em compressão. . . . . . 39

3.11 Uma das imagens utilizadas na avaliação da assinatura gerada pela metodologia desenvolvida e as respectivas regiões selecionadas. . . . . . . . . . . . . . . . . 40

4.1 Aplicação da primeira metodologia descrita para o sinal de variação de pressão . . . 44

4.2 Aplicação da primeira metodologia descrita para o sinal de variação de fluxo sanguíneo 45

4.3 Aplicação da primeira metodologia descrita para o sinal de variação de diâmetro

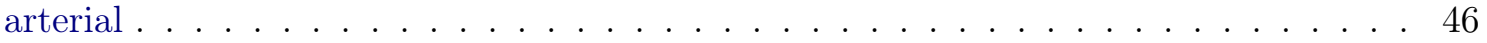

4.4 Aplicação da primeira metodologia descrita para o sinal de ECG . . . . . . . . . . . 47

4.5 Aplicação da segunda metodologia descrita para o sinal de variação de pressão . . . . 48

4.6 Aplicação da segunda metodologia descrita para o sinal de variação de fluxo sanguíneo 49

4.7 Aplicação da segunda metodologia descrita para o sinal de variação de diâmetro arterial 50

4.8 Aplicação da segunda metodologia descrita para o sinal de ECG . . . . . . . . . . . . 51

4.9 Evolução dos tamanhos finais e do SNR dos arquivos dos sinais de 256 amostras comprimidos com uma, duas e três iterações por ambas as metodologias descritas. . . 52

4.10 Boxplots das razões de compressão das técnicas estudadas para os sinais com mais de 256 amostras. . . . . . . . . . . . . . . . . . . . . . 52 
4.11 Boxplots das razões de compressão das técnicas estudadas para os sinais com mais de 256 amostras, discriminando a natureza dos sinais. . . . . . . . . . . . . . . . . . 54

4.12 Comparativo das codificações para o sinal de variação de pressão com uma iteração . 55

4.13 Comparativo das codificações para o sinal de variação de fluxo sanguíneo com uma iteração . . . . . . . . . . . . . . . . . . . . . . . . . . 56

4.14 Comparativo das codificações para o sinal de variação de diâmetro arterial com uma iteração . . . . . . . . . . . . . . . . . . . . . . . . . . . 57

4.15 Comparativo das codificações para o sinal de ECG com uma iteração . . . . . . . . . 58

4.16 Boxplot das razões sinal-ruído para a codificação dos sinais de ECG descritos na seção 3.6 usando as técnicas estudadas. . . . . . . . . . . . . . . . . . . . . . . . . . 59

4.17 Boxplot das razões sinal-ruído para a codificação dos sinais de pressão venosa central descritos na seção 3.6 usando as técnicas estudadas. . . . . . . . . . . . . . . . . . . . 60

4.18 Boxplot das razões sinal-ruído para a codificação dos sinais de pressão intraesofágica descritos na seção 3.6 usando as técnicas estudadas. . . . . . . . . . . . . . . . . . . . 60

4.19 Boxplot das razões sinal-ruído para a codificação dos sinais de pressão de via aérea descritos na seção 3.6 usando as técnicas estudadas. . . . . . . . . . . . . . . . . . . . 61

4.20 Boxplot das razões sinal-ruído para a codificação dos sinais de pressão arterial de um suíno descritos na seção 3.6 usando as técnicas estudadas.

4.21 Boxplot das razões sinal-ruído para a codificação dos sinais de fluxo de sangue na artéria de um suíno descritos na seção 3.6 usando as técnicas estudadas.

4.22 Boxplot das razões sinal-ruído para a codificação dos sinais de variação de diâmetro da artéria de um suíno descritos na seção 3.6 usando as técnicas estudadas.

4.23 Comparativo entre razão de compressão e razão sinal-ruído para as técnicas de compressão com perdas estudadas . . . . . . . . . . . . . . . . . . . . . . . 6

4.24 Codificação de uma imagem de RM com a segunda metodologia descrita usando a ordenação de pixels em espiral . . . . . . . . . . . . . . . . . . . . . . . . . . . . 65

4.25 Codificação de uma região de uma imagem de RM com a segunda metodologia descrita usando a ordenação de pixels em espiral . . . . . . . . . . . . . . . . . . . . . . 65

4.26 Codificação de uma imagem de tomografia com a segunda metodologia descrita usando a ordenação de pixels em espiral . . . . . . . . . . . . . . . . . . . . . . . . 66

4.27 Codificação de uma região de uma imagem de tomografia com a segunda metodologia descrita usando a ordenação de pixels em espiral . . . . . . . . . . . . . . . . . 66

4.28 Codificação de uma imagem de PET com a segunda metodologia descrita usando a ordenação de pixels em espiral . . . . . . . . . . . . . . . . . . . . . . . . 67

4.29 Codificação de uma região de uma imagem de PET com a segunda metodologia descrita usando a ordenação de pixels em espiral . . . . . . . . . . . . . . . . . . . . 68

4.30 Razão sinal-ruído das imagens comprimidas de acordo com a ordenação de pixels escolhida.

4.31 Evolução da razão sinal-ruído para cada imagem codificada de acordo com o número de iterações usando a ordenação em espiral. . . . . . . . . . . . . . . . . . . . . . . .

4.32 Comparativo da aplicação do filtro Sobel na imagem de RM comprimida com a segunda metodologia descrita e o algoritmo JPEG 
4.33 Comparativo da aplicação do filtro Sobel na região da imagem de RM comprimida com a segunda metodologia descrita e o algoritmo JPEG . . . . . . . . . . . . . 71

4.34 Comparativo da aplicação do filtro Sobel na imagem de CT comprimida com a segunda metodologia descrita e o algoritmo JPEG . . . . . . . . . . . . . . . 72

4.35 Comparativo da aplicação do filtro Sobel na região da imagem de CT comprimida com a segunda metodologia descrita e o algoritmo JPEG . . . . . . . . . . . . . 72

4.36 Comparativo da aplicação do filtro Sobel na imagem de PET comprimida com a segunda metodologia descrita e o algoritmo JPEG . . . . . . . . . . . . . 73

4.37 Comparativo da aplicação do filtro Sobel na região da imagem de PET comprimida com a segunda metodologia descrita e o algoritmo JPEG . . . . . . . . . . . . . 74

4.38 Razão sinal-ruído das imagens comprimidas após a aplicação do filtro Sobel de acordo com a ordenação de pixels escolhida e o número de iterações. . . . . . . . . . . . 75

4.39 Evolução da razão sinal-ruído para cada imagem codificada e filtrada com Sobel de acordo com o número de iterações usando a ordenação em espiral. . . . . . . . . . . 76

4.40 Evolução da taxa de compressão obtida de acordo com o número de iterações e a ordenação de pixels escolhida. . . . . . . . . . . . . . . . . 76

4.41 Boxplot da taxa de compressão da segunda metodologia descrita com uma, duas e três iterações, usando a ordenação de pixels em espiral, e das taxas de compressão dos algoritmos JPEG e PNG. . . . . . . . . . . . . . . . 77

4.42 Comparativo da distribuição dos parâmetros em imagens com e sem tumor . . . . . 78

4.43 Comparativo de desempenho entre as técnicas estudadas . . . . . . . . . . . . . . 79 


\section{Capítulo 1}

\section{Introdução}

Sinais estão presentes nas mais diversas aplicações do nosso dia-a-dia: rádio, televisão, internet, telefonia, diversas formas de transmitir informação. Na medicina, temos equipamentos que, baseados em princípios biofísicos, geram sinais a partir de um ser vivo que permitem uma análise estrutural e funcional dele e, assim, tornam possível a quantificação de anomalias e doenças. Tais sinais são classificados como biomédicos.

Com a evolução e o surgimento de novos mecanismos de aquisição de sinais, a quantidade de informação gerada é cada vez maior, de forma que torna-se cada vez mais importante analisar e armazenar sinais eficientemente.

Para a análise de sinais, foram desenvolvidas técnicas das mais genéricas, que procuram analisar um sinal com o mínimo de conhecimento sobre ele possível, às mais específicas. Por exemplo, na área de Detecção de Anomalias, há técnicas para detectar comportamentos fora do padrão em sinais quaisquer [CBK09]. Por outro lado, temos técnicas para a deteç̧ão de uma anomalia específica em um sinal específico, como arritmia num sinal de batimentos cardíacos [WZTX01].

Técnicas para armazenamento e transmissão eficientes de sinais começaram a ser desenvolvidas com o surgimento dos primeiros dispositivos de armazenamento e transmissão de dados, pois sempre houve a preocupação de conseguir usá-los eficientemente. Sendo assim, há uma grande área do conhecimento denominada Teoria da Informação que já apresenta uma abordagem formal e diversas soluções para esse problema.

Apesar de terem se desenvolvido separadamente, tanto a área da Teoria da Informação como a área de Detecção de Anomalias têm uma característica fundamental em comum: quanto maior o conhecimento que se tem sobre o sinal a ser tratado, melhor se torna a técnica desenvolvida. $\mathrm{O}$ conhecimento prévio sobre o sinal pode ser embutido na metodologia desenvolvida, tornando-a mais eficiente e precisa.

Por outro lado, há uma divergência entre as técnicas desenvolvidas pelas duas áreas. De um modo geral, técnicas que conseguem comprimir bem um sinal tornam difícil analisá-lo sem antes descomprimi-lo. Já técnicas que conseguem extrair características relevantes de um sinal não costumam resultar numa taxa de compressão boa. Esse é um grande problema quando uma grande base de dados precisa ser processada. Por um lado, é desejável que os dados sejam armazenados comprimidos; por outro, é interessante conseguir analisá-los em grandes quantidades rapidamente. Porém, se esses dados forem armazenados de forma a tornar sua análise eficiente, perde-se em compressão.

Sendo assim, este trabalho tem como objetivo descrever uma técnica de modelagem de sinais, sobretudo biomédicos, capaz de gerar uma assinatura de um sinal, ou seja, capaz de gerar uma 
representação que permita caracterizar o sinal original e, ao mesmo tempo, seja compacta. Com isso, torna-se possível realizar análises no sinal a partir apenas de sua assinatura, sem a necessidade de reconstruí-lo para isso.

\subsection{Objetivos}

Os objetivos deste trabalho são:

1. Analisar as principais técnicas de compressão e representação de sinais biomédicos;

2. Desenvolver uma técnica de codificação de sinais utilizando funções sigmoides, com foco em sinais biomédicos, capaz de gerar uma assinatura de um sinal;

3. Aplicar a técnica desenvolvida para sinais de natureza diversa;

4. Avaliar a capacidade de compressão da nova técnica de codificação;

5. Aplicar a técnica desenvolvida para sinais de natureza diversa e avaliar a capacidade de extrair informações quantitativas sobre o sinal.

\subsection{Estrutura do trabalho}

No capítulo 2, as técnicas de compressão e análise de sinais mais representativas são discutidas. No capítulo 3, a técnica desenvolvida é descrita com maiores detalhes. No capítulo 4, algumas aplicações da metodologia desenvolvida e seus resultados são mostrados e discutidos. Por fim, no capítulo 5, discute-se o resultado deste trabalho e possíveis direções futuras de pesquisa. 


\section{Capítulo 2}

\section{Trabalhos relacionados}

Muitas das técnicas de análise de sinais existentes atualmente focam apenas na análise e, assim, não comprimem o sinal. Um dos objetivos deste trabalho é desenvolver uma técnica que, além de permitir a análise de um sinal, também é capaz de comprimi-lo. Sendo assim, o foco nesta seção será em trabalhos desenvolvidos na área de compressão de sinais. Algumas dessas técnicas são genéricas e, por isso, não permitem a análise direta do sinal mas, por outro lado, são bastante eficientes, podendo ser usadas conjuntamente com uma técnica de análise para aumentar a eficiência no armazenamento do sinal. Outras são mais específicas, ou seja, partem de um conhecimento prévio do sinal a ser codificado, baseiam-se num modelo do sinal para codificá-lo. Assim, o resultado que produzem pode ser aproveitado como base para algumas análises.

Sinais de origem não-aleatória, ou seja, que carregam uma informação, apresentam redundâncias em geral, causadas por redundâncias presentes na própria mensagem. Isso ocorre porque mensagens com redundâncias são mais fáceis de serem compreendidas por um humano. Por outro lado, redundâncias prejudicam a transmissão e o armazenamento desses sinais, uma vez que exigem mais banda do meio de transmissão ou mais espaço no meio de armazenamento. Uma forma de aliviar a carga no meio de transmissão ou de armazenamento, portanto, é tentar diminuir a redundância no sinal, re-escrevendo a mensagem original sem redundâncias.

Em alguns sinais, a redundância pode aparecer não na sua representação temporal, mas sim na sua primeira derivada, como mostra a figura 2.1. Assim, o domínio no qual se representa um determinado sinal pode ser determinante na sua compressibilidade.

Como dito anteriormente, quanto mais se conhece sobre o sinal a ser comprimido, mais eficiente é sua compressão. Conhecendo o sinal, conhece-se as redundâncias tipicamente presentes nele e, assim, pode-se atacá-las mais eficientemente.

Um exemplo disso pode ser visto em compressão de imagens. Um formato simples, porém ineficiente para representar imagens, é o formato PGM ASCII [Pos03]. Um exemplo de imagem neste formato pode ser visto na figura 2.2. A imagem original ocupa 1037 bytes. Comprimi-la usando diretamente o algoritmo DEFLATE [Deu96] resulta num arquivo de 469 bytes. Enquanto isso, se o algoritmo de compressão do formato PNG [ISO04b] for aplicado com compressão máxima e nenhum metadado da imagem for armazenado, obtém-se um arquivo de 80 bytes.

Portanto, para comprimir uma mensagem, é desejável encontrar um método eficiente de remover a redundância na mensagem original, concentrando a informação em poucos bits.

No entanto, muitas vezes remover a redundância não é suficiente para se obter uma taxa de compressão satisfatória. Nestes casos, pode-se explorar ainda mais o conhecimento sobre o sinal para 


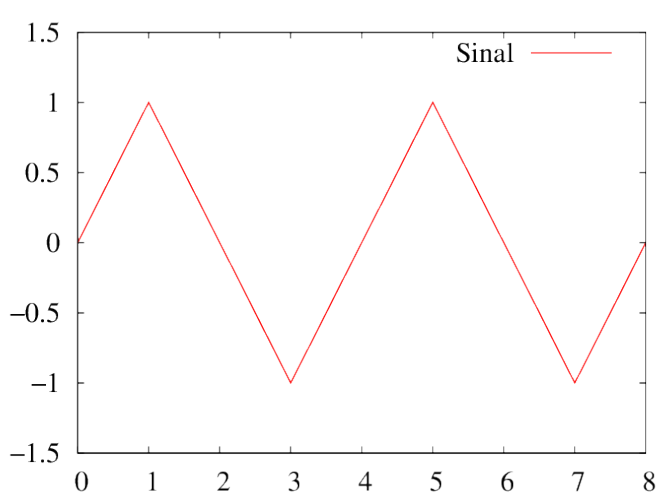

(a) Representação temporal



(b) Primeira derivada

Figura 2.1: Na onda triangular, há pouca redundância se sua representação temporal for analisada. Porém, a sua primeira derivada é altamente redundante.
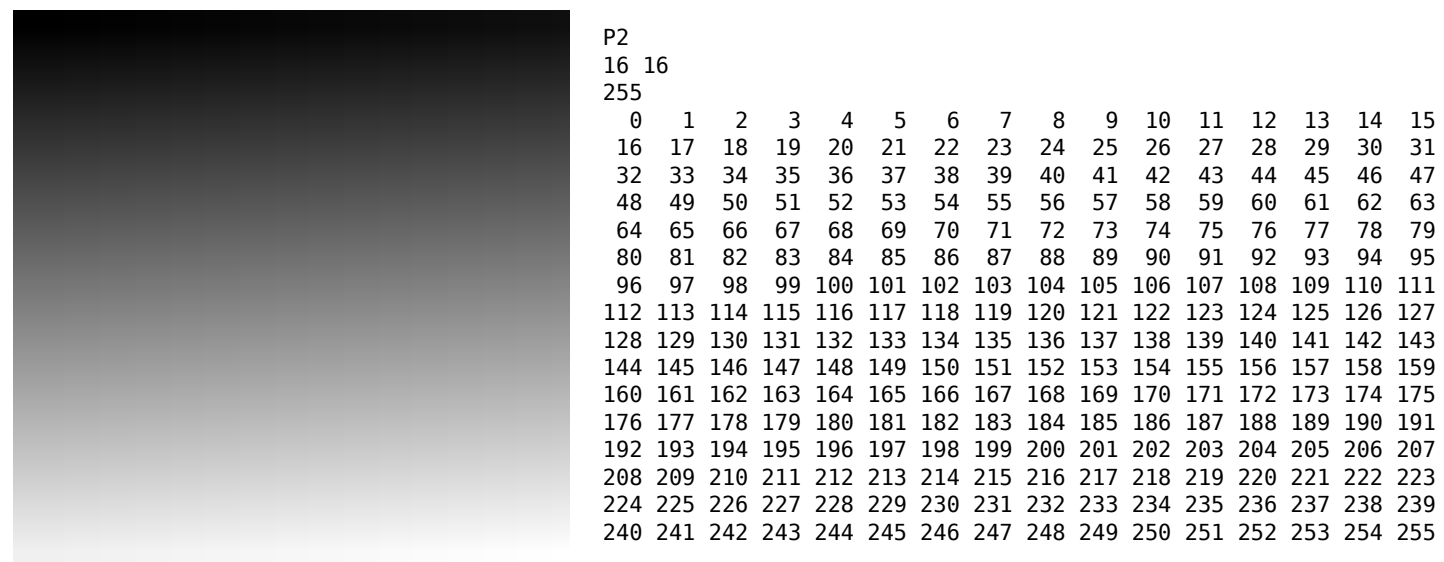

Figura 2.2: Exemplo de imagem no formato PGM ASCII. À esquerda, a imagem ampliada; à direita, sua representação no formato PGM ASCII. 
tentar simplificar a mensagem original, introduzindo mudanças imperceptíveis para um ser humano. No caso de uma imagem, por exemplo, o valor de pixels próximos poderia ser aproximado por um único valor. Isso vai resultar numa imagem ligeiramente diferente mas muito mais compressível. Obviamente, algoritmos desse tipo somente podem ser aplicados a alguns tipos de sinais. Para um texto, por exemplo, uma técnica como essa dificilmente poderia ser aplicada, já que qualquer alteração poderia mudar completamente seu sentido original.

Pode-se classificar, então, as técnicas de compressão em duas grandes categorias: sem perdas (lossless), em que apenas as redundâncias no sinal original são exploradas, e com perdas (lossy), em que o sinal é alterado de forma a introduzir mais redundância.

\subsection{Compressão sem perdas}

Muitas das técnicas de compressão sem perdas, sobretudo as mais genéricas, fazem uso das mesmas ferramentas para tentar reduzir a redundância da mensagem original, explorando características comuns a sinais dos mais diversos tipos. A seguir, algumas delas serão descritas.

\subsubsection{Dicionários}

Uma forma de reduzir a redundância na mensagem original é representar trechos dessa mensagem que ocorrem com frequência usando poucos bits. Tal técnica consiste, então, em criar um mapeamento, ou dicionário, que associe um trecho da mensagem original a uma sequência de bits. Essa associação deve ser feita de forma a associar sequências de bits menores a trechos que se repetem com maior frequência.

Existem diversas formas de se criar um mapeamento. Dentre elas, podemos citar a codificação de Huffman, a codificação de Golomb e o algoritmo LZW [Huf52, Gol66, Wel84]. Esses métodos tentam criar um modelo estatístico da mensagem de entrada e prever quais sequências serão mais frequentes para, assim, associar um código menor para elas.

Por exemplo, considere a seguinte sequência de letras:

aaaaabbaacaaa

Para representá-la de forma mais compacta, pode-se associar as seguintes sequências de bits para cada uma das sequências de letras:

$$
\begin{aligned}
& \text { aaa } \rightarrow 0 \\
& \text { aa } \rightarrow 10 \\
& \mathrm{bb} \rightarrow 110 \\
& \mathrm{c} \rightarrow 111
\end{aligned}
$$

Desta forma, a sequência toda pode ser representada por

$$
00110101110
$$

Vale notar que um mapeamento não precisa fixo para a mensagem toda. Pode-se usar alguma técnica para detectar uma mudança na frequência com que os trechos da mensagem ocorrem e, desta forma, decidir trocar ou manter um determinado mapeamento. 


\subsubsection{Codificação run-length}

Em alguns tipos de sinal, é comum a presença de trechos em que uma mesma informação se repete constantemente: um trecho de silêncio numa música ou o fundo de uma imagem, por exemplo. Nestes casos, é possível aplicar uma técnica conhecida como codificação run-length, ou simplesmente RLE.

Essa técnica consiste em substituir uma sequência em que um mesmo valor aparece várias vezes seguidamente pelo seguinte par: o valor original e o número de vezes que ele se repete. Como exemplo, a sequência de números 333333222100 seria representada pelos pares $(6,3),(3,2),(1,1)$ e $(2,0)$.

Há casos em que a mensagem original não apresenta esse tipo de redundância. Nestes casos, é possível aplicar uma transformação, como a de Burrows-Wheeler, para produzir esse tipo de redundância na mensagem e, assim, torná-la mais compressível [BW94].

\subsubsection{Codificação diferencial}

Como exemplificado no início deste capítulo, a redundância pode aparecer, não no sinal original, mas em sua primeira derivada. Esse fenômeno acontece, por exemplo, em regiões de uma imagem que apresentam sombreamento. Nestes casos, valores consecutivos não são idênticos, mas apresentam uma variação contínua. Nestes casos, se calcularmos a diferença entre valores consecutivos, possivelmente obteremos o mesmo valor várias vezes seguidas.

Codificação diferencial, Differential Pulse Coding Modulation em inglês ou simplesmente DPCM, é uma técnica para tentar capturar a redundância presente nesses casos. A ideia básica da codificação consiste em representar um sinal $x=\left[x_{1}, x_{2}, x_{3}, \ldots\right]$ pela diferença entre coeficientes consecutivos em vez de representá-lo pelo valor absoluto de cada coeficiente. O primeiro coeficiente do sinal codificado $x_{1}^{\prime}$ é idêntico ao primeiro coeficiente $x_{1}$ do sinal original; para $n>1$, o n-ésimo coeficiente $x_{n}^{\prime}$ do sinal codificado é dado pela equação $x_{n}^{\prime}=x_{n}-x_{n-1}$. Um exemplo pode ser visto abaixo. Nele, é possível ver um sinal $x$ e sua codificação diferencial $x^{\prime}$.

$$
\begin{aligned}
x & =[10,3,9,7,5,2,0,3] \\
x^{\prime} & =[10,-7,6,-2,-2,-3,-2,3]
\end{aligned}
$$

Uma vez aplicada a codificação diferencial, é possível aplicar algum outro esquema de codificação para remover a redundância resultante, como o RLE.

\subsection{Compressão com perdas}

Em técnicas de compressão com perdas, duas ferramentas são usadas muito frequentemente: quantização e transformação.

\subsubsection{Quantização}

Quantização, num sentido genérico, é o nome que se dá ao mapeamento de um domínio para uma representação mais compacta. Por exemplo, o processo de arredondamento, comumente utilizado 
em sistemas digitais, é um tipo de quantização. Ou seja, a transformação de um sinal analógico para um sinal digital pode ser chamada de quantização.

Com base num conhecimento prévio da estrutura do sinal a ser quantizado, é possível construir um processo de quantização que facilite a compactação do sinal. Tal processo pode, por exemplo, mapear coeficientes menos informativos do sinal original para um pequeno conjunto de valores. Assim, o resultado é pouco distorcido e os coeficientes menos informativos podem ser representados com menos bits.

Uma possível quantização é dividir cada coeficiente do sinal por um valor fixo. Em outras palavras, dado um sinal $x=\left[x_{1}, x_{2}, x_{3}, \ldots, x_{n}\right]$ e um vetor de quantização $q=\left[q_{1}, q_{2}, q_{3}, \ldots, q_{n}\right]$, o sinal quantizado $b=\left[b_{1}, b_{2}, b_{3}, \ldots, b_{n}\right]$ é dado pela equação

$$
b_{i}=\left\lfloor\frac{x_{i}}{q_{i}}\right\rfloor, \quad i=1,2, \ldots, n .
$$

Um exemplo mais concreto desse tipo de quantização pode ser visto na equação 2.2. Nele, o processo descrito pela equação 2.1 é aplicado a um sinal representado no vetor $x$. Cada coeficiente $q_{i}$ do vetor $q$ divide um coeficiente $x_{i}$ do vetor $x$. O resultado da divisão é posteriormente arrendondado, resultando no sinal quantizado representado pelo vetor $b$.

$$
\begin{aligned}
x & =[-415,38 ;-30,19 ;-61,20 ; 27,24 ; 56,13 ;-20,10 ;-2,39 ; 0,46] \\
q & =[16 ; 11 ; 10 ; 16 ; 24 ; 40 ; 51 ; 61] \\
b & =[-26 ;-3 ;-6 ; 2 ; 2 ;-1 ; 0 ; 0]
\end{aligned}
$$

No exemplo dado, o vetor $q$ é construído de forma a mapear os valores do final do vetor $x$ para valores muito mais próximos de zero. Tal processo introduz um erro maior na representação final desses valores, mas isso é proposital: assume-se que estes são menos informativos e, portanto, podem ser distorcidos sem distorcer demais a informação representada pelo sinal.

Além da técnica apresentada, existem ainda outras técnicas de quantização, tais como a quantização logarítmica e a quantização logarítmica esférica, que procuram limitar o erro introduzido pelo processo numa grande faixa de valores [HM04].

O processo de quantização não precisa necessariamente mapear um valor da entrada para um valor da saída. É possível mapear uma sequência de valores da entrada para um único valor na saída, num processo conhecido como quantização vetorial. Como o mapeamento leva em conta sequências de valores, ele tende a ser mais eficiente do ponto de vista de compressão [Gra84].

\subsubsection{Compressão por transformadas}

Uma possível abordagem para o problema de comprimir o sinal é tentar encontrar um domínio onde sua representação concentre a informação da mensagem em poucos coeficientes. Tal representação permite uma boa compressão com poucas perdas pela exclusão dos coeficientes menos informativos. 


\section{Transformada de Karhunen-Loève}

Sinais de origem natural, em geral, possuem uma característica que pode ser muito bem aproveitada na compressão: a correlação entre amostras consecutivas do sinal. Isso significa que há uma redundância que pode ser eliminada nesses sinais, uma vez que uma alta correlação entre amostras consecutivas do sinal indica que é possível prever, dado um valor, os valores seguintes.

Uma forma de remover essa redundância e, assim, representar o sinal de forma mais compacta, é encontrar uma transformação linear que descorrelacione amostras consecutivas do sinal. Desta forma, concentra-se a informação do sinal em uma parte dos coeficientes, permitindo uma representação bastante compacta para os demais. Essa é a ideia da transformada de Karhunen-Loève.

Dado um sinal $x(t)$, é possível definir sua matriz de autocovariância como

$$
C_{x}=E\left[(x-m)(x-m)^{T}\right],
$$

em que $m=E[x]$ é a média do sinal $x$. Deseja-se encontrar uma transformação linear $W$ tal que o sinal transformado por essa matriz tenha amostras descorrelacionadas entre si. Ou seja, deseja-se que a matriz de autocovariância $C_{y}$ de $y=W x$ seja diagonal. Isso é equivalente a encontrar a decomposição espectral da matriz $C_{x}$. Assim, as colunas $w_{i}$ da matriz $W$ são dadas pela equação:

$$
C_{x} w_{i}=\lambda_{i} w_{i}
$$

em que $\lambda_{i}$ é o autovalor associado ao autovetor $w_{i}$.

Para calcular a transformada, portanto, é necessário conhecer a matriz de autocovariância do sinal a ser codificado. Essa matriz é normalmente estimada a partir de uma parte da amostra ou de amostras de treinamento.

É necessário observar que, para que seja possível posteriormente decodificar o sinal, a matriz utilizada para a codificação deve ser fácil de inverter e conhecida por quem for decodificar. O primeiro problema é resolvido facilmente se $W$ for ortonormal, caso em que $W^{-1}=W^{T}$. Para obter uma matriz $W$ ortonormal, basta aplicar o processo de ortonormalização de Gram-Schimdt. Já o segundo problema é resolvido enviando-se a matriz utilizada juntamente com o sinal codificado ou, uma vez estimada a matriz para um tipo de sinal, utilizando-se a mesma matriz para todo sinal de entrada. A primeira solução implica que, para que a transformada seja interessante para compressão, é necessário limitar o tamanho da matriz, de forma a obter um equilíbrio entre esse tamanho e o tamanho do sinal comprimido. A segunda solução pressupõe que os sinais a serem codificados possuem covariância semelhante à do sinal de treino e, portanto, limita a aplicação da transformada a um conjunto limitado de sinais.

Encontrar a decomposição espectral de um sinal é um processo computacionalmente caro. Por isso, em aplicações que exigem processamento em tempo real, a abordagem para utilizar a transformada de Karhunen-Loève precisa ser a de estimar a matriz de autocovariância para um determinado tipo de sinal e, posteriormente, utilizar essa estimativa para codificar e decodificar sinais em tempo real. Em particular, essa abordagem produz bons resultados para a compressão de sinais de ECG, alcançando taxas de compressão de até 17:1 [OMGL96].

A transformada de Karhunen-Loève produz uma representação com entropia mínima para um sinal cujos coeficientes sigam uma distribuição gaussiana e, portanto, é ótima para a compressão deste tipo de sinal [Don00]. Na prática, sinais de origem natural são bem aproximados por essa 
distribuição [Don00].

Mesmo depois de aplicada a transformada, ainda é possível verificar que os coeficientes significativos consecutivos apresentam uma correlação forte. Por isso, é comum utilizar-se uma codificação diferencial dos coeficientes (DPCM) em cima do resultado da transformada [Don00, OMGL96].

\section{Transformada de Fourier}

A transformada de Fourier permite representar qualquer sinal integrável em função de senos e cossenos. Dada uma função $f: \mathbb{C} \rightarrow \mathbb{C}$ que represente o sinal, sua transformada de Fourier $F$ é dada pela expressão

$$
F(\nu)=\int_{-\infty}^{\infty} f(x) e^{-2 \pi i x \nu} d x
$$

Quando a variável independente $x$ do sinal representa o tempo, a variável independente da transformada $\nu$ representa a frequência. Neste caso, diz-se que a transformada de Fourier leva uma função $f$ do domínio do tempo para o domínio de frequências. Isso tem uma implicação muito importante para o processamento de sinais: a transformada de Fourier permite analisar quais frequências compõem um sinal e com que intensidade. Algumas transformações no sinal, como filtragem de ruídos, suavização e reconhecimento de padrões, são feitas mais facilmente ao se analisar as frequências de um sinal.

A transformada de Fourier, tal como formulada na equação 2.5, é aplicável a sinais contínuos de duração infinita. No entanto, os sinais com os quais costuma-se trabalhar em aplicações computacionais, tais como os biomédicos, são discretos e de duração finita. Assim, costuma-se utilizar a transformada discreta de Fourier, dada pela equação

$$
F(k)=\sum_{n=0}^{N-1} f(n) \exp \left(\frac{-i 2 \pi k n}{N}\right),
$$

em que $N$ é o número de amostras de um sinal finito $f$ [Mal99].

A representação do sinal no domínio de frequências também pode ser utilizada para compressão. No processo de quantização, é possível, por exemplo, zerar coeficientes de frequências com menor participação no sinal. Outra possibilidade é utilizar menos bits para representar coeficientes de frequências mais altas, em que pequenas variações de intensidade são menos visíveis.

Vale também observar que a transformada de Fourier produz como resultado um conjunto de números complexos, mesmo que o sinal original pertença ao domínio dos números reais. A princípio, isso significaria que, ainda que metade dos coeficientes fossem zerados, ainda teríamos um número de coeficientes não zerados igual ao número de valores no sinal original. No entanto, para sinais $f(n)$ reais, temos que

$$
F(N-k) \equiv F(-k)=\overline{F(k)},
$$

em que $\bar{x}$ representa o conjugado do número complexo $x$. Ou seja, os $N / 2$ primeiros valores da transformada determinam-na por completo. Assim, é possível reconstruir um sinal real a partir de apenas metade dos coeficientes complexos de sua transformada de Fourier.

A transformada de Fourier pode ser calculada eficientemente pelo algoritmo conhecido como FFT (Fast Fourier Transform). Isso a torna interessante para filtragens e compressão em tempo 
real. No entanto, alguns valores importantes para a análise médica de um sinal, tais como picos e amplitudes de vales, não são facilmente obtidos a partir da representação no domínio de frequências. Ainda assim, a FFT foi aplicada para sinais de ECG por Kulkarni, Kumar e Verma [KKV97], atingindo taxas de compressão da ordem de 8:1 com boa qualidade e filtragem de ruídos.

\section{Transformada de cossenos}

A transformada de cossenos é uma variante da transformada de Fourier. Como o nome implica, a diferença inicial está na formulação da transformada: enquanto a transformada de Fourier utiliza senos e cossenos, a transformada de cossenos utiliza apenas esta função para codificar um sinal.

A principal motivação para a utilização da transformada de cossenos é que, para imagens, ela provê uma boa aproximação da transformada de Karhunen-Loève. Suas funções base aproximam bem a matriz de autocovariância típica de uma imagem [ANR74].

A transformada de cossenos generalizada se aplica a sinais contínuos de duração infinita. No processo de tornar a transformada finita, se faz necessário definir condições de borda para o sinal a ser analisado. Como a função cosseno é par, i.e, $f(x)=f(-x)$, a transformada só pode ser aplicada a funções pares. Assim, para aplicar a transformada num sinal finito qualquer, é necessário analisar uma extensão par desse sinal.

A extensão par de um sinal finito qualquer $x(t), t=0,1, \ldots, N$ envolve a escolha de duas condições. Primeiramente, é possível escolher uma extensão $X(t)$ de $x(t)$ que seja par somente ao redor de $t=0$, somente ao redor de $t=N$ ou ambos. Além disso, é possível escolher um ponto central para o critério de paridade que não o ponto inicial $t=0$. Essa variedade de escolhas nos leva a uma família de transformadas de cossenos discretas (DCT). No entanto, há algumas DCT mais comuns, listadas a seguir.

- DCT-I: a extensão de um sinal $x(t)$ é par ao redor de $t=0$ e de $t=N-1$. A transformada $X(k)$ é dada por

$$
X_{k}=\frac{1}{2}\left(x_{0}+(-1)^{k} x_{N-1}\right)+\sum_{n=1}^{N-2} x_{n} \cos \left[\frac{\pi}{N-1} n k\right], \quad k=0, \ldots, N-1 .
$$

- DCT-II: a extensão do sinal $x(t)$ é par ao redor de $t=-1 / 2$ e ao redor de $t=N-1 / 2$.

$$
X_{k}=\sum_{n=0}^{N-1} x_{n} \cos \left[\frac{\pi}{N}\left(n+\frac{1}{2}\right) k\right], \quad k=0, \ldots, N-1 .
$$

- DCT-III: a extensão do sinal $x(t)$ é par ao redor de $t=0$ e ímpar ao redor de $t=N$.

$$
X_{k}=\frac{1}{2} x_{0}+\sum_{n=1}^{N-1} x_{n} \cos \left[\frac{\pi}{N} n\left(k+\frac{1}{2}\right)\right], \quad k=0, \ldots, N-1 .
$$

- DCT-IV: a extensão do sinal $x(t)$ é par ao redor de $t=-1 / 2$ e ímpar ao redor de $t=N-1 / 2$.

$$
X_{k}=\sum_{n=0}^{N-1} x_{n} \cos \left[\frac{\pi}{N}\left(n+\frac{1}{2}\right)\left(k+\frac{1}{2}\right)\right], \quad k=0, \ldots, N-1 .
$$


A transformada discreta de cossenos, ao contrário da transformada de Fourier, mapeia valores reais em valores reais. Isso simplifica sua implementação para compressão. No entanto, assim como a transformada de Fourier, ela mapeia sinais para o domínio de frequências, que é muito útil para alguns tipos de análises clínicas, mas não é adequado para análises baseadas nos picos e vales de um sinal. Ainda assim, a transformada pode ser aplicada a sinais de ECG, atingindo taxas de compressão de até 20:1 com filtragens e quantizações adequadas [AB92].

\section{Wavelets}

Um dos problemas com a transformada de Fourier e as transformadas de senos e cossenos é que elas representam as frequências de um sinal em toda a sua duração. Isso significa que, se as frequências predominantes num sinal variarem com o tempo, não será possível extrair essa informação facilmente de uma transformada como essas. Além disso, a representação perde em precisão e compactação, já que a representação dessa variação na composição de frequências não é facilmente modelada nessas transformadas.

A análise temporal de frequências surgiu, inicialmente, com a transformada de Gabor. A partir dela, surgiram a transformada de Fourier de intervalo reduzido e as transformadas de wavelets. Essas transformadas são baseadas na decomposição de um sinal em pequenos trechos de onda que, por sua vez, são aproximados por funções de suporte limitado.

$\mathrm{Na}$ transformada de wavelets contínua, uma função base $\psi$ é escalada e transladada de forma a construir uma base ortonormal do espaço de sinais (também conhecido como espaço de funções de energia finita), denotado como $\mathbf{L}^{2}(\mathbb{R})$. A função base $\psi$ deve ter média zero:

$$
\int_{-\infty}^{\infty} \psi(t) d t=0
$$

centralizada na vizinhança de $t=0$ e ser normalizada:

$$
\|\psi\|=\sqrt{\int_{-\infty}^{\infty}|\psi(t)|^{2} d t}=1 .
$$

A escala e a translação da função $\psi$ são dadas pela equação

$$
\psi_{u, s}(t)=\frac{1}{\sqrt{s}} \psi\left(\frac{t-u}{s}\right) .
$$

A função base também é conhecida como wavelet mãe, enquanto que as escalas e translações dessa função são conhecidas como wavelets filhas.

Com base nessas definições, a transformada de wavelets de uma função $f$ na escala $s$ na posição $u$ é dada pela equação

$$
W f(u, s)=\int_{-\infty}^{\infty} f(t) \frac{1}{\sqrt{s}} \psi^{*}\left(\frac{t-u}{s}\right) d t
$$

Uma função contínua $f$ pode ser, então, recuperada a partir da integração dos coeficientes $W f(u, s)$ para $u \in \mathbb{R}$ e $s>0$ :

$$
f(t)=\frac{1}{C_{\psi}} \int_{0}^{\infty} \int_{-\infty}^{\infty} \frac{1}{s^{2}} W f(u, s) \frac{1}{\sqrt{s}} \psi\left(\frac{t-u}{s}\right) d u d s
$$


em que $C_{\psi}$ é a constante de admissibilidade de uma wavelet, definido como

$$
C_{\psi}=\frac{1}{2} \int_{-\infty}^{\infty} \frac{|\hat{\psi}(\zeta)|^{2}}{|\zeta|} d \zeta
$$

em que $\hat{\psi}$ denota a transformada de Fourier de $\psi$ [Mal99].

A transformada de wavelets contínua é aplicada em todas as possíveis escalas. No entanto, para sinais discretos, algumas escalas exigiriam interpolações. Além disso, muitas dessas escalas tornamse redundantes. A transformada discreta de wavelets elimina essas redundâncias e a necessidade de interpolação do sinal discreto aplicando escalas de tempo e frequência em passos discretos.

Na transformada discreta de wavelets, os intervalos discretos são dados por $\gamma$ e $\tau$ na equação 2.16 .

$$
\psi_{u, s}(t)=\frac{1}{\sqrt{\gamma^{s}}} \psi\left(\frac{t-u \tau \gamma^{s}}{\gamma^{s}}\right), u, s \in \mathbb{Z}
$$

Então, dado um sinal discreto $x=\left[x_{1}, x_{2}, \ldots, x_{N}\right]$, é possível calcular os coeficientes $W x(u, s)$ pela equação

$$
W x(u, s)=\sum_{m=1}^{N} x(m) \psi_{u, s}^{*}(m) .
$$

Assim, para ser possível reconstruir o sinal $x$ sem perda de informação, basta obter os coeficientes $W x(u, s)$ para $1 \leq s \leq N$ e $u=k \gamma^{s}, k \in\left\{0,1, \ldots, N / \gamma^{s}\right\}$. Com esses coeficientes, é possível reconstruir o sinal $x$ somando-os para os valores de $u$ e $s$ mencionados:

$$
x(n)=\frac{1}{C_{\psi}} \sum_{s=1}^{N} \sum_{u} \frac{1}{s^{2}} W x(u, s) \frac{1}{\sqrt{\gamma^{s}}} \psi_{u, s}(n) .
$$

Em geral, $\gamma=2$ e $N$ é uma potência de 2, o que simplifica a implementação e permite uma interpretação mais intuitiva dos coeficientes da transformada.

Para aplicações de compressão, é desejável que as funções $\psi_{u, s}$ sejam ortogonais entre si. Assim, eliminam-se redundâncias na representação da transformada.

Existem diversas famílias de funções $\psi$ já bastante utilizadas. Dentre elas, podem ser citadas as wavelets de Haar e de Daubechies. Ambas geram funções ortogonais entre si e, por isso, são bastante utilizadas para compressão de sinais.

As wavelets de Haar são bastante simples e fáceis de implementar eficientemente. A wavelet mãe é descrita pela equação:

$$
\psi(t)= \begin{cases}1 & \text { se } 0 \leq t<1 / 2 \\ -1 & \text { se } 1 / 2 \leq t<1 \\ 0 & \text { caso contrário. }\end{cases}
$$

As wavelets de Daubechies são, na verdade, uma família de wavelets. As wavelets mãe da família são construídas de modo a terem o número desejado de momentos nulos, ou seja, de modo a conseguirem representar sinais complexos eficientemente. As wavelets de Daubechies não possuem uma forma analítica: são calculadas numericamente. 


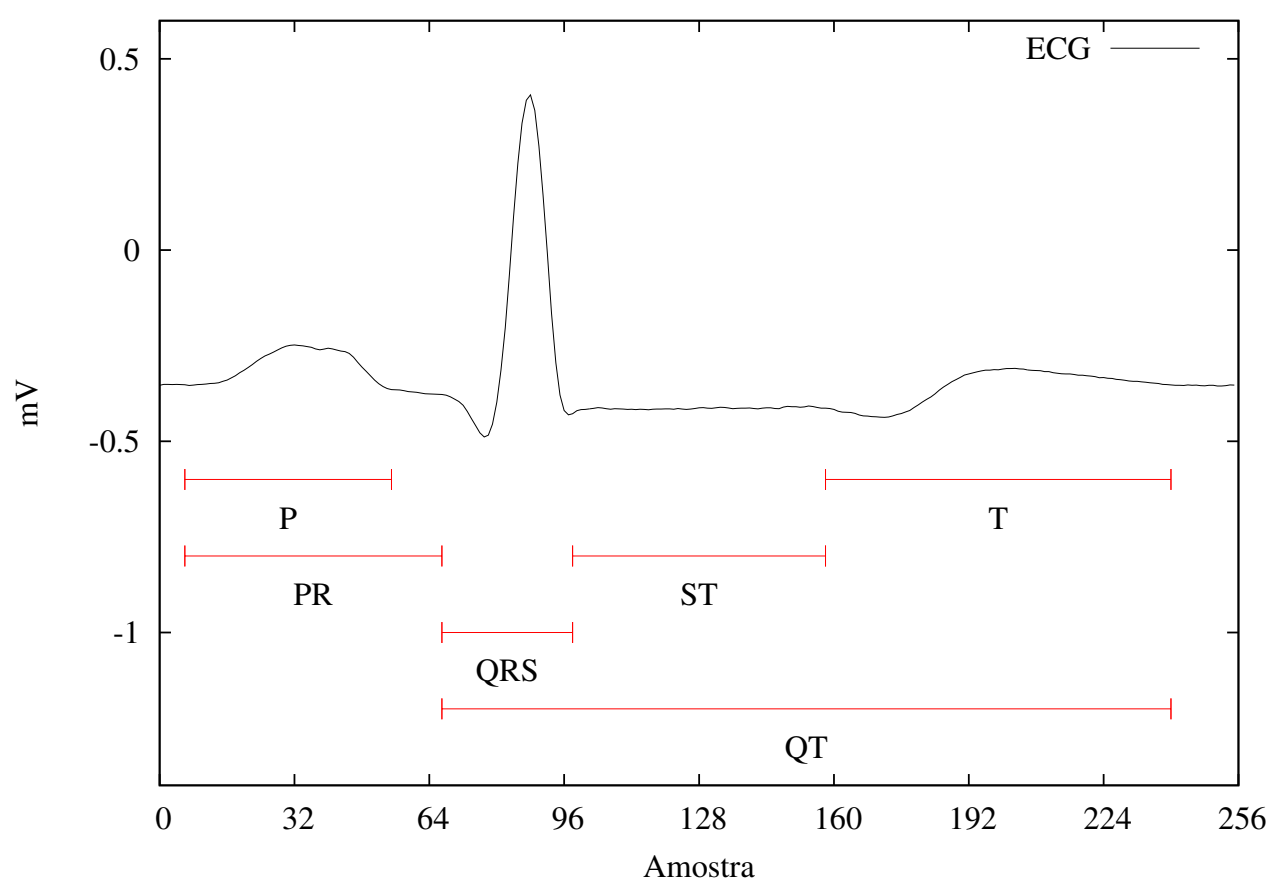

Figura 2.3: Sinal típico de ECG com suas regiões marcadas.

\subsection{Técnicas para sinais específicos}

As técnicas listadas até agora são genéricas, isto é, podem ser aplicadas a qualquer tipo de sinal. Podem, também, ser combinadas: o formato de compressão de imagens JPEG [Wal91], muito utilizado atualmente, mistura transformadas, quantização e, por fim, um tipo de dicionário.

No entanto, em alguns casos pode-se explorar mais o conhecimento prévio sobre o sinal para modelá-lo melhor e, assim, comprimi-lo mais eficientemente. No caso de sinais biomédicos, as técnicas que exploram esse conhecimento prévio podem ser classificadas em três categorias: compressão direta, compressão por transformada (utilizando uma transformada específica para o tipo de sinal a ser codificado) e compressão por extração de parâmetros.

\subsubsection{Compressão direta}

Algoritmos de compressão direta codificam o sinal de entrada com base em algumas características conhecidas desse sinal. O algoritmo AZTEC, por exemplo, baseia-se no fato de que o sinal de ECG possui três regiões bem definidas, visíveis na figura 2.3: duas onde o sinal praticamente não varia (PR e ST) e uma onde há uma variação rápida (QRS) [CNFO68].

Algoritmos nessa categoria são baseados no princípio de compressão baseado em tolerância, o que significa que a entrada é filtrada, aproximando-se o máximo possível de dados da entrada por um único ponto, de acordo com um critério de tolerância. Esse tipo de algoritmo é bastante utilizado devido à facilidade de implementação com boa capacidade de compressão [KSGS05, KKV97].

\section{Método Turning Point}

O método Turning Point comprime um sinal qualquer com uma taxa fixa de 2:1, isto é, reduzindo o tamanho do arquivo pela metade [MSM87]. Para cada par de pontos amostrados do sinal de 
entrada, o algoritmo gera um ponto de saída, que é sempre o segundo ponto do par, a não ser que o primeiro seja um ponto de extremo local (um Turning Point).

O sinal resultante da compressão preserva bem as características do sinal original, tanto nas regiões de baixa frequência como nas de alta, uma característica importante para a análise visual do sinal por cardiologistas [MSM87].

O algoritmo pode ser aplicado seguidas vezes para alcançar uma taxa de compressão maior. No entanto, esse processo pode deformar a onda, uma vez que o método, a cada vez que é aplicado, diminui pela metade a frequência máxima possível de ser representada no sinal de saída.

Existem diversos algoritmos baseados neste método. Dentre eles, podemos citar o algoritmo TRIM (Turning point Recursive IMprovement) [MSM87]. Este algoritmo escolhe, inicialmente, alguns pontos extremos do sinal de entrada e, recursivamente, refina a escolha até atingir um nível de erro desejado. O resultado é uma taxa de compressão bem maior e com resultado clinicamente aceitável. No entanto, a escolha dos pontos de refinamento não leva em conta o erro entre a aproximação e o sinal original. Além disso, a interpolação linear entre dois pontos escolhidos não aproxima bem algumas curvas típicas de um sinal de ECG, como a segunda metade da curva QRS, o que leva a um particionamento maior do sinal original.

\section{Algoritmo AZTEC}

O algoritmo AZTEC comprime um sinal de ECG em tempo real aproximando-o por retas, alcançando taxas de compressão em torno de 10:1 para esse tipo de sinal ao mesmo tempo em que fornece uma boa codificação para detecção de anomalias nos batimentos cardíacos [CNFO68, CK00].

Seu funcionamento pode ser descrito da seguinte maneira: dado um sinal $f=\left\{f_{0}, f_{1}, \ldots, f_{n}\right\}$, definimos, no início, $f_{\text {min }}=f_{0}=f_{\max }$. As variáveis $f_{\min }$ e $f_{\max }$ representam o menor e o maior valor encontrado no sinal até um dado momento, respectivamente. O sinal é percorrido e os valores de $f_{\min }$ e $f_{\max }$ são atualizados de acordo, até o momento em que a diferença $f_{\max }-f_{\min }$ se torna maior que um dado $K$. Consideramos, então, o sinal analisado até o momento passível de representação por um sinal de valor constante igual a $\left(f_{\max }+f_{\min }\right) / 2$. Em seguida, as variáveis $f_{\min }$ e $f_{\max }$ são atualizadas com o último valor analisado do sinal de entrada $f$ e o processo recomeça.

Trechos de grande variação do sinal, como o trecho QRS de um ECG, gerarão várias pequenas retas. Para otimizar a representação desses trechos, o algoritmo reconhece sequências de pequenas retas, com quatro ou menos amostras do sinal de entrada, e as aproxima por uma rampa de inclinação constante.

A figura 2.4 mostra o resultado da compressão de um sinal típico de ECG com a utilização do algoritmo AZTEC. É possível notar que o sinal resultante possui diversas descontinuidades, o que o torna inadequado para análise por cardiologistas [CK00].

Uma abordagem comum para tentar melhorar a qualidade do resultado desse algoritmo é filtrar sua saída, aproximando-a por uma função polinomial, por exemplo. Isso torna o resultado visualmente muito melhor, mas tem a desvantagem de distorcer vales e picos do sinal, que são importantes para o diagnóstico de algumas anomalias [AT82].

Foram propostas algumas melhorias para o algoritmo AZTEC. Um dos problemas do algoritmo é determinar a constante $K$. Aumentar seu valor também aumenta a taxa de compressão do algoritmo, mas introduz mais erro e torna o resultado menos aceitável para uso clínico. Por outro lado, diminuir o valor de $K$ melhora visualmente o resultado, mas reduz a taxa de compressão final. Assim, 

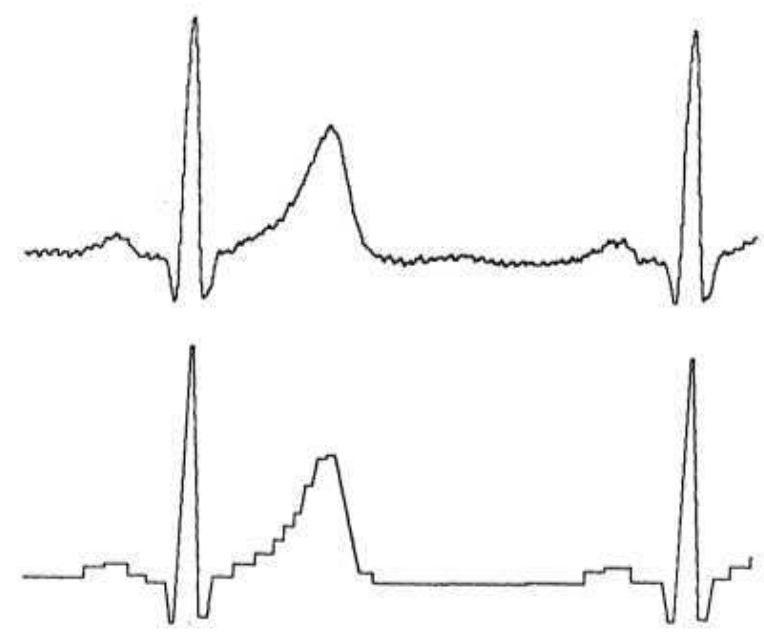

Figura 2.4: Sinal de ECG e o resultado de sua compressão pelo algoritmo AZTEC. Figura extraída de [CNFO68].

Fuhrt e Perez [FP88] propuseram um algoritmo baseado no AZTEC, chamado AZTEC modificado (mAZTEC), no qual $K$ deixa de ser uma constante, e é ajustado a cada amostra obtida do sinal com base na média, no desvio padrão e no terceiro momento do sinal calculados até o momento, desde o início do sinal. Desta forma, o algoritmo se adapta às diferentes regiões do sinal. No entanto, esta solução também depende de duas constantes, que regulam a influência do valor de $K$ calculado anteriormente em seu novo valor.

Kumar et al. [KSGS05] propuseram melhorias para o mAZTEC, tornando o cálculo dos parâmetros estatísticos local a cada segmento de reta gerado pelo algoritmo, em vez de utilizar o sinal inteiro nesse cálculo, o que, associado a um esquema de suavização do sinal comprimido, melhorou consideravelmente a qualidade do resultado. A suavização proposta torna o resultado mais aceitável para uso clínico, preservando algumas características importantes para diagnóstico e eliminando ruído, mas, por outro lado, distorce o resultado inicial do algoritmo AZTEC, eliminando pequenas variações que podem ser significativas.

Um outro algoritmo baseado no AZTEC, que procura melhorar a qualidade do sinal comprimido na região QRS de um sinal típico de ECG, foi proposto por Abenstein e Tompkins [AT82]. Chamado de CORTES, o algoritmo mescla as abordagens do algoritmo AZTEC e do método Turning Point. Nas regiões de pouca variação, o algoritmo AZTEC tende a produzir retas (platôs) mais longas e comprimir melhor o sinal. Já no complexo QRS, o algoritmo AZTEC gera rampas, que possuem boa capacidade de compressão, mas não representam o sinal tão bem quanto o método Turning Point. O algoritmo CORTES, então, seleciona qual dos dois métodos aplicar para comprimir uma determinada região baseado no comprimento de um platô produzido pelo algoritmo AZTEC. Se o platô tiver comprimento menor que uma constante determinada empiricamente, o algoritmo CORTES utiliza o método Turning Point para comprimir a região analisada. Caso contrário, o platô do algoritmo AZTEC é utilizado. O resultado é uma taxa de compressão um pouco menor que a do algoritmo AZTEC, mas com um resultado mais aceitável para análise clínica, apesar de ainda apresentar descontinuidades nas regiões de menor variação do sinal. 


\section{Algoritmo AZTDIS}

O algoritmo AZTDIS é baseado na ideia de aproximação de um sinal de ECG por pontos relevantes conectados por retas [Tai93]. Ele processa o sinal em tempo real e em duas fases, alcançando taxas de compressão similares às do algoritmo AZTEC, porém com menos erro.

Em sua primeira fase, o algoritmo funciona de modo similar ao AZTEC. Cada ponto que introduz uma nova reta é considerado como relevante, exceto quando o algoritmo AZTEC gera uma rampa. Neste caso, o algoritmo AZTDIS aplica uma heurística para tentar eliminar rampas consecutivas com inclinação semelhante sem sacrificar a precisão dos trechos de alta frequência.

$\mathrm{Na}$ segunda fase, os segmentos de reta são refinados calculando-se a distância de cada ponto do sinal de entrada às retas geradas até o momento. Caso um ponto esteja mais distante de uma reta do que um certo $\epsilon$ determinado pelo usuário, tal ponto é escolhido como relevante. A distância calculada pelo algoritmo é dada pela diferença entre as ordenadas do ponto do sinal de entrada e da reta aproximada pelo algoritmo na mesma abscissa do ponto de entrada. Tal distância exige menos operações aritméticas para ser calculada e torna-se mais conservadora em regiões de maior frequência, o que aumenta a precisão do algoritmo nessas regiões. Nessa fase ocorre, também, a junção de retas consecutivas com inclinações próximas.

O resultado do algoritmo é bastante aceitável do ponto de vista clínico e atinge boas taxas de compressão. No entanto, a codificação gerada pelo algoritmo pode não ser adequada para a análise computacional de um sinal de ECG pois, até o momento da escrita deste texto, não se sabe de uma aplicação do algoritmo para análise computacional de sinais de ECG. Além disso, é possível que o algoritmo possa ser melhorado utilizando-se uma aproximação por polinômios de maior grau ou funções que representem melhor a curvatura natural do sinal.

\subsubsection{Compressão por transformadas}

Como já foi exemplificado, compressões por transformadas podem ser aplicadas a diversos tipos de sinal, inclusive sinais biomédicos. No entanto, no caso da transformada de wavelets, pode-se levar em conta a origem do sinal na escolha da wavelet mãe. Em outras palavras, sabendo que o sinal a ser codificado é um EEG, por exemplo, pode-se escolher uma wavelet mãe mais adequada a esse tipo de sinal.

A transformada de wavelets já foi extensivamente aplicada no processamento de sinais biomédicos. Unser [UA96] cita algumas dessas aplicações: análise bioacústica para detecção de anomalias no fluxo sanguíneo, detecção do complexo QRS em sinais de ECG, detecção de anomalias no ciclo cardíaco baseado no sinal de ECG, deteç̧ão de picos e variações abruptas relacionados à epilepsia em ondas de EEG, redução de ruído em EEG e em imagens de ressonância magnética. Addison [Add05] fez uma revisão de aplicações de wavelets especificamente para sinais de ECG.

Em particular, a transformada de wavelets já foi aplicada para a compressão de sinais de ECG, EMG (eletromiografia) e EEG [Raj02, $\mathrm{NKA}^{+}$06, CBLGRV04].

Para a codificação e compressão de sinais de ECG, taxas de compressão de até 23:1 foram obtidas com erros bastante aceitáveis [Raj02]. No entanto, o sinal comprimido apresenta algumas deformações que podem dificultar a análise visual do sinal por um especialista. Em particular, o algoritmo introduz impulsos em regiões onde o sinal original é praticamente constante, como é possível notar na figura 2.5. 

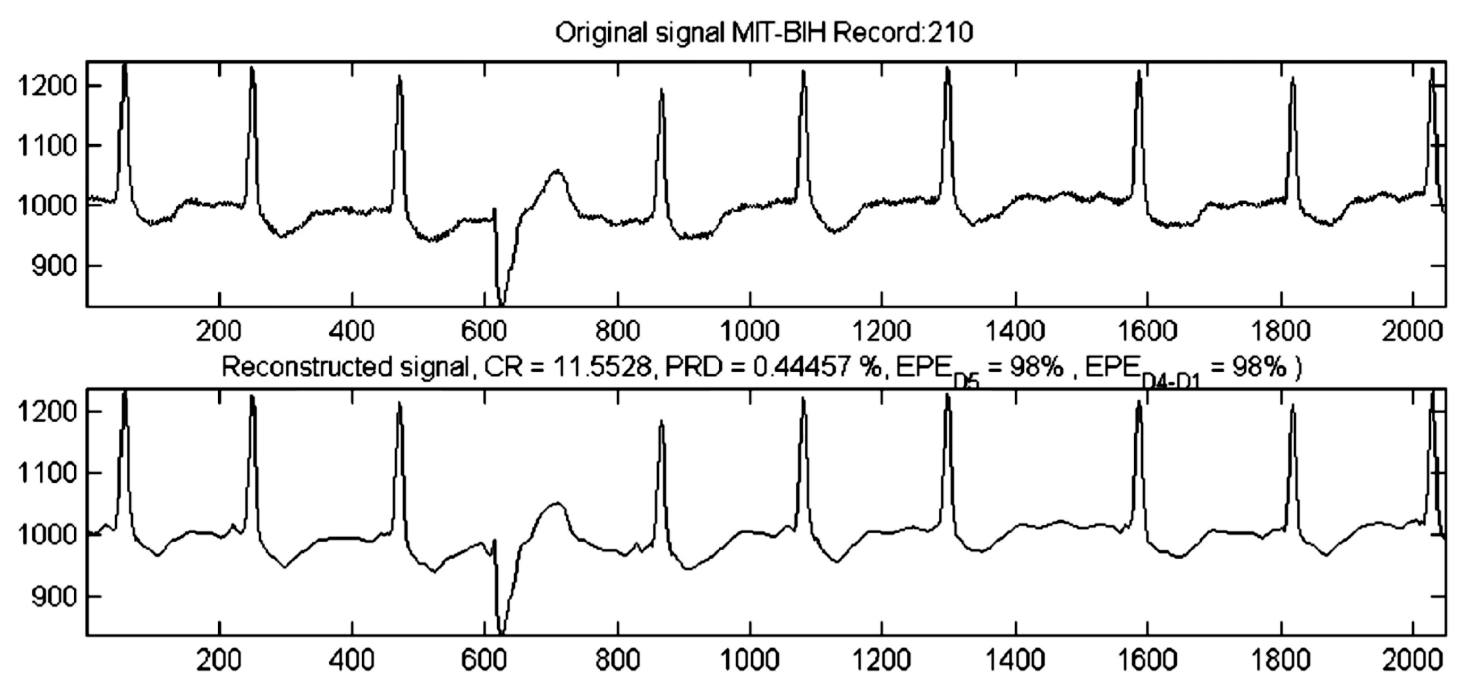

Figura 2.5: Comparativo entre um sinal de ECG e o resultado de sua compressão utilizando wavelets. É possivel notar que o algoritmo de compressão introduz artefatos que podem levar a interpretações incorretas do sinal, tais como os picos introduzidos antes de alguns trechos QRS. Figura extraída de [Raj02].

Nielsen $\left[\mathrm{NKA}^{+} 06\right]$ elaborou uma estratégia para escolher a wavelet ótima, dentre algumas possíveis, para cada sinal e taxa de compressão desejada. Para sinais de ECG e EEG, uma taxa de compressão de 10:1 resultou num sinal bastante aceitável. Para sinais de EMG, taxas de compressão de até 4:1 foram atingidas com pouca distorção.

A transformada de wavelets também é aplicável a imagens médicas. O formato de compressão de imagens JPEG 2000 é baseado nessa transformada e é parte do formato de imagens médicas DICOM [ISO04a, ISO06].

É importante observar que tanto a qualidade de compressão como a análise do sinal dependem da escolha da wavelet. É possível, portanto, que uma wavelet que dê bons resultados para compressão não seja eficiente para a detecção de anomalias.

\subsubsection{Compressão por extração de parâmetros}

Compressão por extração de parâmetros foi o termo usado por Nave e Cohen [NC93] e, mais tarde, por Cetin e Köymen [CK00], para designar técnicas de compressão baseadas em algum tipo de predição sobre o sinal, como séries temporais ou redes neurais. Tais técnicas também são conhecidas como "baseadas em contexto" [MKC99].

\section{Séries temporais}

A ideia principal dessa técnica é tentar modelar o sinal de entrada a partir de amostras anteriores do próprio sinal e de outros sinais. Modelos mais sofisticados podem, inclusive, aproveitar conhecimento prévio sobre a periodicidade do sinal, tal como o ciclo cardíaco num ECG, para prever com maior precisão os próximos valores de um sinal. A partir dessa modelagem, calcula-se a diferença entre o sinal esperado pelo modelo e o sinal de entrada. A diferença, então, é utilizada como codificação do sinal.

Se o sinal for bem aproximado pelo modelo, os valores da diferença tendem a ficar bastante próximos de zero e, portanto, podem ser facilmente expressos em poucos bits no sinal comprimido. 
Para codificação de ECG, Nave e Cohen [NC93] desenvolveram um algoritmo baseado em dois tipos de preditores: de curto prazo e de longo prazo. Os preditores de curto prazo aproximam melhor variações do sinal dentro de um único batimento cardíaco. Já os preditores de longo prazo eliminam redundância entre batimentos. $\mathrm{O}$ algoritmo proposto por eles obtém taxas de compressão bastante significativas com um erro aceitável. O algoritmo foi posteriormente melhorado por Zigel, Cohen e Katz [ZCK00], no algoritmo chamado ASEC, com o uso de um dicionário de formas de onda de ECG e quantização adaptativa baseada no erro da própria modelagem, alcançando taxas de compressão de até 30:1. No entanto, as codificações geradas por essas técnicas não parecem ser adequadas para a deteç̧ão de anomalias em ECG.

Para sinais de EEG, muitas das técnicas de análise automatizada de anomalias são baseadas em modelagens do sinal como uma série temporal [MKC99]. Assim, torna-se natural usar a mesma modelagem para tentar comprimir o sinal. Memon et al. [MKC99] aplicaram essa técnica para obter uma codificação quase sem perdas (near lossless), utilizando a predição de séries temporais com uma restrição de distância máxima entre um ponto do sinal original e o correspondente no sinal modelado.

\section{Redes neurais}

Nesta técnica, redes neurais são utilizadas para tentar modelar o sinal a ser codificado. Uma vez o sinal modelado, os pesos das interconexões da rede e os valores de ativação de cada neurônio permitem a reconstrução do sinal. Assim, para conseguir comprimir o sinal de entrada, é necessário que a rede neural consiga representá-lo por um período suficientemente longo para que o número de pesos e valores de ativação a ser armazenado seja menor do que o número de amostras do sinal representado.

Iwata, Nagasaka e Suzumura [INS90] aplicaram redes neurais para comprimir sinais de ECG, obtendo taxas de compressão de até 100:1 em alguns casos, com baixas taxas de erro em geral. No algoritmo proposto por eles, o sinal é modelado por uma rede neural com uma camada oculta ao mesmo tempo em que uma outra rede neural aprende o sinal. Os pesos das interconexões entre a primeira camada e a camada oculta são armazenados inicialmente. A partir daí, os níveis de ativação da camada oculta são utilizados como codificação, até que o erro entre a modelagem e o sinal real ultrapasse um determinado limiar. Quando isso ocorre, a rede é substituída pela rede de aprendizado e os novos pesos são armazenados.

Bartolini et al. [BCNM95] aplicaram redes neurais para comprimir EEG, com resultados comparáveis a técnicas baseadas em séries temporais. Ao contrário da rede proposta por Iwata, Nagasaka e Suzumura descrita acima, que possui 70 nós na primeira camada, as redes usadas para comprimir EEG possuem apenas um ou dois nós na primeira camada e apenas mais um ou dois nós numa segunda camada. Essa pequena rede neural vai se adaptando ao sinal por meio de retroalimentação do erro.

Redes neurais também já foram bastante estudadas para detecção de anomalias em ECG [SM98] e EEG [KO95, VRCP02]. Em particular, Kalayci [KO95] utilizou wavelets juntamente com redes neurais na detecção de epilepsia em EEG. Um dos problemas no uso de redes neurais é a necessidade de treiná-las para um determinado uso, e o número de amostras necessárias para treinar uma rede cresce bastante com o número de elementos que a compõem. Assim, a transformada de wavelets foi utilizada para comprimir uma janela do sinal; o sinal comprimido é, então, passado à rede neural 
para detecção de anomalias. Sternickel [Ste02] utilizou uma abordagem semelhante para a detecção de variações na onda P de um ECG. No entanto, nenhuma das técnicas baseadas em redes neurais estudadas utiliza a mesma rede tanto para compressão como para detecção de anomalias.

\subsection{Resumo}

Neste capítulo, diversos trabalhos relacionados à compressão e codificação de sinais biomédicos foram abordados. Alguns deles apresentam ótimos resultados para compressão, mas não geram uma codificação que permite a análise do sinal sem primeiro descomprimi-lo, o que pode dificultar seu uso para análise de uma base grande de sinais.

Por outro lado, alguns dos algoritmos descritos usam características do sinal relevantes na análise médica para codificá-lo e, por isso, geram uma codificação boa para esse tipo de análise. Porém, tais técnicas levam a taxas de compressão mais baixas.

Com base nisso, no próximo capítulo será descrita uma técnica que procura unir os dois fatores positivos dos trabalhos já vistos: boa compressão e boa codificação para análise. 


\section{Capítulo 3}

\section{Metodologia desenvolvida}

Algumas das técnicas discutidas no capítulo 2 para codificação e compressão podem ser utilizadas tanto como assinaturas para análise como para compressão. No entanto, as técnicas com melhores resultados para compressão não geram assinaturas adequadas e, por outro lado, as técnicas que geram boas assinaturas não alcançam boas taxas de compressão.

Um dos problemas com as técnicas analisadas que geram boas assinaturas é que elas não comprimem tão bem o sinal de entrada por não modelarem bem o sinal de entrada entre os pontos marcados como relevantes.

Assim, o objetivo deste trabalho é formular e avaliar uma técnica para a codificação e a compressão de sinais biomédicos iterativa que permita a deteç̧ão de anomalias e a extração de medidas importantes para análise médica ao mesmo tempo em que comprime.

Para a análise de sinais biomédicos, os pontos extremos locais são muito importantes, pois permitem a extração de medidas diretamente relacionadas com a fisiologia e o diagnóstico de anomalias [KKV97]. Assim, uma boa codificação deve preservar tais pontos inalterados e facilmente acessíveis. Por outro lado, para que uma codificação como essa também seja uma boa compressão, é desejável que o sinal entre esses pontos seja bem modelado. Assim, evita-se o uso de pontos irrelevantes na compressão do sinal.

Sinais biomédicos, como, por exemplo, ECG, apresentam uma curvatura marcante entre os pontos extremos locais, decorrente da própria natureza destes sinais. Essa curvatura tem uma forma sigmoidal, ou seja, pode ser bem aproximada por uma função sigmoide, como mostra a figura 3.1 .

Assim, no algoritmo que será descrito neste capítulo, o sinal de entrada é aproximado iterativamente por funções sigmoides, até que a aproximação esteja satisfatória.

\subsection{Uma primeira abordagem}

A cada iteração, o sinal de entrada $x(t), t=0, \ldots, n$, é quebrado em seus pontos de máximo e mínimo locais $\left(T_{i}, x\left(T_{i}\right)\right)$ e $\left(t_{i}, x\left(t_{i}\right)\right)$, respectivamente, gerando os segmentos $S_{i}, i=0, \ldots, p_{0}$. Cada segmento é, então, aproximado por uma função sigmoide construída como descrito a seguir.

Seja $f(t)$ uma função sigmoide dada por

$$
f(t)=-\frac{1}{2} \tanh t=\frac{1}{2}\left(\frac{1-e^{t}}{1+e^{t}}\right) .
$$




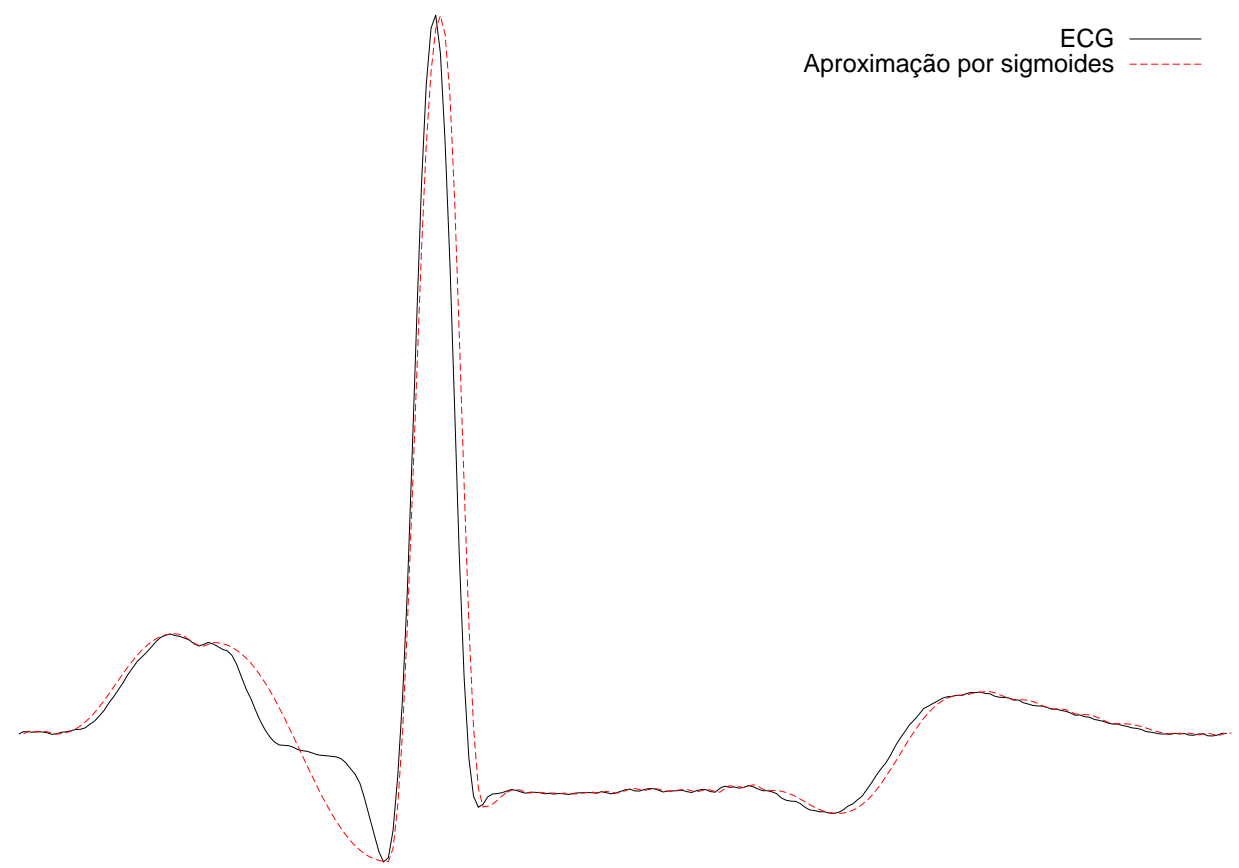

Figura 3.1: Aproximação de um sinal de ECG por sessenta sigmoides

Podemos definir como função base $\phi(t)$, então, a segunda derivada de $f(t)$ :

$$
f^{\prime \prime}(t)=\phi(t)=\frac{e^{3 t}-e^{t}}{\left(1+e^{t}\right)^{4}} .
$$

No entanto, desejamos apenas considerar a função $\phi(t)$ entre seu mínimo e seu máximo locais ao redor de $t=0$. Resolvendo $\phi^{\prime}(t)=0$, obtemos os valores $t_{m}=-1,317$ para o mínimo e $T_{m}=1,317$ para o máximo. Podemos, então, definir a função retangular

$$
\Pi(t)= \begin{cases}1 & \text { se } t_{m} \leq t \leq T_{m} \\ 0 & \text { caso contrário }\end{cases}
$$

e multiplicá-la por $\phi(t)$ para obter uma função sigmoide monotonicamente crescente: $\bar{\phi}=\phi(t) \cdot \Pi(t)$.

Para ajustar a função ao trecho que queremos aproximar, é necessário levar em conta o deslocamento e a diferença de escala entre a função e o trecho. Dado um trecho $S_{i}$, definimos os seguintes parâmetros:

$$
\begin{gathered}
\alpha_{i}=\frac{\left|x\left(T_{i}\right)-x\left(t_{i}\right)\right|}{\left|\phi\left(T_{m}\right)-\phi\left(t_{m}\right)\right|} \\
\beta_{i}=\frac{\left|T_{i}-t_{i}\right|}{\left|T_{m}-t_{m}\right|} \\
\gamma_{i}=\frac{x\left(t_{i}\right)+x\left(T_{i}\right)}{2} \\
\delta_{i}=\frac{t_{i}+T_{i}}{2} \\
\eta_{i}=\frac{x\left(T_{i}\right)-x\left(t_{i}\right)}{\left|x\left(T_{i}\right)-x\left(t_{i}\right)\right|}
\end{gathered}
$$


Os parâmetros $\alpha_{i}$ e $\beta_{i}$ fazem o papel de escala da função sigmoide no eixo das ordenadas e das abscissas, respectivamente. Já os parâmetros $\gamma_{i}$ e $\delta_{i}$ fazem o papel de translação da função sigmoide no eixo das ordenadas e das abscissas, respectivamente.

Com os parâmetros assim definidos, podemos escrever a aproximação do segmento $S_{i}$ pela função $\Phi_{i}$ como

$$
\Phi_{i}(t)=\eta_{i} \cdot \alpha_{i} \cdot \bar{\phi}\left(\frac{t-\delta_{i}}{\beta_{i}}\right)+\gamma_{i}
$$

e, portanto, a primeira aproximação $\xi_{0}(t)$ do sinal $x(t)$ pode ser escrita como

$$
\xi_{0}(t)=\sum_{i=0}^{p_{0}} \Phi_{i}(t)
$$

Tendo a primeira aproximação dada pela equação 3.6, podemos calcular o erro desta aproximação com relação ao sinal original:

$$
E_{0}(t)=x(t)-\xi_{0}(t)
$$

Aplicando o mesmo processo de aproximação para o sinal $E_{0}(t)$, obtemos

$$
\xi_{1}(t)=\sum_{j=0}^{p_{1}} \Phi_{j}(t),
$$

em que $p_{1}$ é o número de segmentos monotônicos em $E_{0}(t)$. Da mesma forma, obtemos o erro desta aproximação:

$$
E_{1}(t)=E_{0}(t)-\xi_{1}(t)=x(t)-\xi_{0}(t)-\xi_{1}(t)=x(t)-\left\{\xi_{0}(t)+\xi_{1}(t)\right\} .
$$

Aplicando novamente o processo para $E_{1}(t)$, obtém-se

$$
\xi_{2}(t)=\sum_{k=0}^{p_{2}} \Phi_{k}(t)
$$

em que $p_{2}$ é o número de segmentos monotônicos em $E_{1}(t)$, e o erro correspondente a essa aproximação:

$$
E_{2}(t)=E_{1}(t)-x i_{2}(t)=x(t)-\left\{\xi_{0}(t)+\xi_{1}(t)+\xi_{2}(t)\right\}
$$

Assim, pode-se repetir o processo aproximativo quantas vezes for necessário para aproximar bem o sinal $x(t)$. Supondo que o processo foi repetido $N$ vezes, obtém-se a seguinte aproximação final para o sinal $x(t)$ :

$$
\Omega(t)=\sum_{m=0}^{N} \xi_{m}(t)
$$

Ou seja, quando $N \rightarrow \infty, \Omega \rightarrow x$.

Para armazenar e, posteriormente, recuperar uma representação de um sinal qualquer criada a partir desse algoritmo, basta armazenar o ponto inicial e final (coordenadas temporais e respectivos 


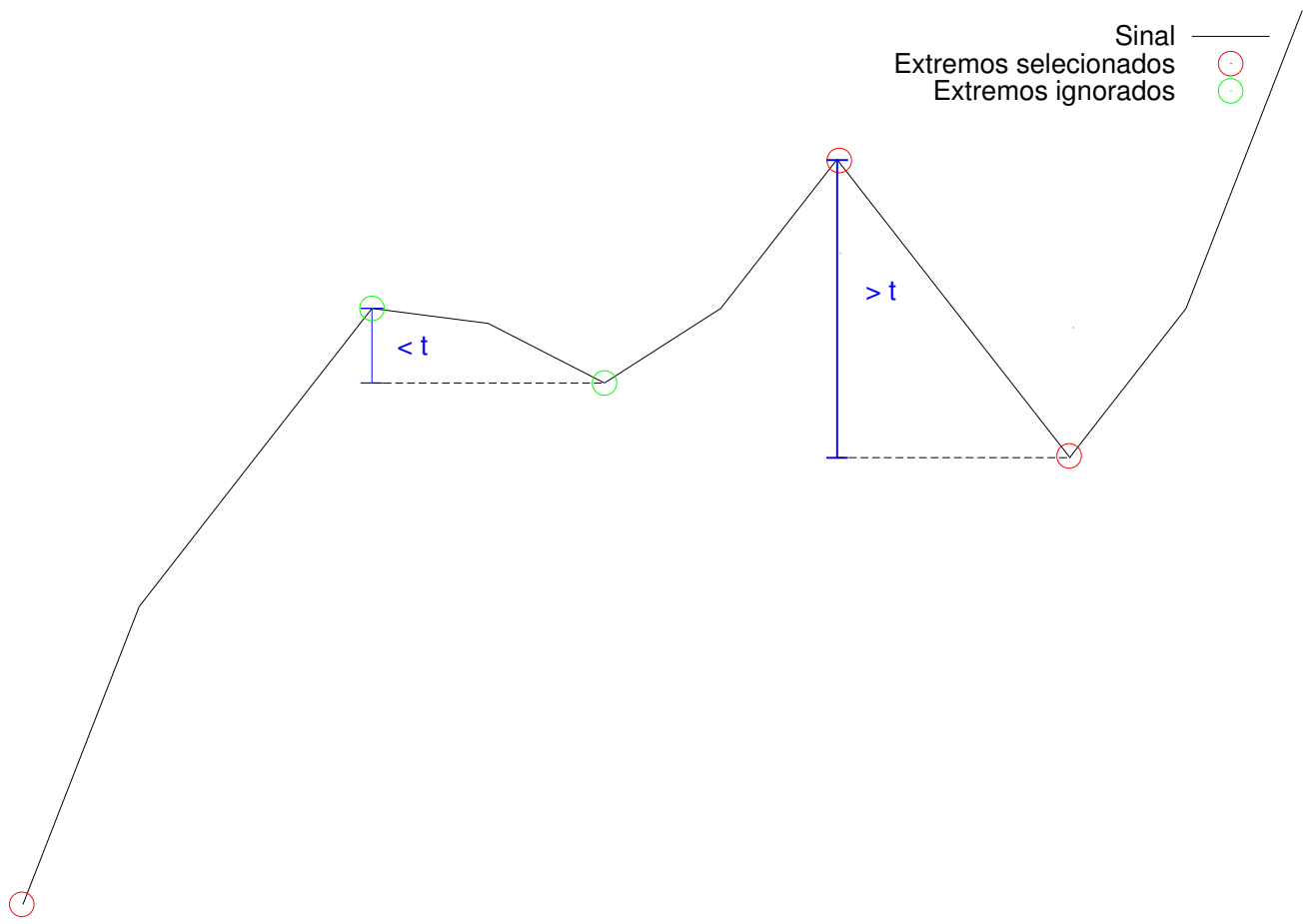

Figura 3.2: Explicação visual da tolerância a erros implementada na seleção dos pontos extremos. Os pontos em verde não são marcados como extremos locais pois a distância entre eles é menor do que a tolerância $t$ definida na execução do algoritmo.

valores) de cada segmento monotônico gerado em cada uma das iterações. A partir desses dois pontos, é possível calcular os coeficientes expressos nas equações 3.4 e, assim, reconstruir o sinal.

\subsubsection{Algoritmos}

A ideia básica de um algoritmo que implemente esta metodologia deve ser localizar os pontos de mínimo e máximo locais para, a partir deles, gerar uma aproximação por sigmoides e, com base nela, calcular o erro da aproximação. Esse erro, que também é um sinal, pode ser passado como entrada para uma nova chamada do algoritmo.

Para identificar máximos e mínimos locais, a ideia é percorrer os pontos do sinal mantendo como estado uma variável crescente que indique se o trecho atual é crescente ou decrescente. A cada novo ponto da entrada, verifica-se a continuidade da monotonicidade. Por exemplo, se o ponto atual tiver um valor menor que o último e se o trecho era crescente, isso significa que o último ponto era um extremo local. Então o algoritmo marca o último ponto como um extremo, muda o valor da variável crescente e prossegue, até que encontre um novo extremo local ou o fim do sinal.

Para a implementação do algoritmo, é necessário considerar que o computador não consegue representar números reais com precisão. Sendo assim, o algoritmo de compressão tem como parâmetro, além do sinal de entrada, a tolerância a erros de arredondamento. A tolerância a erros permite, também, filtrar ruído no sinal de entrada, eliminando máximos e mínimos locais pouco relevantes.

A tolerância a erros é implementada da seguinte forma: dado um trecho monotônico do sinal, um valor de tolerância $t$ e o valor do último ponto $p$, o último ponto será considerado extremo local somente se o valor do ponto atual $v$ for menor que $|p-t|$. A figura 3.2 explica visualmente a ideia.

Como dito anteriormente, para reconstruir uma aproximação do sinal criada por esse algoritmo, é necessário apenas armazenar as coordenadas dos máximos e mínimos locais selecionados. No 
entanto, quando temos mais de uma aproximação, isto é, mais de uma iteração do algoritmo, é necessário identificar de alguma forma a iteração à qual cada conjunto de extremos locais pertence. No algoritmo que se segue, os extremos locais de uma mesma iteração são armazenados contiguamente. Assim, basta indicar onde termina uma iteração e começa outra. Isso é feito adicionando ao início de uma iteração um ponto com valores especiais, denotado PONTO_INICIO, que pode ser facilmente identificado como início de iteração.

Por fim, para calcular o sinal de erro da aproximação, podemos usar uma estrutura de dados para armazenar o trecho sendo aproximado para que, quando este trecho acabe, seja possível calcular a diferença entre cada ponto do sinal original e da aproximação. Chamamos essa estrutura de CalculadoraDeErro e definimos duas operações para ela: inserePontoEntrada, para colocar mais um ponto do sinal de entrada dentro dessa estrutura, e finalizaSegmento, que gera o sinal de erro para o sinal acumulado. A operação inserePontoEntrada pode ser implementada como uma inserção em lista ligada e, por isso, não será detalhada aqui. A operação finalizaSegmento é detalhada no algoritmo 1. Vale observar que, para que essa estrutura funcione, é necessário que ela tenha acesso à saída de erro. Assim, essa saída é um parâmetro para a construção da estrutura CalculadoraDeErro.

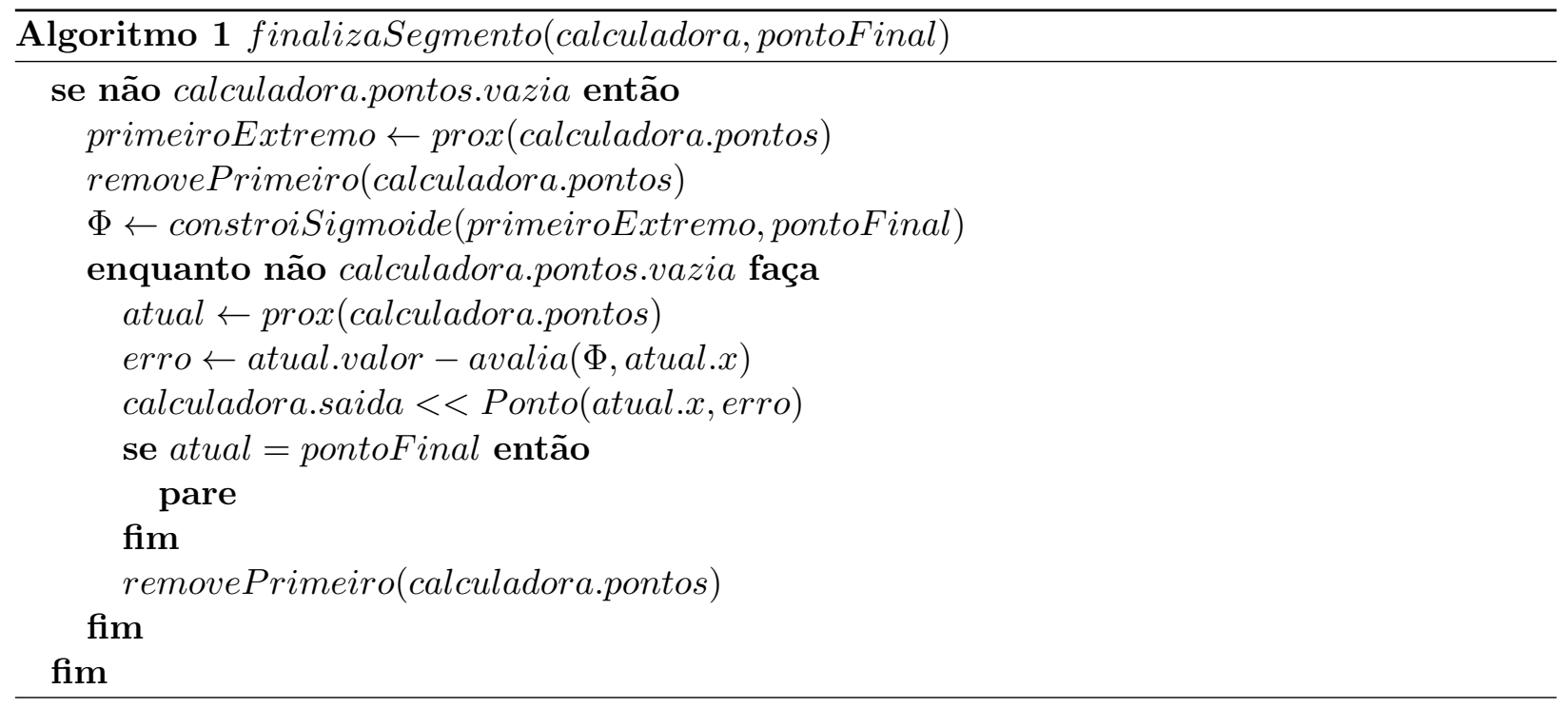

O algoritmo 2 descreve a sequência de passos necessários para aplicar uma iteração da metodologia descrita para um sinal. Como entrada, o algoritmo recebe uma estrutura do tipo lista ligada com o sinal de entrada e duas estruturas que permitem a inserção de valores em tempo constante: uma para a saída do sinal codificado e outra para o sinal de erro. O algoritmo pode ser facilmente estendido para várias iterações com o uso de uma estrutura de dados do tipo FIFO (First In First Out) para passar o sinal de erro gerado como entrada para uma outra chamada do algoritmo.

Enquanto o algoritmo de compressão é online, isto é, gera saída enquanto ainda está processando a entrada, o algoritmo de descompressão precisa ler todo o arquivo de entrada para conseguir gerar o sinal original a partir dele.

O primeiro passo para a descompressão é ler todos os pontos extremos a partir da entrada, agrupados por iteração, e gerar as funções $\Phi$ correspondentes. As funções são armazenadas em listas - uma para cada iteração - de forma que, para reconstruir o sinal original, basta percorrer todas as listas até o final. Os pontos do sinal original são obtidos somando-se as funções selecionadas 


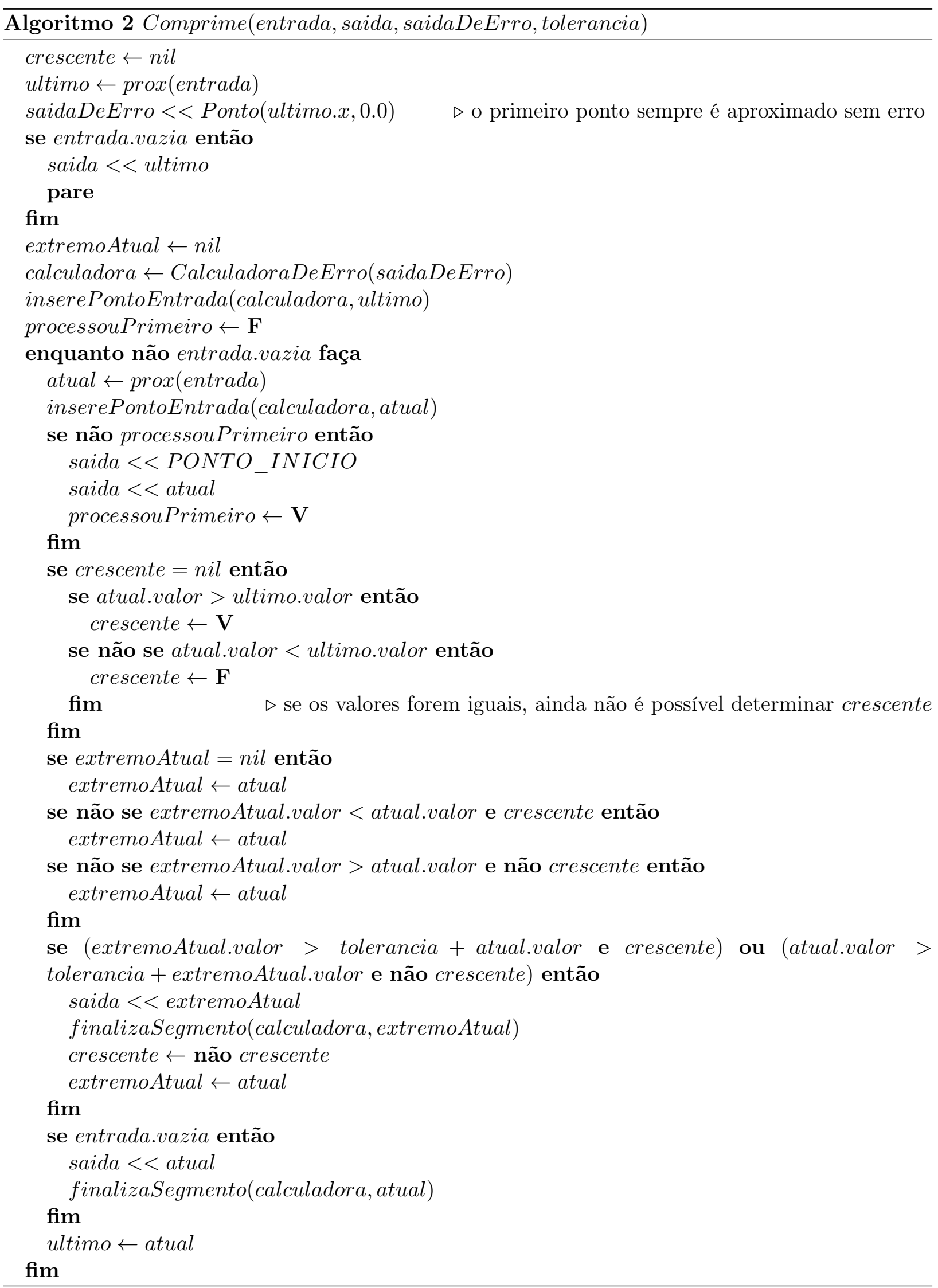


no momento em cada lista. A função selecionada de uma lista é trocada pela seguinte quando ela passa a valer zero por causa da função $\Pi$ de corte.

O algoritmo 3 descreve uma sequência de passos para obter a lista de funções por iteração. Como entrada, o algoritmo recebe os pontos armazenados no arquivo do sinal comprimido.

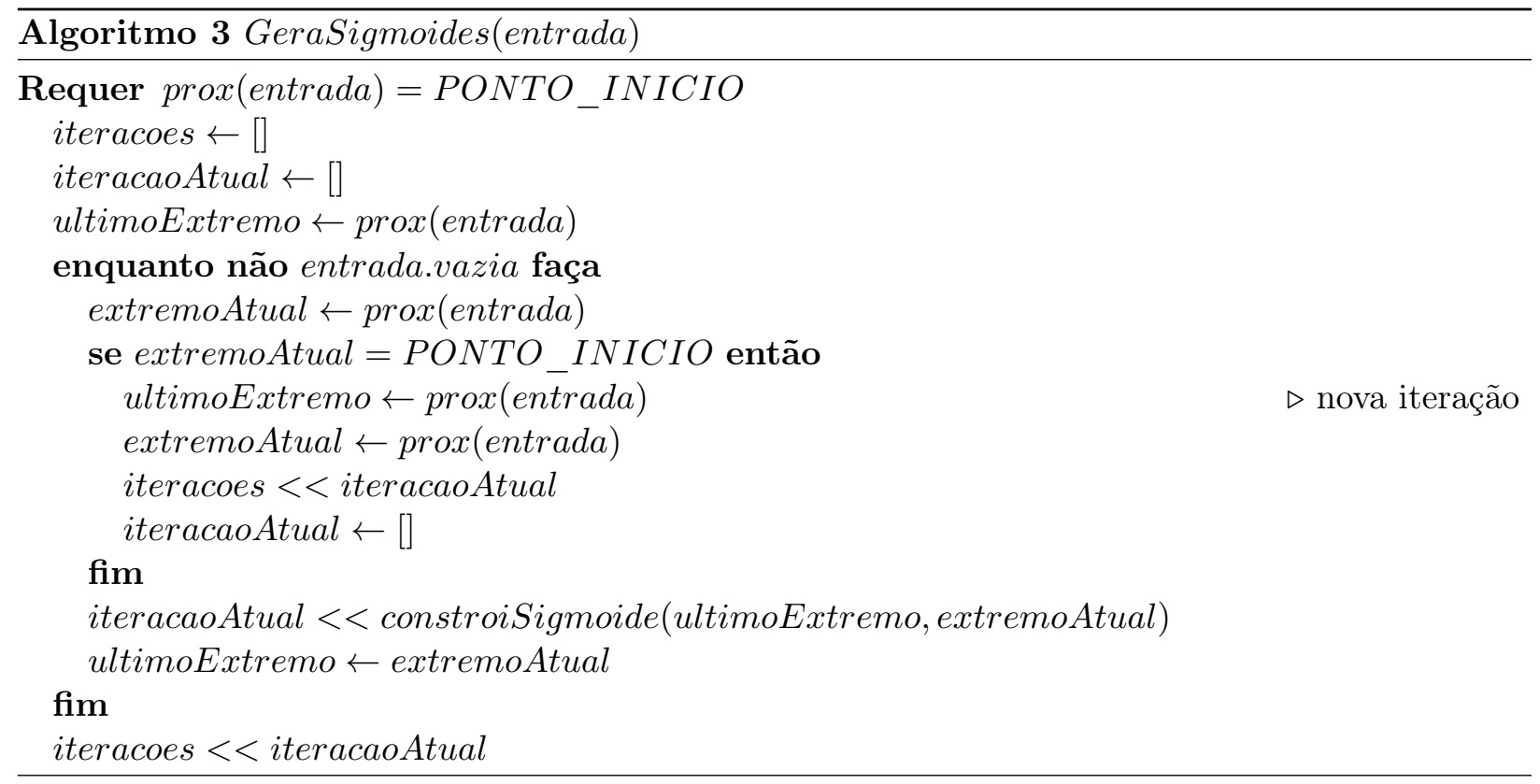

\subsection{Otimização para compressão}

A abordagem apresentada pode ser aprimorada com a observação de dois fatos:

1. Para cada ponto selecionado, dois valores precisam ser armazenados: a coordenada temporal e o valor correspondente.

2. A mesma coordenada $t$ pode ser selecionada em mais de uma iteração.

Ambos os fatos são um problema do ponto de vista de compressão. No primeiro caso, se todos os pontos do sinal original forem selecionados (no caso de um sinal com frequência igual à metade da taxa de amostragem, por exemplo), a codificação resultante terá o dobro do tamanho do sinal original. O segundo fato implica que não é possível determinar que o sinal original será de fato comprimido, uma vez que o sinal resultante pode ter mais pontos.

Tendo em vista esses problemas, a seguinte modificação pode ser feita na primeira abordagem: em vez de codificar o sinal de erro inteiro como se fosse um único sinal, pode-se codificar o sinal de erro considerando apenas cada um dos trechos correspondentes aos pontos selecionados no sinal original.

Mais formalmente, dada uma primeira aproximação

$$
\xi_{0}(t)=\sum_{i=0}^{p_{0}} \Phi_{0, i}(t),
$$

temos que cada função $\Phi_{0, i}(t)$ aproxima um trecho monotônico do sinal original $x(t)$ no intervalo $\left[t_{i}, T_{i}\right]$. Além disso, pela construção da função, sabemos que 


$$
x(t)-\Phi_{0, i}(t)=0
$$

para $t=t_{i}$ e $t=T_{i}$. Ou seja, o erro na aproximação de $x(t)$ por $\Phi_{0, i}(t)$ é nulo nos extremos da função; os extremos desse segmento estão perfeitamente aproximados. Então, para não mudar essa aproximação numa iteração posterior do algoritmo, basta fazer com que esses pontos continuem sendo extremos de um segmento a ser aproximado nas iterações seguintes.

Para conseguir isso, em vez de considerarmos o sinal $E_{0}(t)$ como o sinal a ser aproximado na segunda iteração, consideramos cada um dos sinais $E_{0, i}(t)=x(t)-\Phi_{0, i}(t)$ como os sinais a serem independentemente aproximados (para $t$ no intervalo $\left[t_{i}, T_{i}\right]$ ). Com isso, a segunda iteração do algoritmo passa a ser dada por

$$
\xi_{1}(t)=\sum_{i=0}^{p_{0}}\left(\Phi_{0, i}(t)+\sum_{j=0}^{p_{1, j}} \Phi_{1, i, j}\right),
$$

ou seja, na segunda iteração, cada um dos erros dos $p_{0}$ segmentos monotônicos passa a ser aproximado por $p_{1, j}$ sigmoides.

Como anteriormente, é possível aplicar o mesmo processo iterativamente quantas vezes desejado.

\subsubsection{Armazenamento}

Para entender por que a nova abordagem é mais interessante para compressão do que a primeira abordagem descrita, considere o sinal da figura 3.4. A primeira iteração de ambas as abordagens seleciona os pontos em vermelho na figura 3.5. Na segunda iteração, o resultado de cada abordagem é diferente. Com a primeira abordagem, teríamos os pontos em vermelho na figura 3.6 selecionados. Já com a alteração descrita, teríamos os pontos em vermelho mais os pontos em verde dessa mesma figura.

Veja que os pontos em verde na figura 3.6 não precisam ser armazenados: basta saber que, na primeira iteração, tivemos um ponto selecionado naquele mesmo $t$. Com isso, sabemos que, nessa iteração teremos uma sigmoide começando naquele $t$.

Com base nessa observação, podemos concluir que não é mais necessário armazenar todos os pontos extremos selecionados com suas respectivas coordenadas temporais: podemos gravar o sinal comprimido como um sinal comum, com seus valores em sequência num arquivo. Se, numa determinada coordenada temporal, não houver um ponto extremo selecionado em nenhuma iteração, basta preencher a posição correspondente no arquivo com um valor especial que indique isso.

Como exemplo, considere o sinal da figura 3.2. Ele pode ser representado da seguinte forma:

$$
\begin{array}{llllllllllllll}
1 & 3 & 4 & 5 & 4.9 & 4.5 & 5 & 6 & 5 & 4 & 5 & 7
\end{array}
$$

Após uma iteração do algoritmo, selecionamos os pontos em vermelho dessa figura. Podemos guardar esses pontos num arquivo da seguinte forma:



Pode parecer uma forma ineficiente de armazenar o sinal. Porém, quanto menos pontos extremos selecionados, mais valores especiais repetidos teremos no sinal resultante. Como os valores especiais 


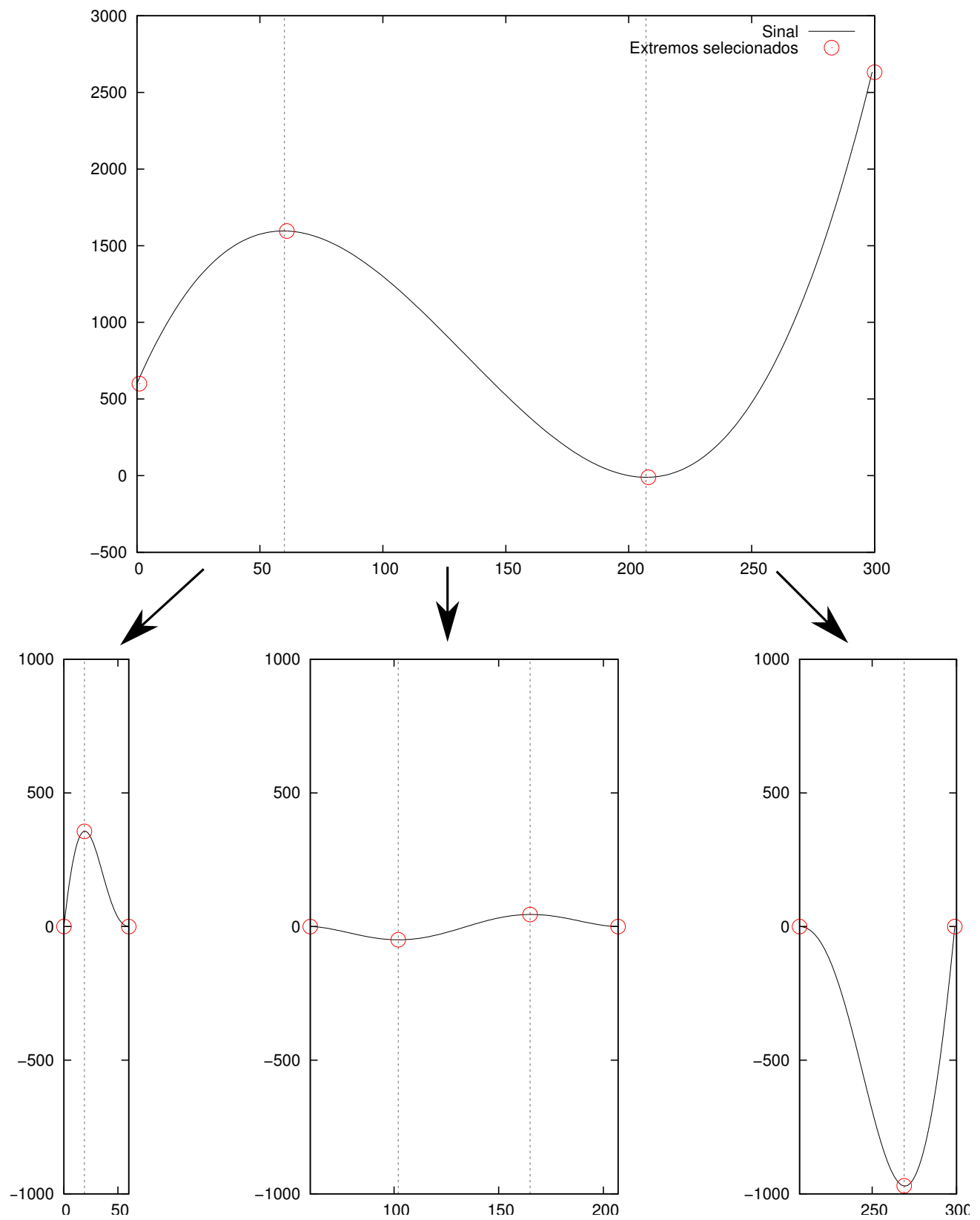

Figura 3.3: Com a alteração proposta, cada segmento monotônico da primeira iteração passa a ser processado independentemente na segunda iteração. 


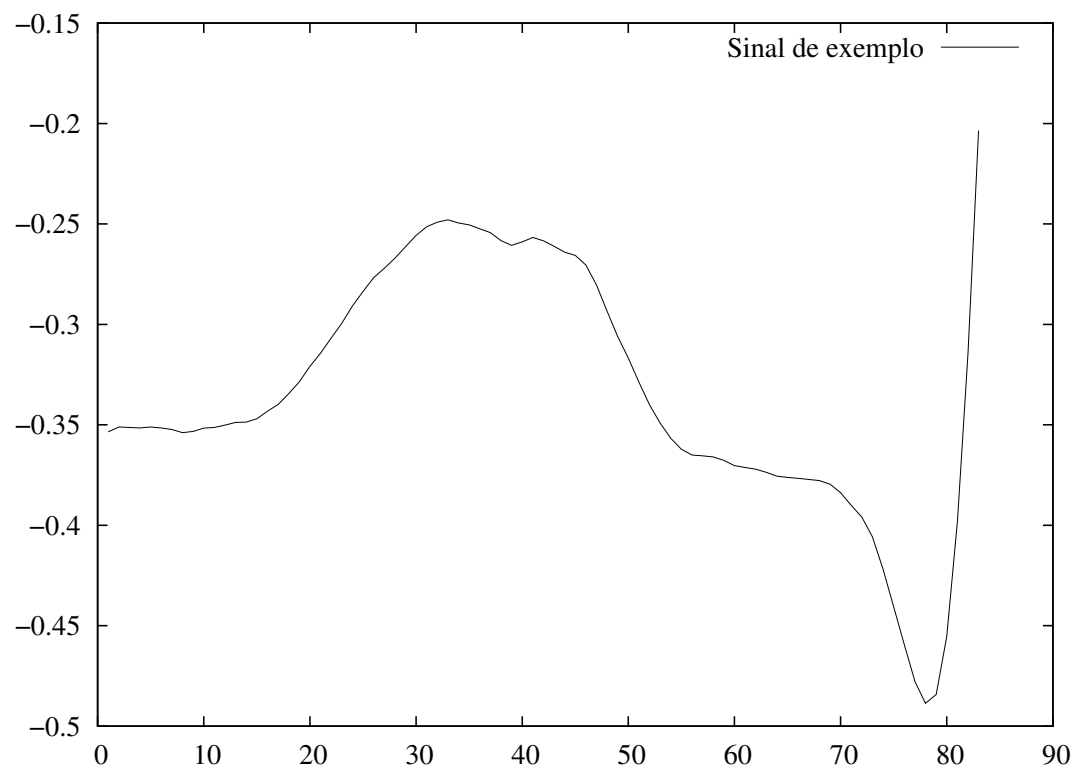

Figura 3.4: Sinal de exemplo para codificação

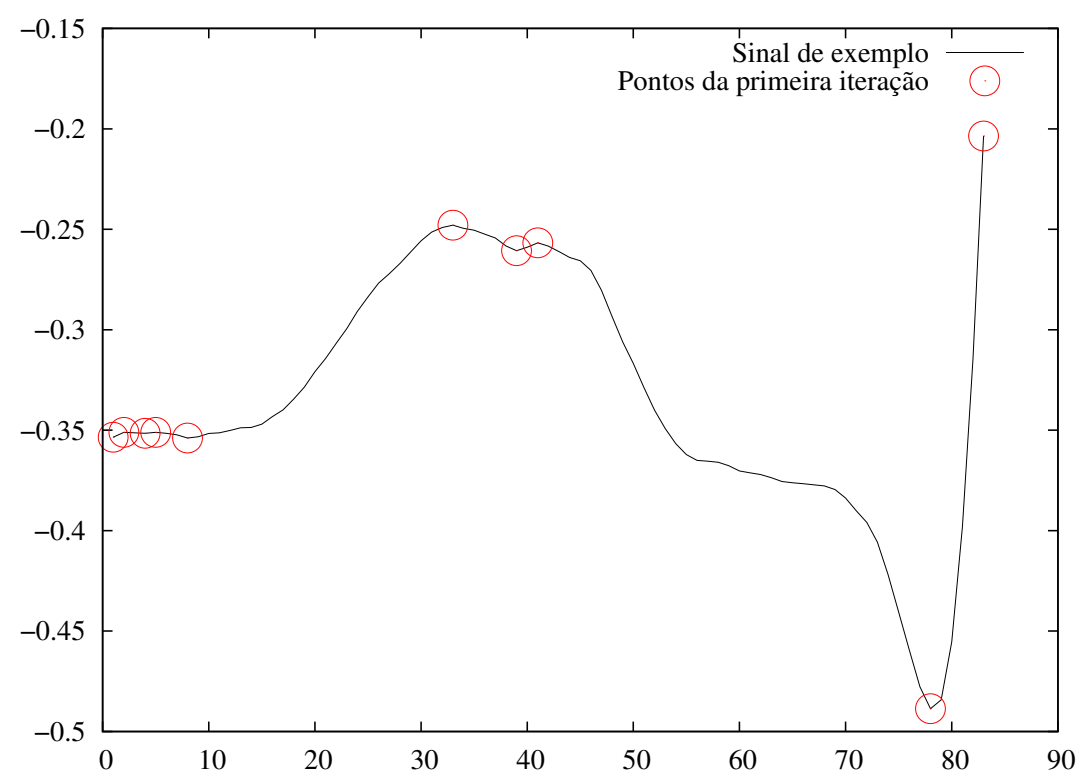

Figura 3.5: Pontos selecionados na primeira iteração por ambos os algoritmos para o sinal da figura 3.4 


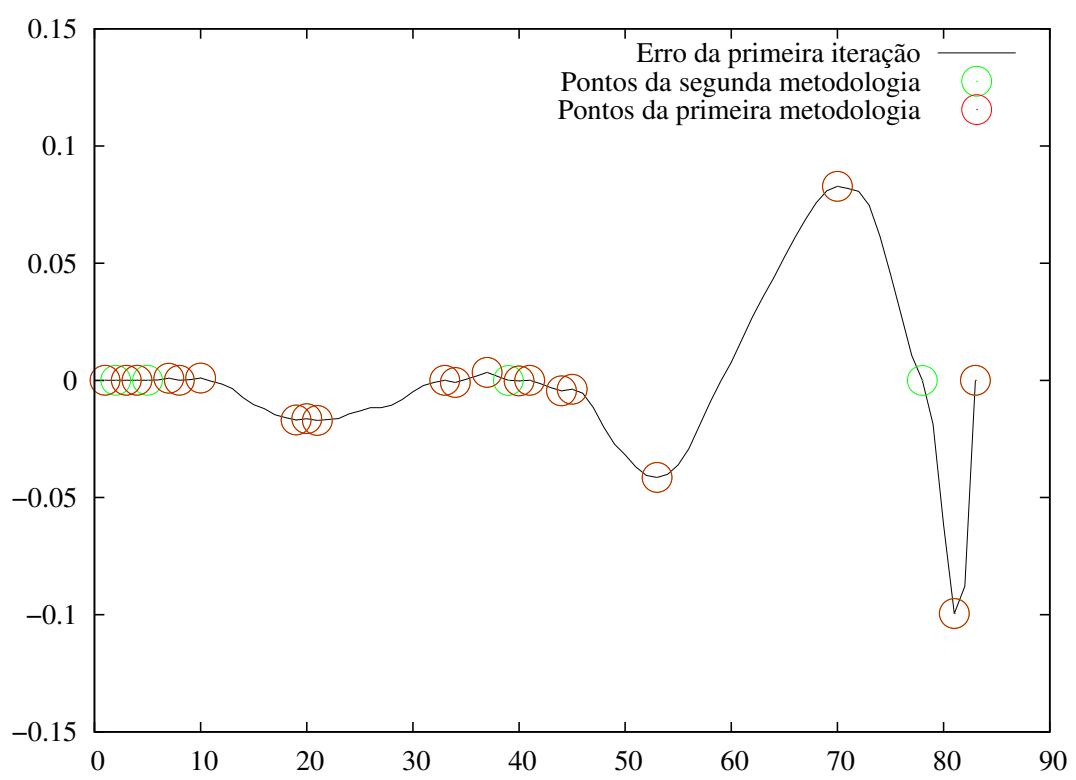

Figura 3.6: Pontos selecionados na segunda iteração por ambos os algoritmos para o sinal da figura 3.4 . Em verde, os pontos selecionados apenas pela segunda metodologia descrita

são muito frequentes, podem ser representados de forma bastante compacta usando uma ou mais técnicas de compressão sem perdas, descritas na seção 2.1. Neste trabalho, optou-se por aplicar o algoritmo DEFLATE no sinal comprimido [Deu96].

No entanto, não basta armazenar os valores dos pontos extremos: é necessário armazenar também em qual iteração um determinado ponto extremo apareceu. Existem diversas formas eficientes de se fazer isso e, em alguns casos, umas são mais adequadas que outras.

Um sinal de ECG, por exemplo, apresenta valores de ponto flutuante. Uma possibilidade para armazenar os valores dos pontos extremos desse sinal é reduzir a precisão dos valores em ponto flutuante, reservando alguns bits na representação do valor para armazenar o número da iteração na qual o valor apareceu.

É possível fazer isso com números de ponto flutuante de 64 (double), 32 (float) e 16 bits (halffloat) facilmente. De acordo com a especificação desses formatos, os últimos bits de cada um desses valores são menos significativos [IEE08]. Assim, podemos reservar esses bits para armazenar o valor da iteração. Em geral, 3 bits são suficientes, permitindo armazenar sinais comprimidos oriundos de até 7 iterações (um dos valores representáveis com 3 bits fica reservado para indicar que nenhum ponto extremo ocorreu naquela coordenada). No caso do half-float, no entanto, a reserva de 3 bits já introduz erros significativos na compressão do sinal. Assim, para esse formato, reservam-se apenas 2 bits, permitindo a codificação de até 3 iterações.

Um sinal de uma imagem, por outro lado, costuma apresentar apenas valores inteiros. Nesses casos, utilizar um sinal de ponto flutuante para representá-la pode introduzir erros desnecessariamente. No caso de sinais inteiros, não é possível reservar bits para armazenar o número da iteração, uma vez que os erros introduzidos ao se fazer isso serão muito grandes: a reserva dos 2 bits menos significativos de um inteiro fará com que apenas múltiplos de 4 sejam representáveis. Sendo assim, para armazenar eficientemente um valor junto do número da iteração, uma possível solução é simplesmente armazenar os dois valores consecutivamente. No entanto, novamente é possível economizar alguns bits. Se os valores do sinal são representados em 8 bits, não é necessário usar 
32 bits

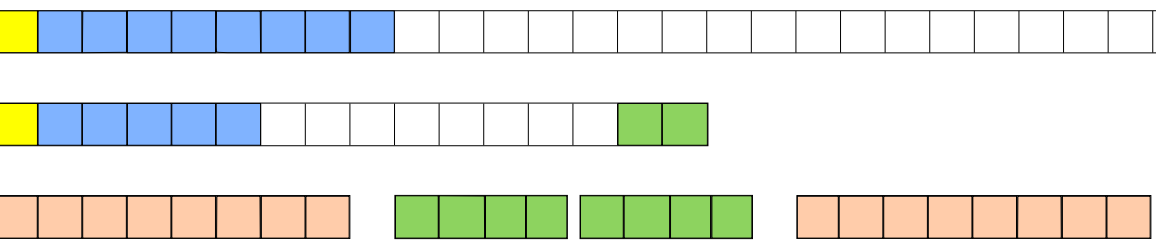

12 bits

Figura 3.7: Codificação do número da iteração de um ponto em diferentes números de bits. As cores representam a função de cada bit: em amarelo, bits de sinal; em azul, bits de expoente; em branco, bits de mantissa; em rosa, bits de representação de inteiro; em verde, bits para armazenamento da iteração correspondente.

outros 8 bits para representar a iteração, pois dificilmente serão usadas mais de 4 iterações (como será mostrado no próximo capítulo). Assim, bastaria usarmos 3 bits, como no caso dos valores de ponto flutuante, para armazenar o valor da iteração. No entanto, fazendo isso, teríamos que cada valor, junto com seu número de iteração, ocuparia 11 bits. Por questões de eficiência e facilidade de implementação, é mais interessante usarmos 12 bits, sendo 8 para o valor e 4 para a iteração. Assim, mantém-se a leitura do sinal alinhada com a leitura de bytes.

A figura 3.7 mostra graficamente cada um dos esquemas de codificação implementados.

\subsubsection{Algoritmos}

O algoritmo utilizado para calcular a modelagem reformulada não muda muito comparado ao algoritmo 2. Porém, a estrutura apresentada pela nova modelagem permite paralelizar o algoritmo mais facilmente: é possível codificar cada trecho de erro recursivamente e em paralelo com o mesmo algoritmo.

Para que o algoritmo possa ser executado em paralelo e gerar uma saída ordenada, como descrito na seção 3.2.1, uma espécie de barreira de sincronização é necessária. Na implementação desenvolvida, foi utilizada uma estrutura de dados do tipo árvore binária, uma por iteração, para que, ao término da execução de uma iteração, os resultados de cada linha de execução (thread) saiam na ordem correta. O acesso à estrutura é controlado, de forma que apenas uma thread pode inserir um novo resultado nela por vez.

Vale notar que o algoritmo não depende do formato de saída escolhido, seja ele de 12, 16, 32 bits ou ainda um outro formato desejado. A formatação da saída pode ser feita num segundo passo, após a organização dos pontos extremos selecionados.

Por uma questão de apresentação e concisão, o algoritmo para essa modelagem reformulada não será apresentado aqui. Uma implementação dele em Java está disponível em https://bitbucket.org/ lreal $/ \mathrm{mjt} / \mathrm{src}$.

Para a decodificação, o algoritmo também não muda muito com relação ao algoritmo 3 . No entanto, uma vez que não há mais o marcador PONTO_INICIO, os pontos selecionados foram armazenados junto de sua iteração correspondente. Além disso, alguns pontos das iterações mais avançadas estão representados implicitamente por pontos de iterações anteriores. Assim, é necessário aplicar um pré-processamento na entrada para extrair o conjunto de funções sigmoides dos pontos armazenados.

O algoritmo 4 descreve a sequência de passos necessários para extrair as funções sigmoides agrupadas por iteração a partir de um sinal comprimido. Com esse conjunto de funções em mãos, é possível aplicar o processo descrito na seção 3.1.1 para obter o sinal original. Como entrada, o 
algoritmo recebe uma lista de estruturas que representam os valores codificados do sinal comprimido, contendo cada uma o valor do ponto extremo selecionado e a iteração à qual ele pertence.

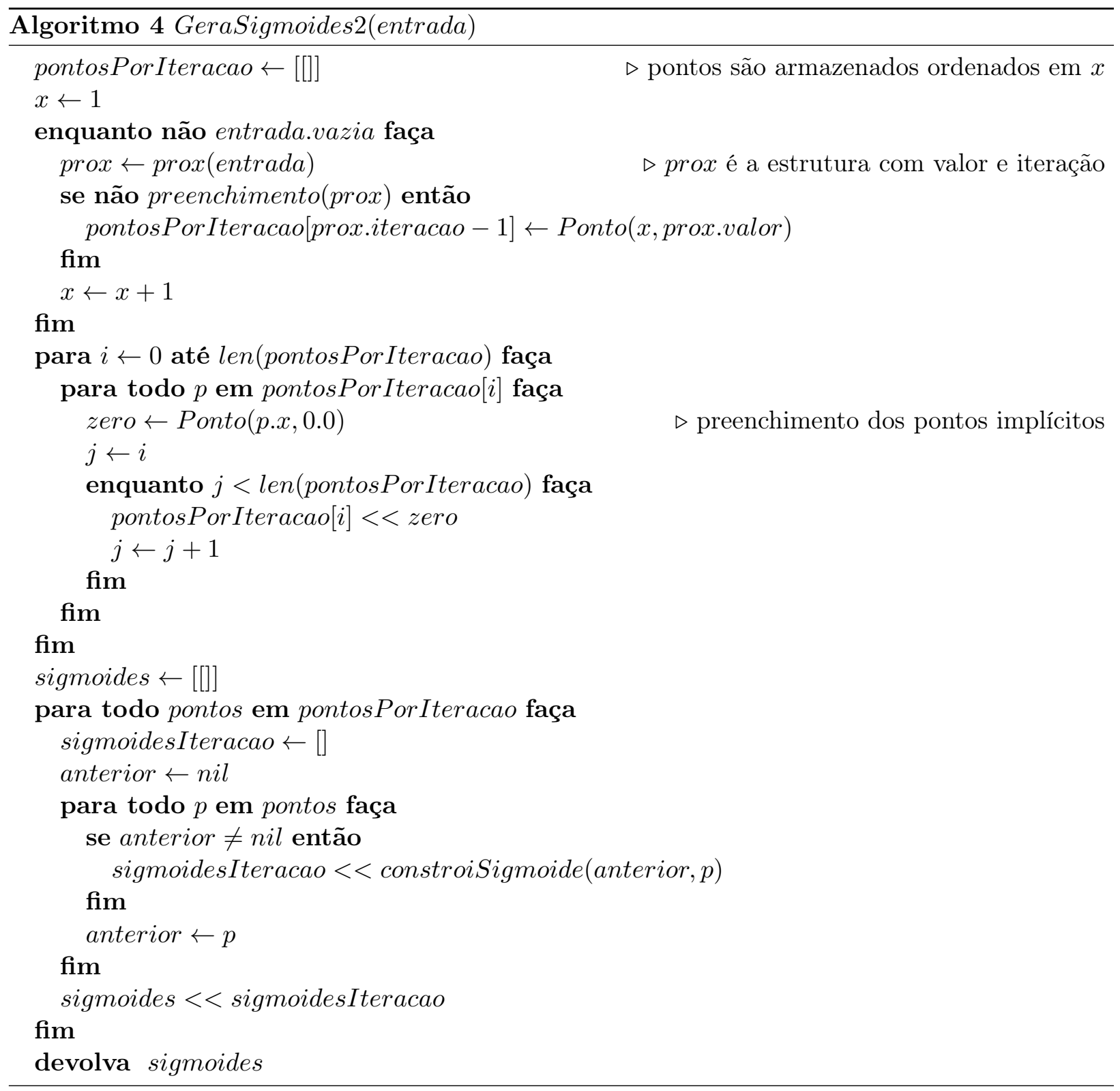

\subsection{Implementação}

Ambos os algoritmos descritos neste capítulo foram implementados para avaliar seu desempenho com sinais biomédicos reais. As implementações, feitas em Java, estão disponíveis num repositório online ${ }^{1}$. Neste repositório, a branch java-version-2 contém a implementação da primeira metodologia descrita neste capítulo. A metodologia otimizada para compressão encontra-se disponível na branch java-version-3.

Além dos algoritmos descritos neste capítulo, foram também implementados o algoritmo AZTEC e seus derivados (mAZTEC, imAZTEC e AZTDIS). A implementação também foi feita em Java e encontra-se disponível online ${ }^{2}$.

\footnotetext{
${ }^{1}$ https://bitbucket.org/lreal/mjt

${ }^{2}$ https://github.com/luiz/aztec-java
} 


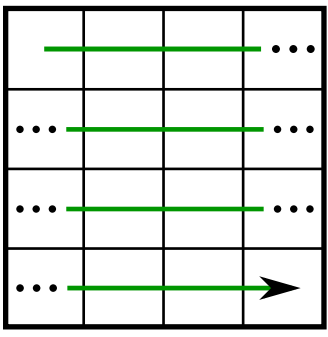

(a) Por linhas

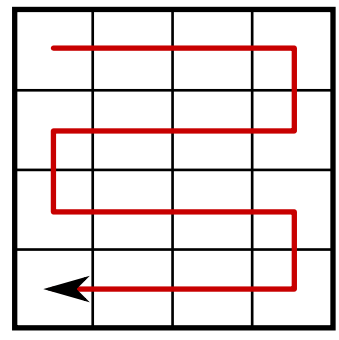

(b) Em zigue-zague

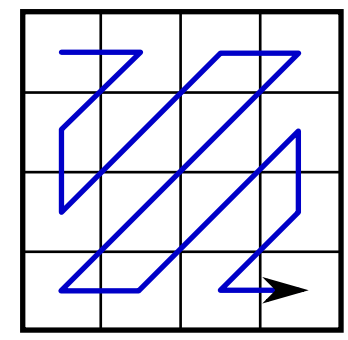

(c) Em zigue-zague na diagonal

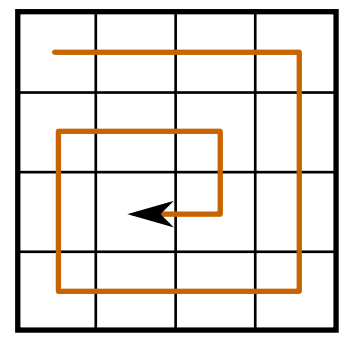

(d) Em espiral, das bordas para o centro

Figura 3.8: Linearizações utilizadas para codificar imagens

Por fim, para efeitos de comparação, foi feita uma implementação de compressão de sinais usando o algoritmo DEFLATE em Java. Essa implementação lê e escreve a representação binária dos números de ponto flutuante que representam o sinal, aplicando o algoritmo DEFLATE na representação binária.

\subsection{Aplicação para imagens}

A codificação apresentada é aplicável apenas para sinais unidimensionais. Para torná-la aplicável para imagens, é necessário tornar a imagem um sinal unidimensional ou, em outras palavras, encontrar uma ordenação para os pontos de uma imagem.

Existem diversas formas de se ordenar os pontos de uma imagem. A figura 3.8 mostra algumas delas. Nenhuma delas leva em conta o tipo de imagem ou a distribuição de intensidades na ordenação. Existem métodos que levam essas informações em conta para tentar encontrar uma ordenação que aproxime pontos com valores semelhantes para, com isso, tornar o sinal resultante mais compressível [BJCO03]. No entanto, torna-se difícil identificar padrões no sinal resultante e associá-los com padrões na imagem original. Por isso, apenas os métodos apresentados na figura 3.8 foram testados neste trabalho.

\subsection{Discussão}

A utilização de pontos extremos para a representação do sinal biomédico permite a extração de informações importantes para análises clínicas diretamente a partir dela. Além disso, pela escolha desses pontos, é garantido que o algoritmo preserva os pontos extremos do sinal original, o que é essencial na análise de ECGs [MSM87].

A metodologia descrita assemelha-se a algumas das técnicas apresentadas, como o método Turning Point e o algoritmo TRIM. No entanto, o esquema de interpolação por sigmoides e a utilização do sinal de erro para aplicação iterativa são inovações.

Por ser um método iterativo, é possível controlar o erro na representação determinando o número de iterações que o algoritmo deve executar. Também é possível controlar o erro por meio do fator de tolerância na escolha dos pontos extremos. 


\subsection{Avaliação}

A avaliação das metodologias descritas leva em conta tanto a capacidade de compressão como a utilização do sinal comprimido na detecção de anomalias.

\subsubsection{Compressão}

Para avaliar a capacidade de compressão, o tamanho dos arquivos com os sinais comprimidos usando diferentes técnicas foi comparado.

No caso dos algoritmos de compressão com perda, foi medida também a diferença entre o sinal original e o sinal recuperado a partir da compressão. Para avaliar essa diferença, foi usada a relação sinal-ruído (em inglês, signal-to-noise ratio, SNR), dada pela equação

$$
\operatorname{SNR}(x, \bar{x})=20 \log _{10}\left(\frac{\sqrt{\frac{1}{n}\left(x_{1}^{2}+x_{2}^{2}+\ldots+x_{n}^{2}\right)}}{\sqrt{\frac{1}{n}\left(\bar{x}_{1}^{2}+\bar{x}_{2}^{2}+\ldots+\bar{x}_{n}^{2}\right)}}\right)
$$

Além dos algoritmos implementados (cf. seção 3.3), também foram avaliados os seguintes algoritmos:

1. Transformada rápida de Fourier

2. Transformada rápida de cossenos (DCT-I)

3. Transformada rápida de wavelets, com as seguintes wavelets:

(a) Haar [Chu92]

(b) Daubechies, com 2 e 4 momentos nulos [Dau92]

4. Vorbis (algoritmo de compressão de áudio bastante utilizado) [Xip12]

Para as transformadas de Fourier e de cossenos, foram utilizadas as implementações da biblioteca Commons Math, da Apache ${ }^{3}$. Para a transformada de wavelets, a biblioteca JWave ${ }^{4}$, com suporte a diversas wavelets mãe, foi utilizada. Para o algoritmo Vorbis, foi utilizado o programa SoX ${ }^{5}$, usando como saída o formato de encapsulamento Ogg [Pfe03]. Foram usadas a versão 2.2 da Commons Math, a revisão 75 do repositório da JWave e a versão 14.3.2 do programa SoX.

Os arquivos foram gerados da seguinte forma:

1. Para a codificação usando a primeira metodologia desenvolvida, a representação binária das coordenadas dos pontos extremos selecionados foi escrita seguindo a especificação da IEEE de ponto flutuante de precisão dupla [IEE08]. Na codificação, foi utilizado um valor de tolerância $t=10^{-6}$ apenas para evitar a seleção de pontos desnecessários por causa de erros de arredondamento, sem o intuito de filtrar o sinal de entrada;

2. Para a codificação usando a segunda metodologia desenvolvida, o sinal foi escrito usando o esquema de codificação em 16 bits descrito na seção 3.2.1. Na codificação, também foi usado um valor de tolerância $t=10^{-6}$;

\footnotetext{
${ }^{3}$ http://commons.apache.org/math/

${ }^{4}$ http://code.google.com/p/jwave/

${ }^{5}$ http://sox.sourceforge.net/
} 
3. Para a codificação usando os algoritmos DEFLATE e Vorbis, nenhuma alteração foi feita nos arquivos gerados pelos programas correspondentes;

4. Para as outras codificações, foi escrita a representação binária dos valores gerados por cada uma.

Além disso, todos os arquivos gerados passaram por uma segunda etapa de compressão usando o algoritmo DEFLATE, exceto os arquivos gerados apenas com o próprio DEFLATE e com o Vorbis.

No caso das compressões por transformada, a compressão ocorre efetivamente no processo de quantização. Como comentado na seção 2.2.1, há diversos processos de quantização possíveis. Para as comparações feitas neste trabalho, a quantização foi feita zerando os coeficientes correspondentes às frequências mais altas de cada sinal, mantendo apenas $1 / 16$ dos coeficientes originais. No caso da transformada de Fourier, também foi usada a propriedade da simetria para sinais reais descrita na equação 2.7 para economizar espaço no armazenamento do sinal. O truncamento, neste caso, foi feito levando em conta apenas os $N / 2$ primeiros valores do sinal transformado.

Nos testes com o algoritmo AZTEC, a codificação foi feita com $K=0.1$ (diferença máxima entre dois pontos representados na mesma reta) e os demais parâmetros em seus valores padrão. Para o algoritmo mAZTEC, todos os parâmetros foram mantidos em seus valores padrão.

Todas as técnicas foram aplicadas a um total de 73 sinais biomédicos dos seguintes tipos:

- 15 sinais de ECG gravados com amostragem de $1000 \mathrm{~Hz}$, com duração variando de 131072 $\left(2^{17}\right)$ a $4194304\left(2^{22}\right)$ amostras;

- 15 sinais de pressão intraesofágica de gravados com amostragem de $1000 \mathrm{~Hz}$, com duração variando de 131072 a 4194304 amostras;

- 15 sinais de pressão venosa central gravados com amostragem de $1000 \mathrm{~Hz}$, com duração variando de 131072 a 4194304 amostras;

- 15 sinais de pressão nas vias aéreas gravados com amostragem de $1000 \mathrm{~Hz}$, com duração variando de 131072 a 4194304 amostras;

- 1 sinal de média de ECG ao longo de 60 batimentos cardíacos com duração de 256 amostras (vide figura 3.9d). O sinal foi gerado a partir do sinal de ECG MLII da gravação número 100 da base de dados MIT-BIH [MM01, GAG $\left.{ }^{+} 00\right]$. A partir deste sinal, foram extraídos os batimentos contidos entre as amostras 3762 e 21323, num total de 60 batimentos, de acordo com as anotações presentes no sinal e considerando o início do sinal como sendo 100 amostras antes do indicado nas anotações. Cada um destes batimentos foi reamostrado linearmente para 256 amostras, para ter o mesmo número de amostras dos outros sinais. Por fim, foi feita uma média dos batimentos reamostrados.

- 4 sinais de variação média da pressão arterial de um suíno ao longo de 60 batimentos cardíacos com duração de 256 amostras (vide figura 3.9a);

- 4 sinais de variação média do fluxo de sangue na artéria de um suíno ao longo de 60 batimentos cardíacos com duração de 256 amostras (vide figura 3.9b); 
- 4 sinais de variação média do diâmetro arterial de um suíno ao longo de 60 batimentos cardíacos com duração de 256 amostras (vide figura 3.9c);

Os sinais gerados a partir de um suíno foram obtidos como descrito por Mekkaoui et al. $\left[\mathrm{MRF}^{+} 03\right]$.

As metodologias descritas também foram testadas na compressão de imagens e, no caso da segunda metodologia desenvolvida, foi utilizada uma codificação com 12 bits para armazenar o sinal. O tamanho do arquivo final, a relação sinal-ruído e a correspondência entre as bordas extraídas pela aplicação do operador Sobel na imagem original e na imagem restaurada (correspondência medida também pela SNR) foram analisados e comparados com aqueles obtidos pelo formato JPEG [Wal91] e pelo formato PNG [Deu96]. Neste último caso, por se tratar de um formato de compressão sem perdas para imagens, apenas os tamanhos dos arquivos foram comparados. O tamanho do arquivo da imagem no formato PGM foi usado como base de medida para a capacidade de compressão de cada técnica.

Para ser possível aplicar as metodologias desenvolvidas, as imagens foram transformadas em sinais unidimensionais seguindo as metodologias descritas na seção 3.4.

A figura 3.10 mostra as imagens utilizadas nos testes. Todas foram extraídas de datasets disponíveis online ${ }^{6}$. A imagem de ressonância magnética (RM) foi obtida a partir da imagem obtida com contraste T2 dentro do dataset BRAINIX; as imagens de tomografia computadorizada (CT) e tomografia por emissão de pósitrons (PET) são parte do dataset PROSTATIX (datasets CT WB e PET WB, respectivamente).

Para cada um dos três tipos de imagem utilizados, todos volumétricos, foi escolhida uma fatia para os testes. No caso da imagem de RM, foi utilizado o $11^{\circ}$ corte axial. No caso da imagem PET, foi utilizado o $84^{\circ}$ corte coronal. No caso da imagem CT, foi utilizado o $369^{\circ}$ corte axial. Além das fatias escolhidas, também foram utilizadas uma região no interior de cada imagem para codificação em separado.

Para que as imagens pudessem também ser convertidas para os formatos PNG e JPEG, as intensidades $I(x, y)$ das imagens originais foram mapeadas para 256 níveis de cinza $\hat{I}(x, y)$ com a fórmula a seguir:

$$
\hat{I}(x, y, L, W)= \begin{cases}0 & \text { se } I(x, y)<L-\frac{W}{2} \\ 255 & \text { se } I(x, y)>L+\frac{W}{2} \\ \frac{I(x, y)-L+\frac{W}{2}}{W} \cdot 255 & \text { caso contrário }\end{cases}
$$

Assim, a imagem de RM foi mapeada com os valores $W=502$ e $L=288.8$, a imagem de CT foi mapeada com os valores $W=400$ e $L=40$ e a imagem de PET foi mapeada com os valores $W=20000$ e $L=10000$.

As fatias originais tinham $512 \times 512$ pixels na imagem de RM, $512 \times 512$ pixels na imagem de CT e $168 \times 437$ pixels na imagem de PET. Vale notar que, pela natureza da aquisição da imagem PET, os 437 pixels de altura da imagem representam, na verdade, 229,425 pixels, se a mesma resolução for utilizada em ambos os eixos. Assim, para facilitar a visualização desta imagem, uma transformação de escala foi aplicada na fatia original. Para os testes e posterior exibição neste trabalho, as fatias foram ampliadas para 1997x1997 pixels na imagem de RM, 2382x2382 pixels na imagem de CT

\footnotetext{
${ }^{6}$ http://www.osirix-viewer.com/datasets/
} 


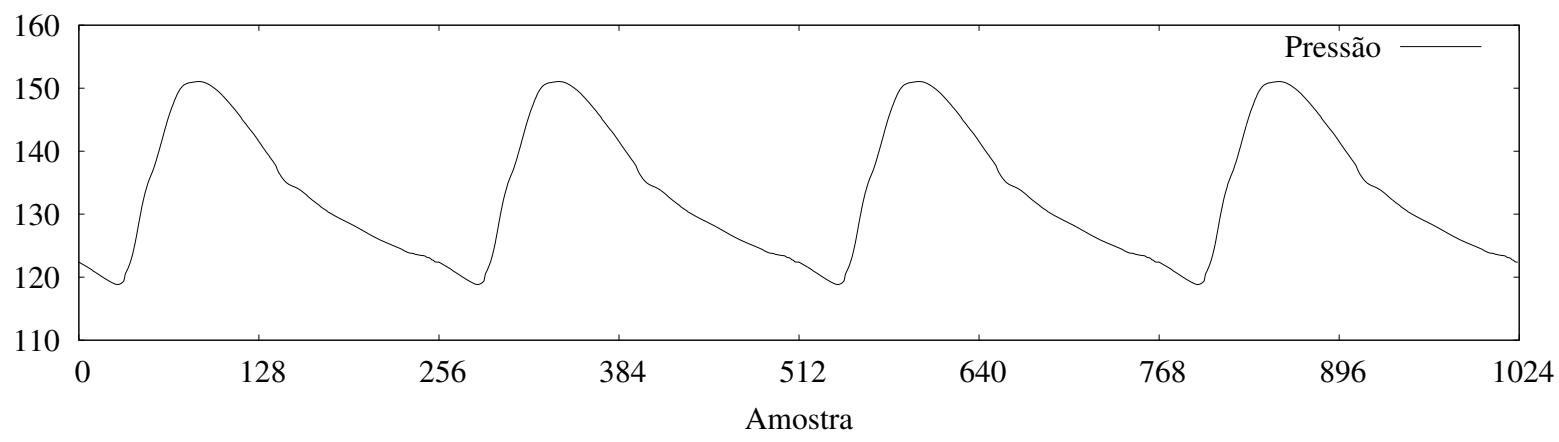

(a) Pressão (em $\mathrm{mm} \mathrm{Hg}$ )

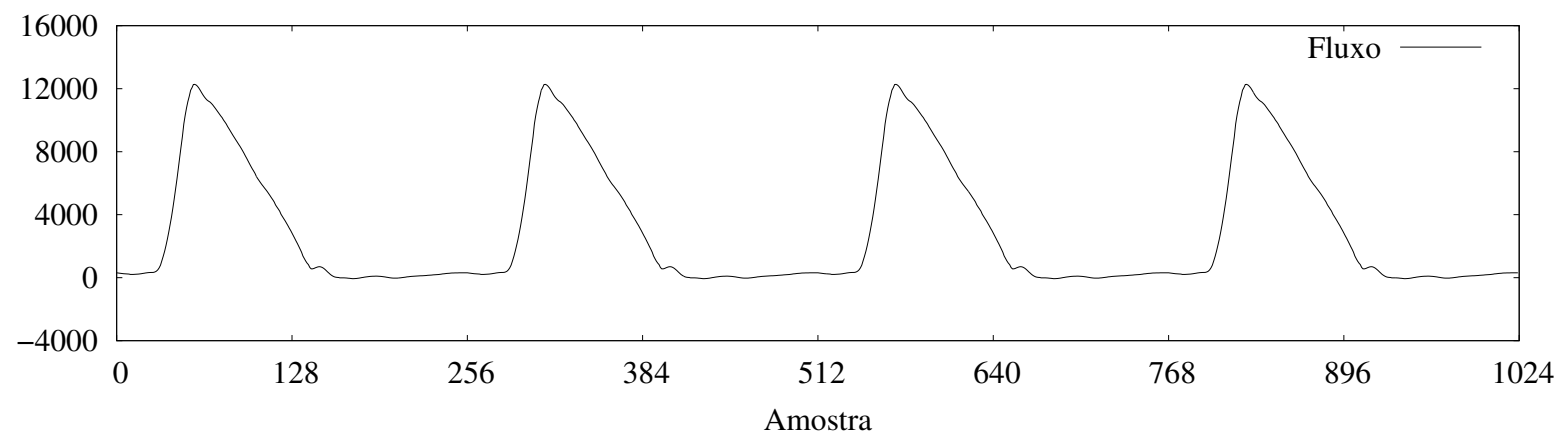

(b) Fluxo (em ml/min)

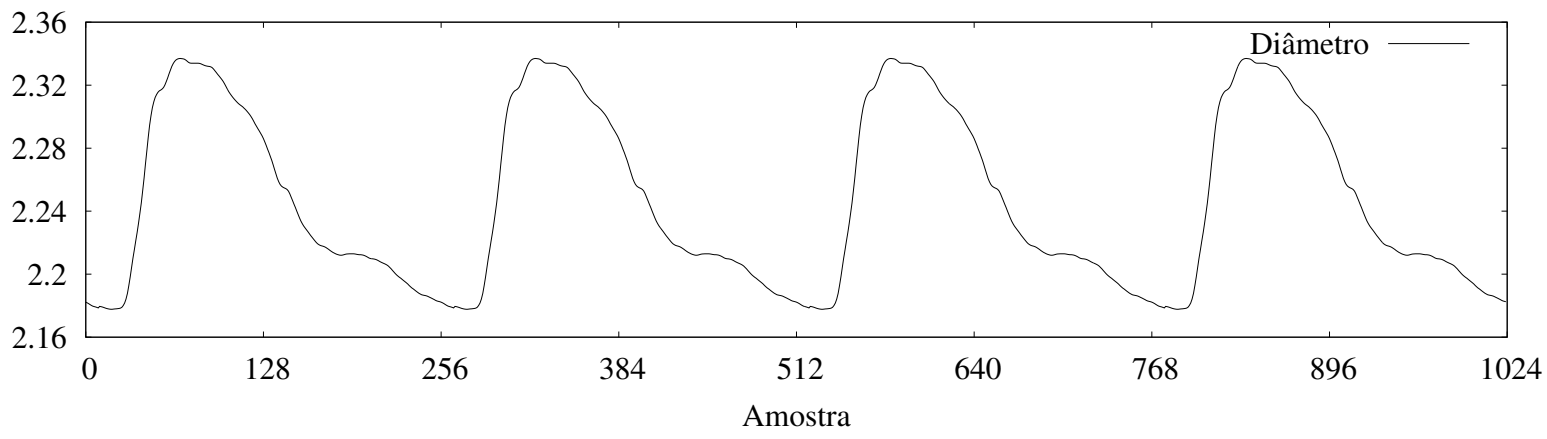

(c) Diâmetro $(\mathrm{em} \mathrm{cm})$

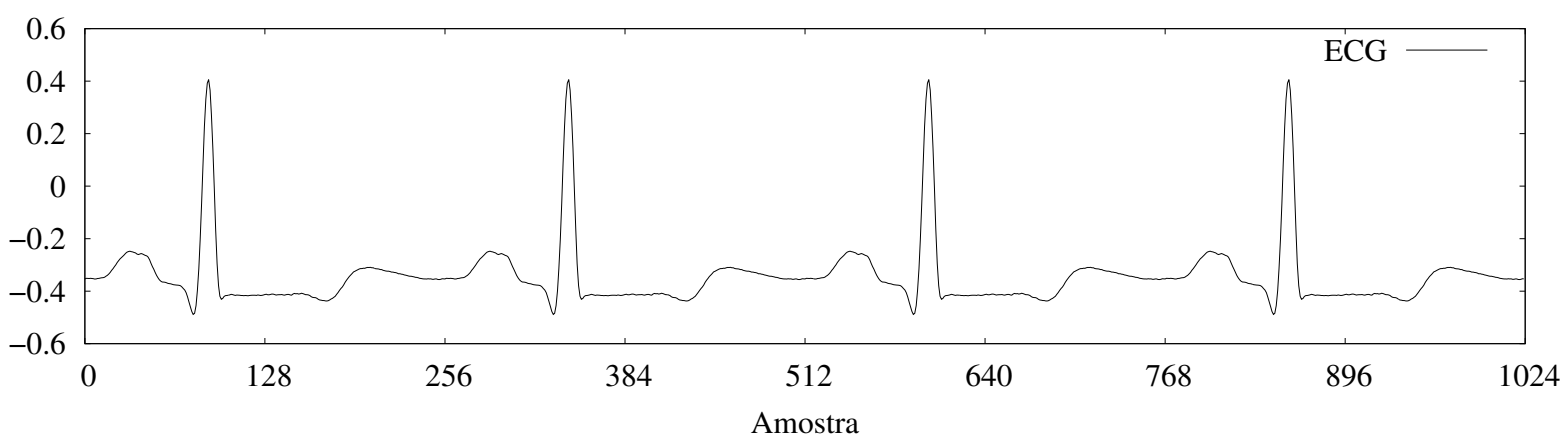

(d) $E C G(e m m V)$

Figura 3.9: Alguns dos sinais utilizados para testar os algoritmos estudados e as metodologias desenvolvidas: variação de pressão, fluxo sanguíneo e diâmetro na aorta de um suíno ao longo de um batimento cardíaco e um ECG. As figuras mostram os sinais repetidos para 4 ciclos cardíacos. 


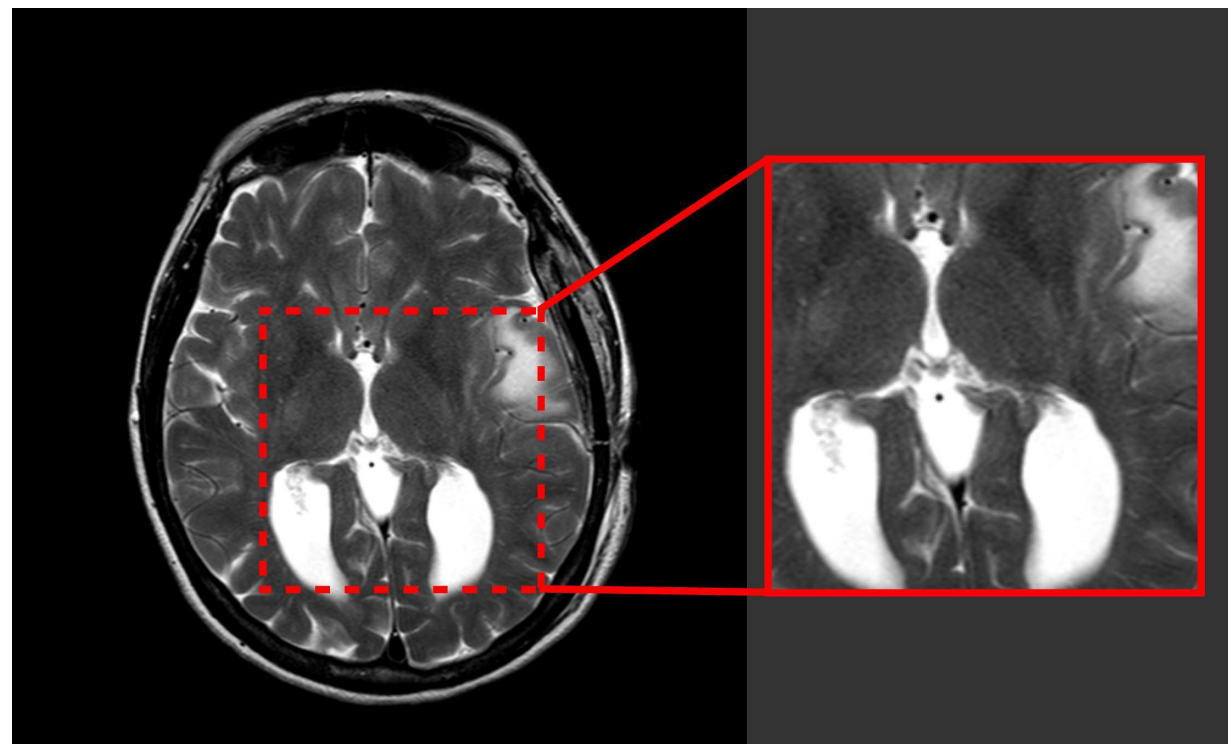

(a) Imagem de ressonância magnética e região

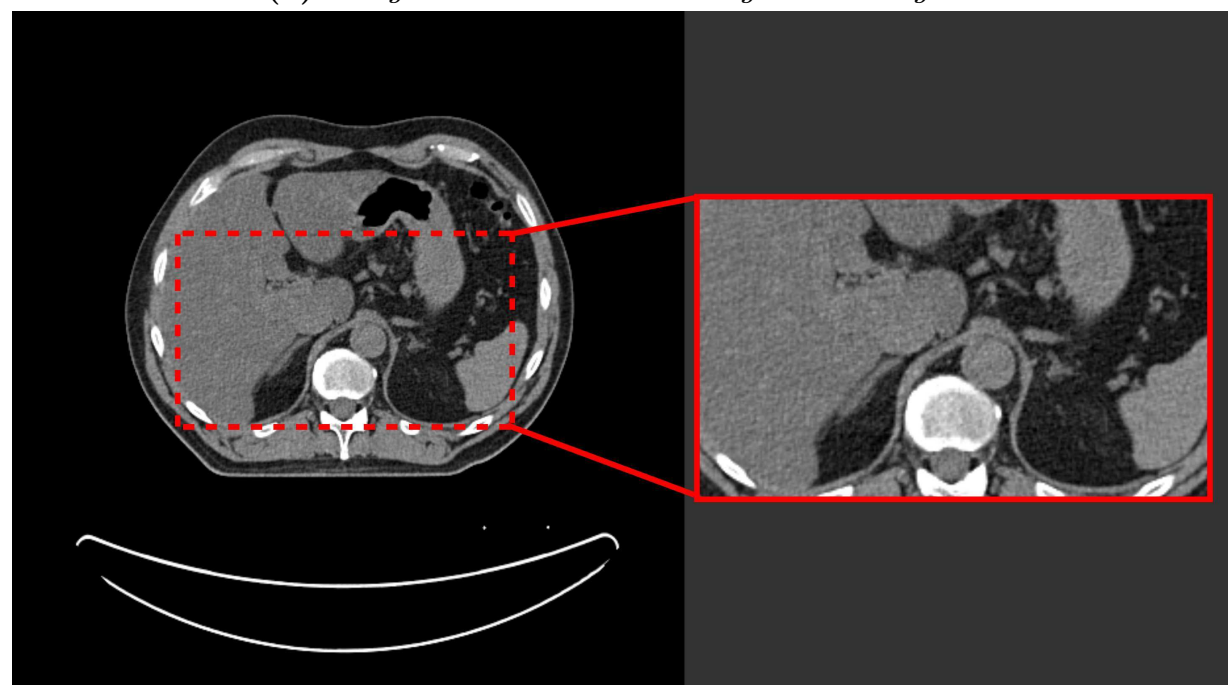

(b) Imagem de tomografia computadorizada e região

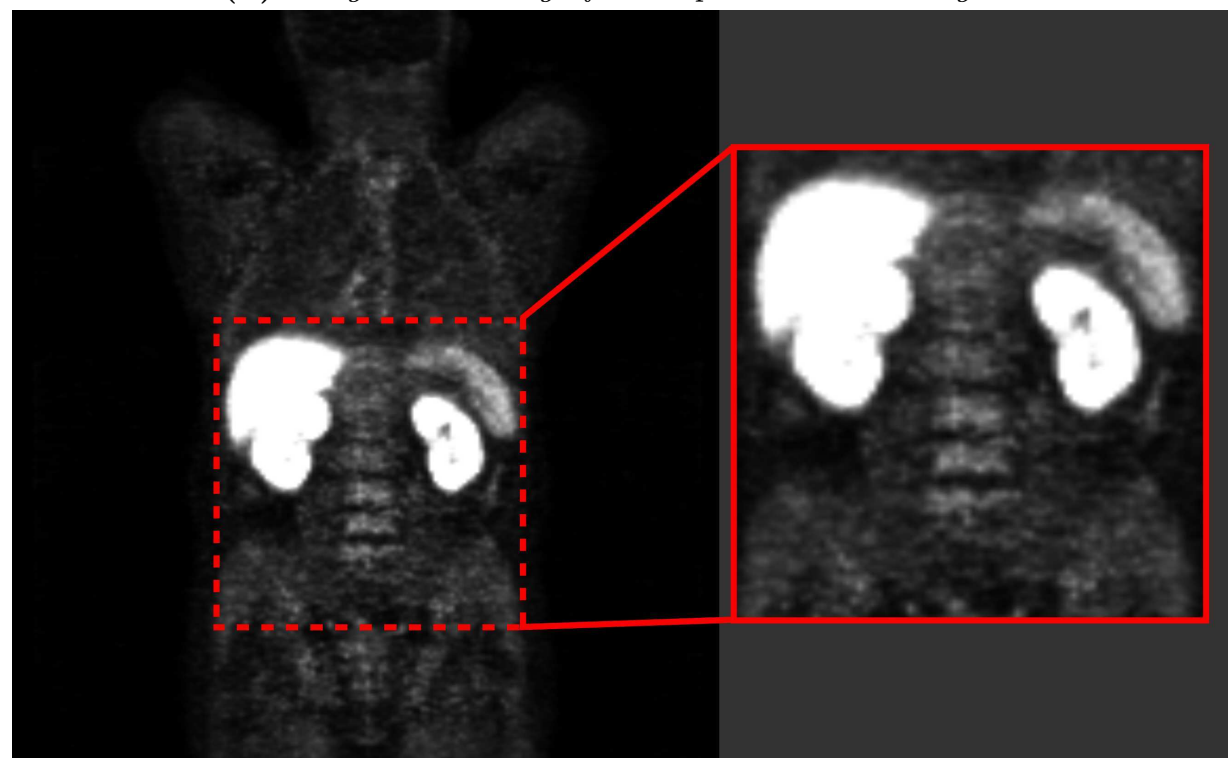

(c) Imagem de tomografia por emissão de pósitrons e região

Figura 3.10: Imagens utilizadas nos testes comparativos de desempenho em compressão. 


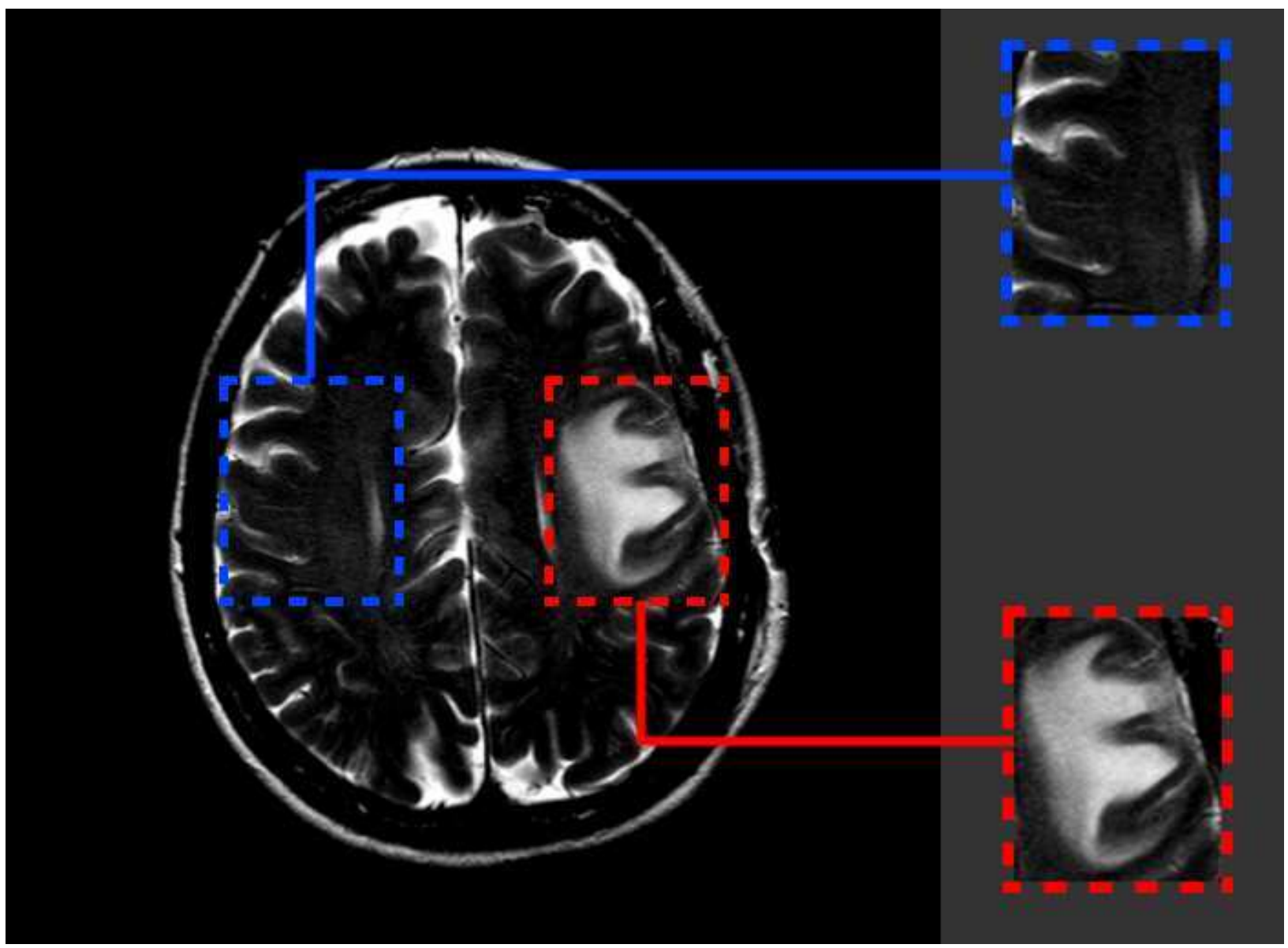

Figura 3.11: Uma das imagens utilizadas na avaliação da assinatura gerada pela metodologia desenvolvida e as respectivas regiões selecionadas.

e 2303x2432 pixels na imagem de PET (após escala para ajustar resolução dos eixos). As regiões selecionadas são de 776x776 pixels, 1205x704 pixels e 1018x1018 pixels, respectivamente.

\subsubsection{Análise}

Um dos objetivos deste trabalho é desenvolver um método de compressão que também seja eficaz para a análise do sinal comprimido, de forma que o sinal comprimido sirva como assinatura do sinal original, capaz de armazenar características importantes do sinal original. Sendo assim, foi avaliada a capacidade de se detectar um tumor cerebral numa imagem de ressonância magnética com base apenas na modelagem gerada pelo algoritmo de compressão.

Para essa análise, uma imagem de ressonância magnética com contraste T2 de um cérebro com apenas um dos hemisférios afetados por um tumor, retirada do dataset BRAINIX. A partir deste dataset, determinou-se um volume contendo o tumor. Foram, então, extraídos os cortes deste volume nas três direções - axial, sagital e coronal - para arquivos de imagem individuais. O mesmo foi feito com o lado oposto do cérebro, não afetado pelo tumor, com o intuito de avaliar as diferenças entre as modelagens do lado afetado e do lado sadio do cérebro. Os cortes foram extraídos para imagens no formato PNG seguindo o mapeamento em níveis de cinza da equação 3.17 , com $W=350$ e $L=320$. A figura 3.11 mostra uma fatia e as regiões selecionadas nela.

Na figura, o lado oposto é mostrado sem nenhuma rotação mas, para eliminar uma possível influência da orientação da imagem nos resultados, a imagem do lado sadio foi espelhada no eixo 
horizontal.

Uma vez extraídas, as fatias foram codificadas utilizando a segunda metodologia descrita com uma, duas, três e quatro iterações. Na conversão da imagem para sinal unidimensional, foi utilizada a ordenação de pixels por linhas, conforme figura 3.8a. Da codificação realizada, foram extraídos os coeficientes $\alpha_{i}, \beta_{i}, \gamma_{i}$ e $\delta_{i}$ de cada sigmoide do modelo gerado (cf. equação 3.5). Por fim, foi feita uma análise estatística dos coeficientes para verificar diferenças no comportamento de cada um dos coeficientes de acordo com a imagem codificada e o número de iterações utilizados na codificação.

Vale observar que, para a extração dos coeficientes a partir do sinal comprimido, não foi necessário descomprimi-lo totalmente; apenas o algoritmo DEFLATE foi aplicado antes da leitura dos pontos extremos armazenados.

\subsubsection{Desempenho}

Para que as metodologias desenvolvidas sejam utilizáveis para grandes quantidades de dados, é desejável que o consumo de tempo das operações de compressão e descompressão seja baixo. Para avaliar esta característica, o tempo para comprimir e descomprimir um sinal de ECG com 1048576 amostras usando cada uma das técnicas estudadas foi medido. O sinal foi comprimido e descomprimido cem vezes com cada técnica. Os tempos foram medidos num computador com processador Intel(CP7350 (dois núcleos de processamento 64 bits de 2,0 GHz com $3 \mathrm{MB}$ de cache L2) e 4 GB de memória RAM executando o sistema operacional Linux versão 3.8.2 (64 bits). 


\section{Capítulo 4}

\section{Resultados}

As figuras 4.1, 4.2 e 4.3 descrevem o processo de codificação de um sinal de pressão, um de fluxo sanguíneo e um de diâmetro arterial de um suíno usando a primeira metodologia descrita. A figura 4.4 mostra a codificação do sinal de ECG de 256 amostras também usando a primeira metodologia descrita.

Nelas, é possível ver os pontos extremos escolhidos para a primeira iteração, o erro entre o resultado da primeira iteração e o sinal original, os pontos extremos escolhidos nesse sinal de erro, o erro entre o resultado da segunda iteração e o sinal original e, por fim, o resultado da segunda iteração.

As figuras 4.5, 4.6, 4.7 e 4.8 descrevem o processo de codificação dos mesmos sinais com a segunda metodologia descrita.

\subsection{Compressão}

A figura 4.9a mostra a evolução do tamanho dos arquivos dos sinais de 256 amostras comprimidos por ambas as metodologias descritas de acordo com o número de iterações.

A figura 4.10 mostra os boxplots da razão de compressão $(\mathrm{CR})$ das técnicas estudadas para os sinais com mais de 256 amostras. A figura 4.11 mostra a mesma informação, porém discriminada por tipo de sinal.

\subsection{Qualidade do sinal comprimido}

A figura 4.9b mostra a evolução da razão sinal-ruído para ambas as metodologias descritas de acordo com o número de iterações, levando em conta os resultados obtidos com os sinais de 256 amostras.

As figuras 4.12, 4.13, 4.14 e 4.15 mostram o resultado da reconstrução de cada codificação comparado ao resultado da codificação com uma iteração da primeira metodologia. Como os resultados da primeira e da segunda metodologia descritas são visualmente bastante parecidos, apenas o resultado da primeira metodologia é mostrado.

As figuras 4.16, 4.17, 4.18, 4.19, 4.20, 4.21 e 4.22 mostram os boxplots das razões sinal-ruído para as técnicas estudadas quando aplicadas aos sinais descritos na seção 3.6 de acordo com o tipo de sinal codificado. 


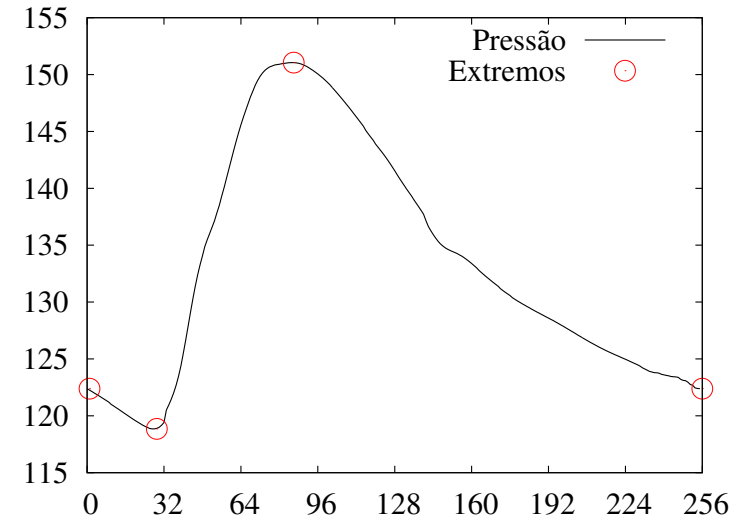

(a) Sinal original



(c) Erro da primeira aproximação

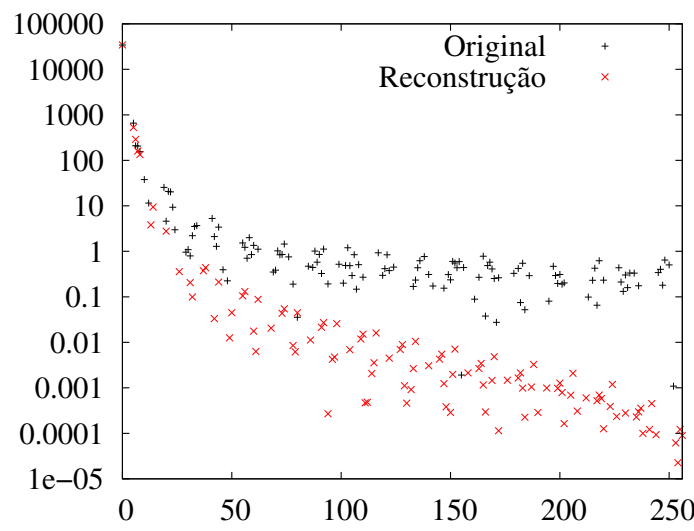

(e) Frequências da primeira aproximação

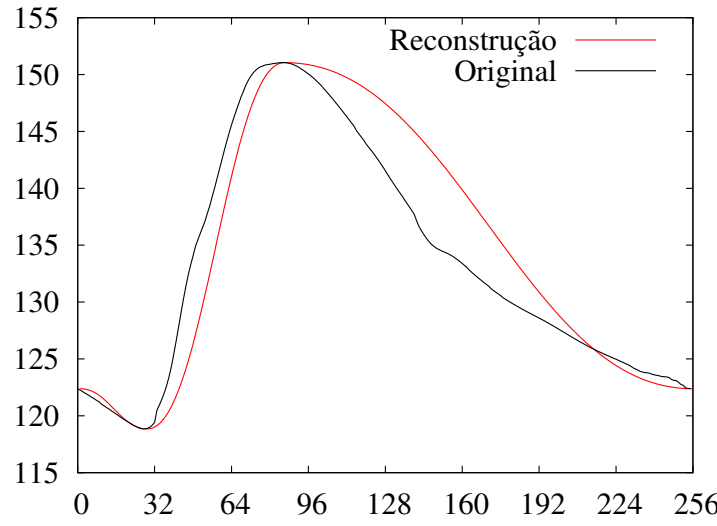

(b) Primeira aproximação

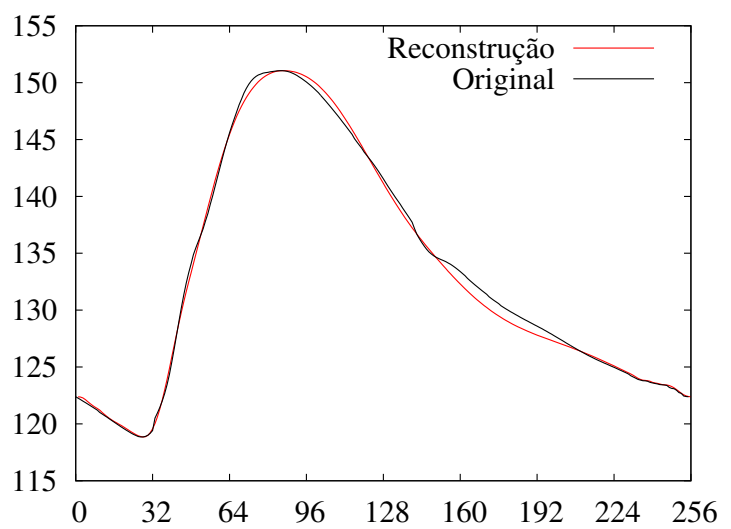

(d) Segunda aproximação

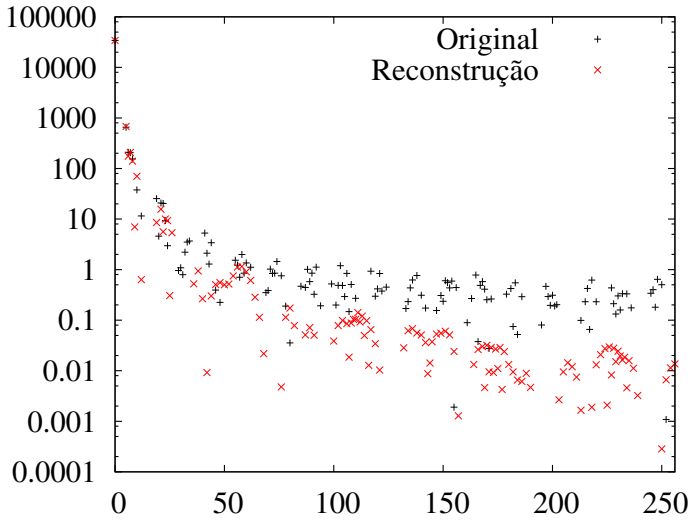

(f) Frequências da segunda aproximação

Figura 4.1: Aplicação da primeira metodologia descrita para o sinal de variação de pressão (figura 3.9a). Em (a), o sinal original com os pontos extremos escolhidos pelo algoritmo em destaque. Em (b), a representação gerada pela primeira iteração comparada com o sinal original. Em (c), o erro entre a primeira iteração do algoritmo e o sinal original com os pontos extremos escolhidos pelo algoritmo em destaque. Em (d), a representação gerada pela segunda iteração comparada com o sinal original. Em (e) e (f), as frequências que compõem o sinal original e a primeira e a segunda aproximações, respectivamente. 


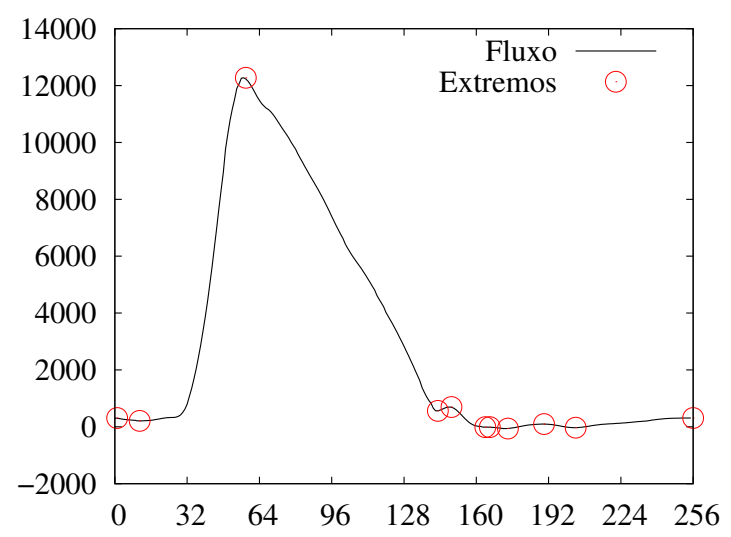

(a) Sinal original

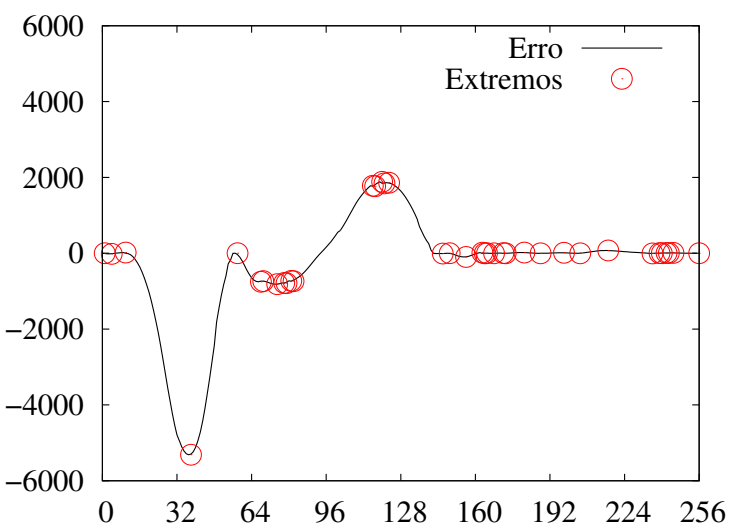

(c) Erro da primeira aproximação

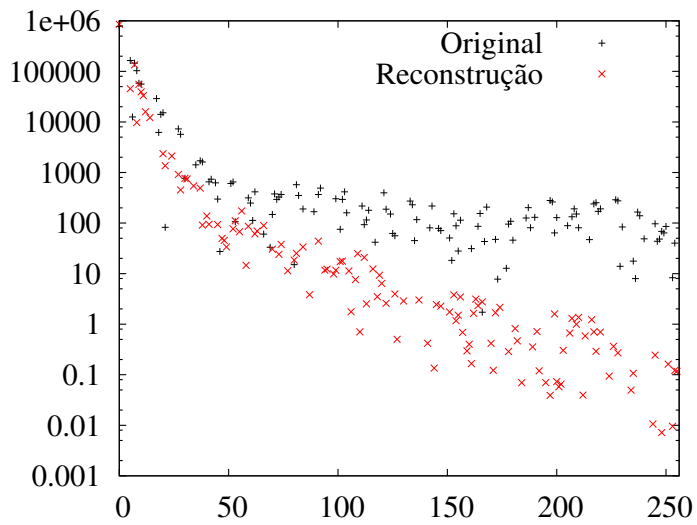

(e) Frequências da primeira aproximação

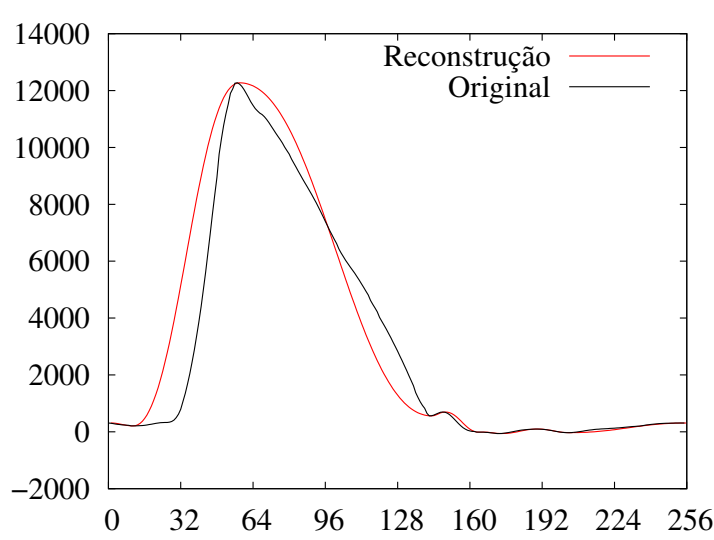

(b) Primeira aproximação

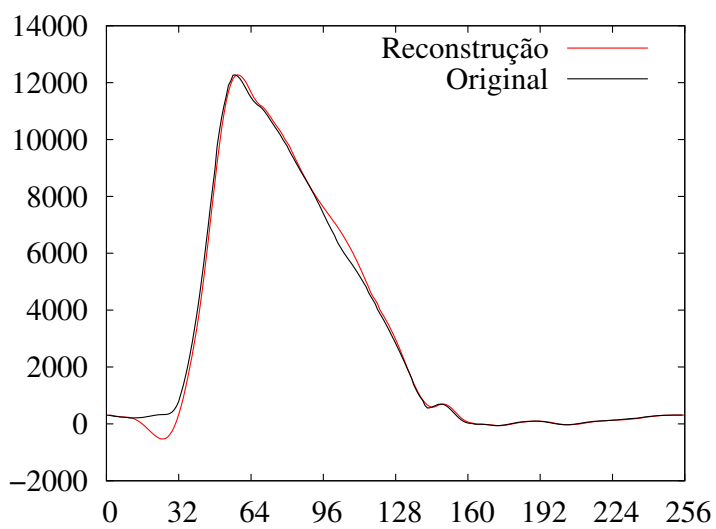

(d) Segunda aproximação

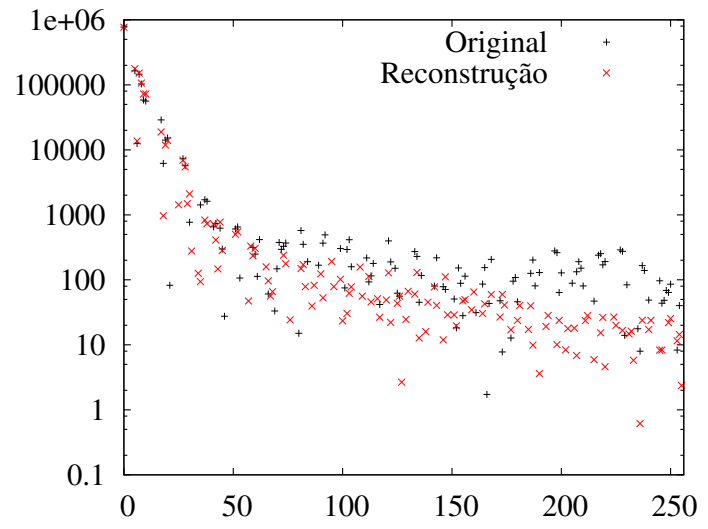

(f) Frequências da segunda aproximação

Figura 4.2: Aplicação da primeira metodologia descrita para o sinal de variação de fluxo sanguíneo (figura 3.9b). Em (a), o sinal original com os pontos extremos escolhidos pelo algoritmo em destaque. Em (b), a representação gerada pela primeira iteração comparada com o sinal original. Em (c), o erro entre a primeira iteração do algoritmo e o sinal original com os pontos extremos escolhidos pelo algoritmo em destaque. Em (d), a representação gerada pela segunda iteração comparada com o sinal original. Em (e) e (f), as frequências que compõem o sinal original e a primeira e a segunda aproximações, respectivamente. 


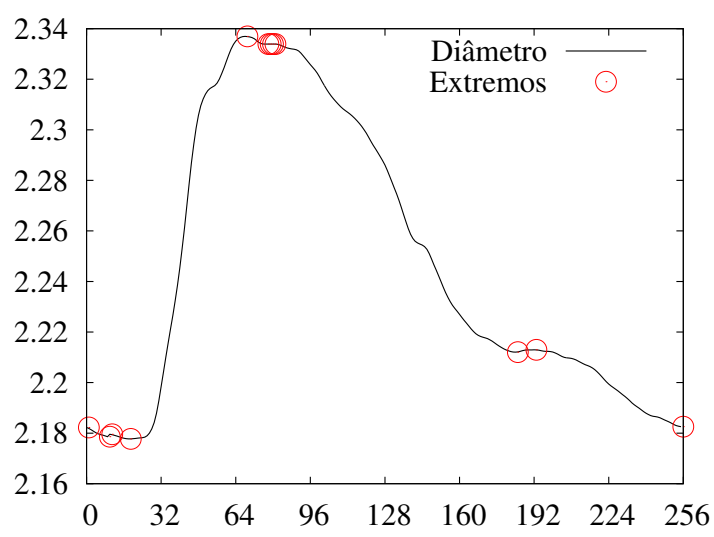

(a) Sinal original

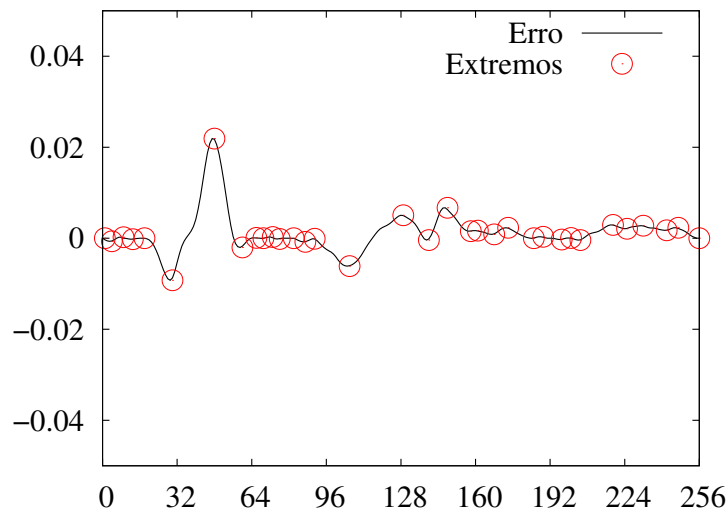

(c) Erro da primeira aproximação

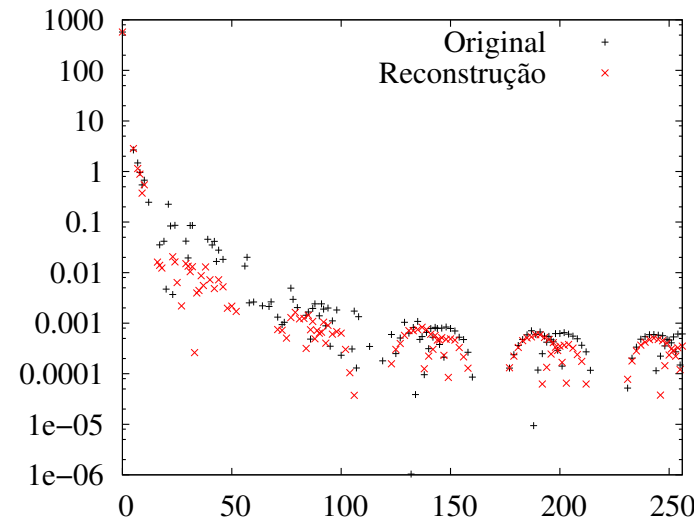

(e) Frequências da primeira aproximação

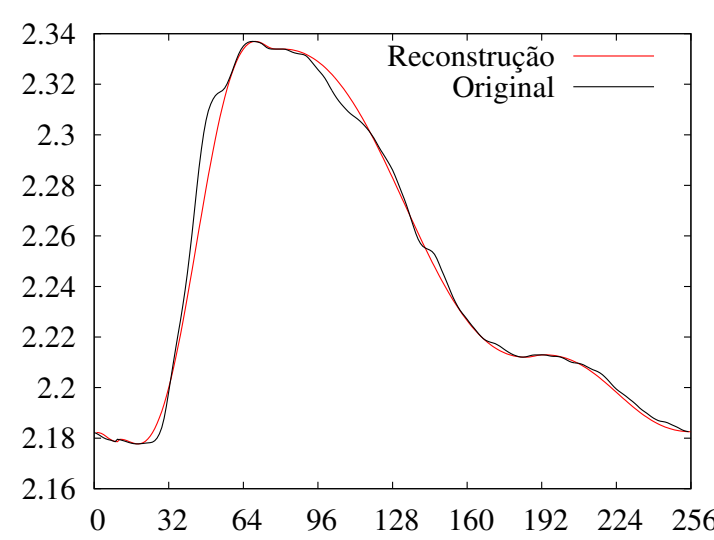

(b) Primeira aproximação

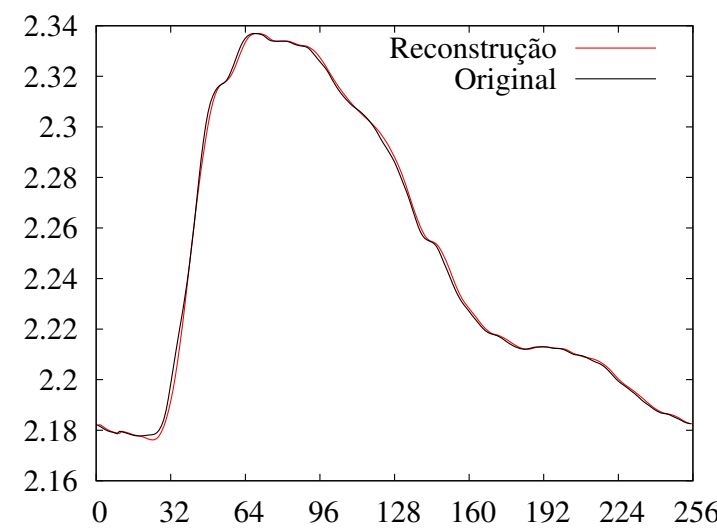

(d) Segunda aproximação

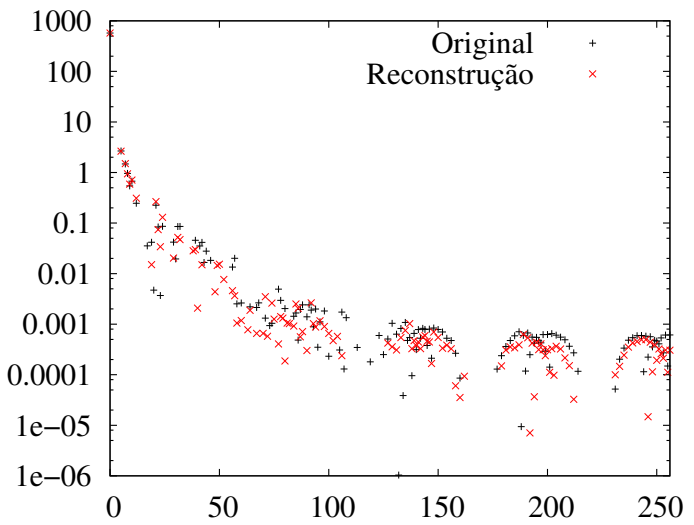

(f) Frequências da segunda aproximação

Figura 4.3: Aplicação da primeira metodologia descrita para o sinal de variação de diâmetro arterial (figura 3.9c). Em (a), o sinal original com os pontos extremos escolhidos pelo algoritmo em destaque. Em (b), a representação gerada pela primeira iteração comparada com o sinal original. Em (c), o erro entre a primeira iteração do algoritmo e o sinal original com os pontos extremos escolhidos pelo algoritmo em destaque. Em (d), a representação gerada pela segunda iteração comparada com o sinal original. Em (e) e (f), as frequências que compõem o sinal original e a primeira e a segunda aproximações, respectivamente. 


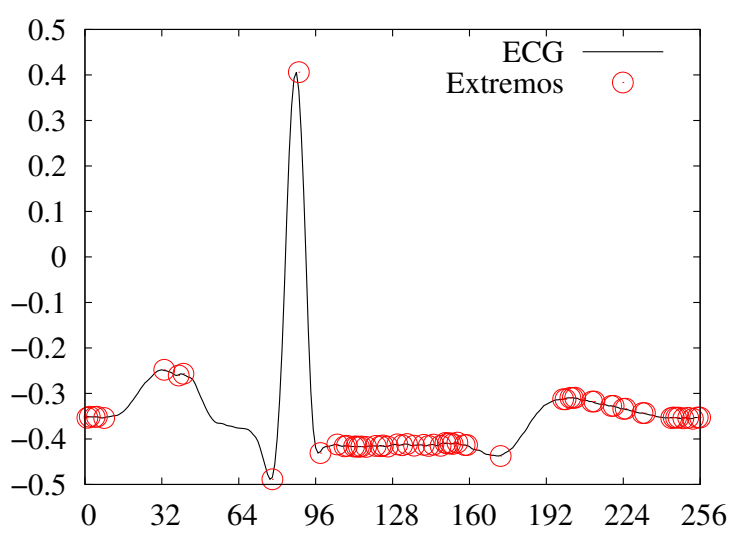

(a) Sinal original

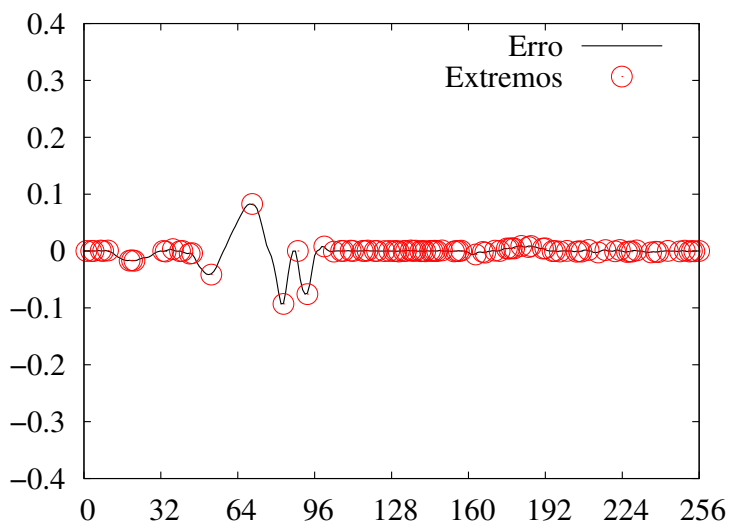

(c) Erro da primeira iteração

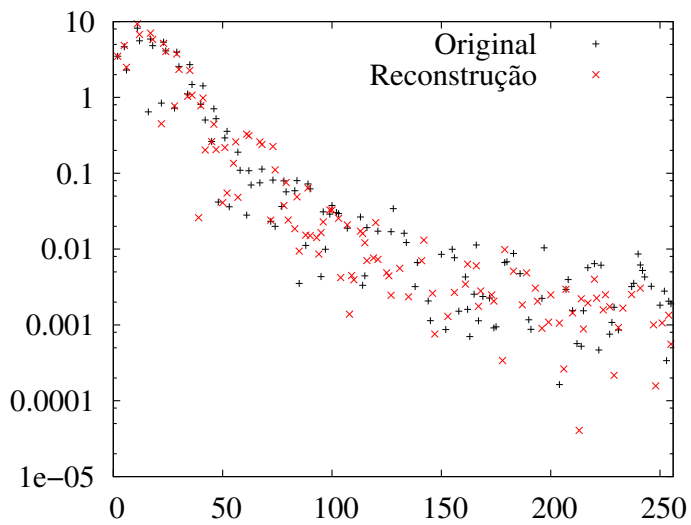

(e) Frequências da primeira aproximação



(b) Primeira iteração

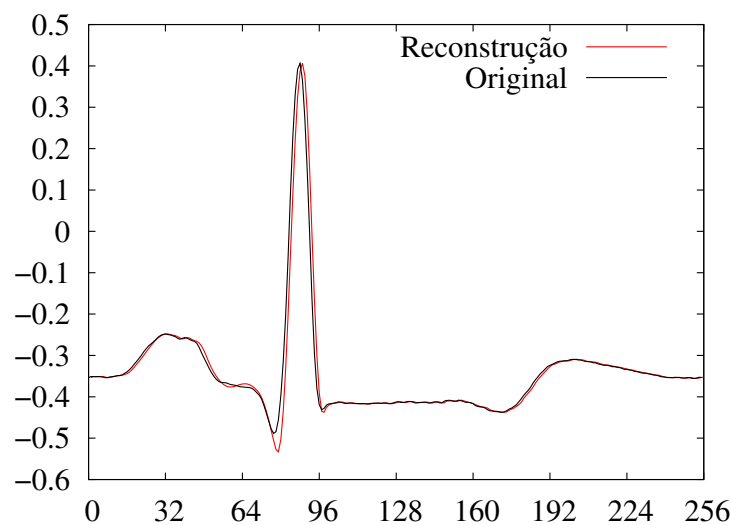

(d) Segunda iteração

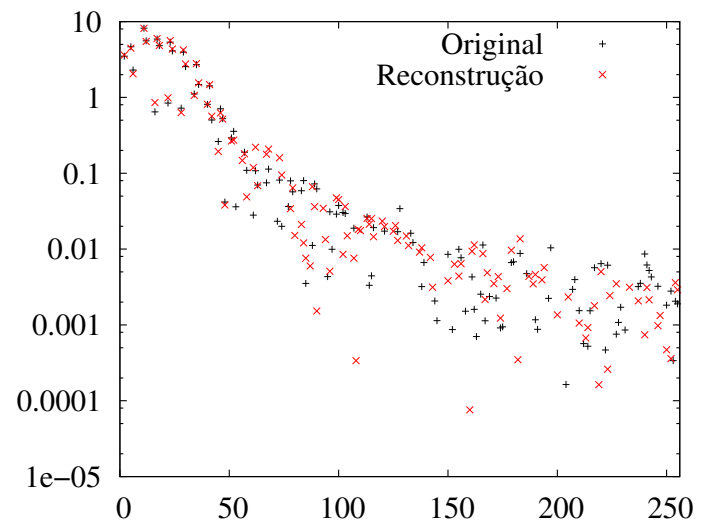

(f) Frequências da segunda aproximação

Figura 4.4: Aplicação da primeira metodologia descrita para o sinal de ECG (figura 3.9d). Em (a), o sinal original com os pontos extremos selecionados pela codificação em destaque. Em (b), o resultado da primeira iteração. Em (c), o erro entre o resultado da primeira iteração e o sinal original, com os pontos selecionados pelo algoritmo para a segunda iteração. Em (d), o resultado da segunda iteração. Em (e) e (f), as frequências que compõem o sinal original e a primeira e a segunda aproximações, respectivamente. 


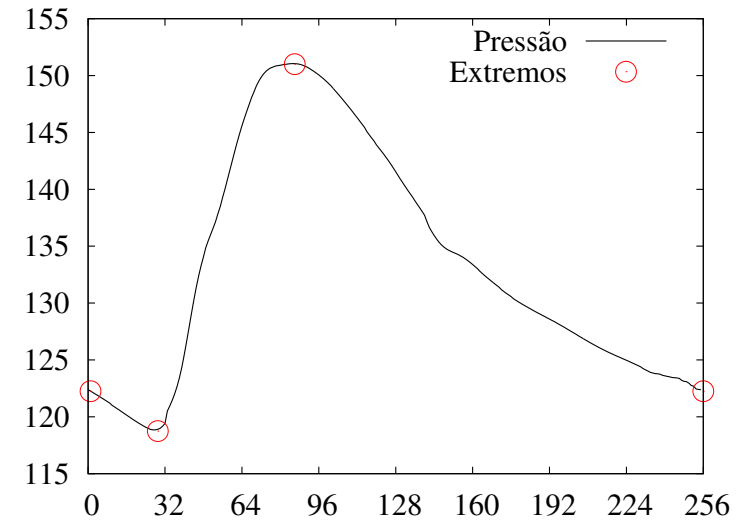

(a) Sinal original

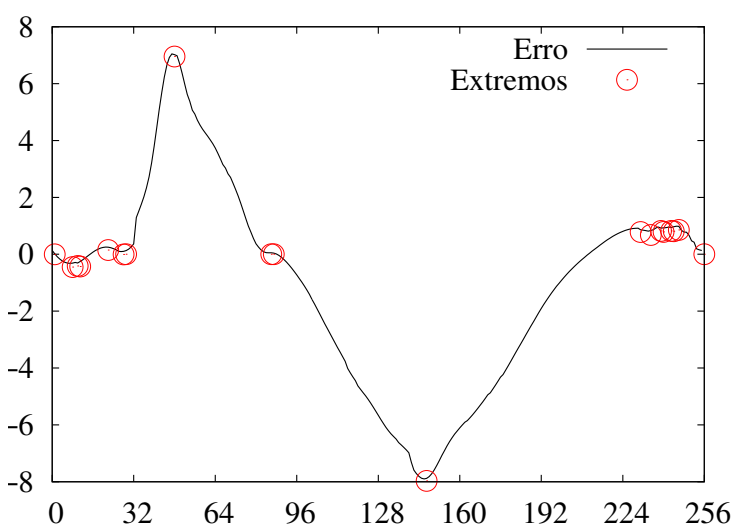

(c) Erro da primeira aproximação

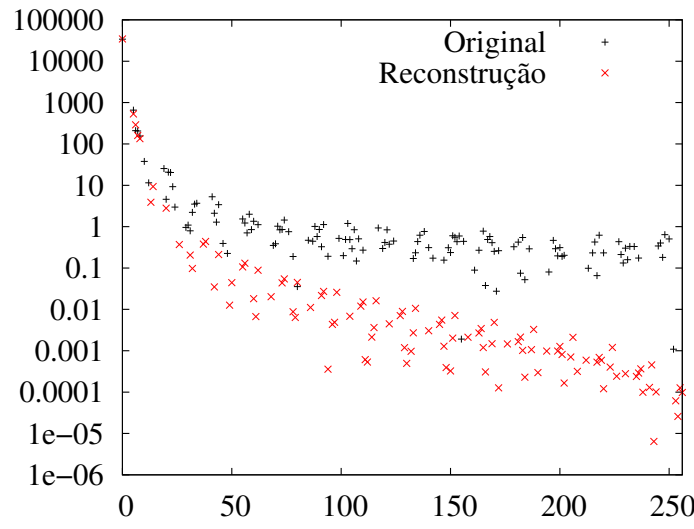

(e) Frequências da primeira aproximação

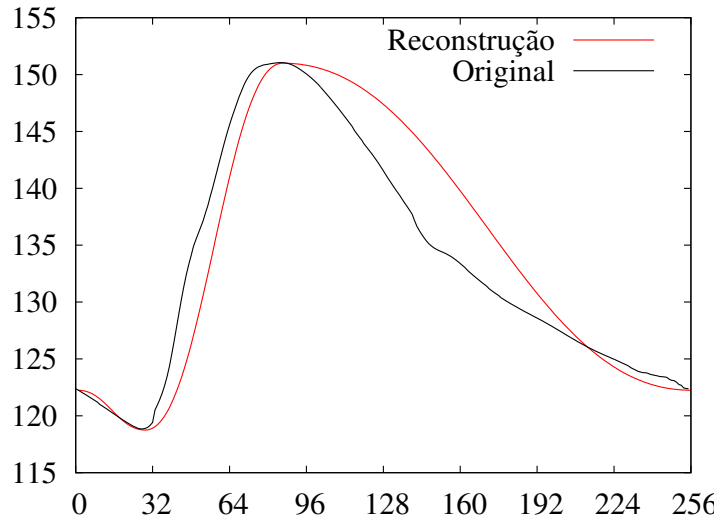

(b) Primeira aproximação

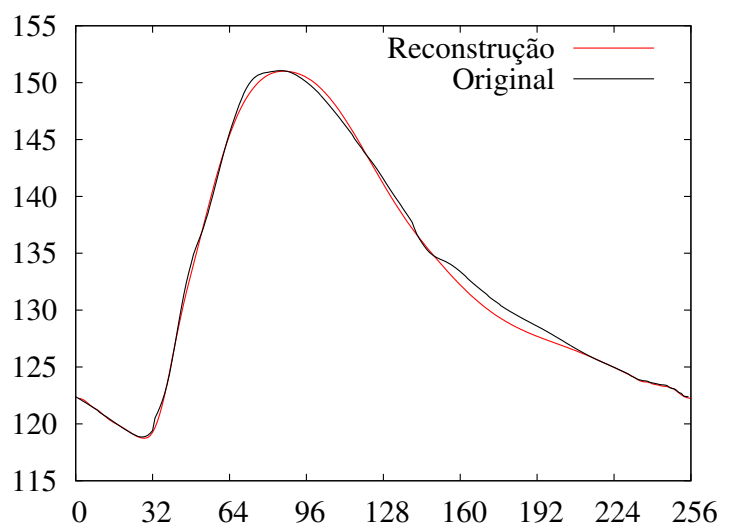

(d) Segunda aproximação

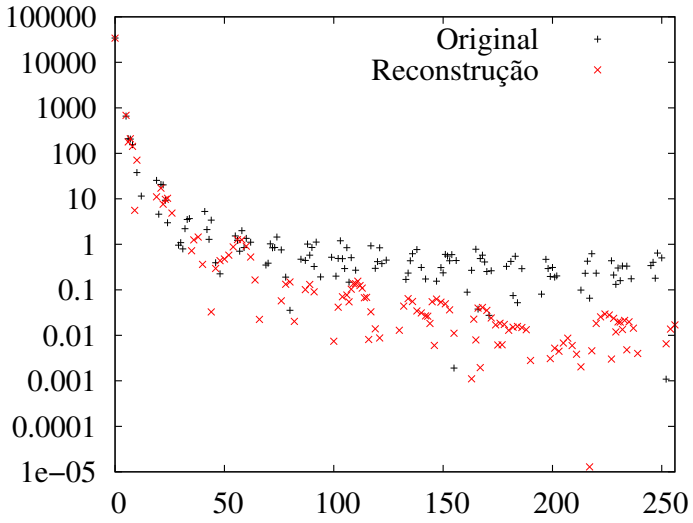

(f) Frequências da segunda aproximação

Figura 4.5: Aplicação da segunda metodologia descrita para o sinal de variação de pressão (figura 3.9a). Em (a), o sinal original com os pontos extremos escolhidos pelo algoritmo em destaque. Em (b), a representação gerada pela primeira iteração comparada com o sinal original. Em (c), o erro entre a primeira iteração do algoritmo e o sinal original com os pontos extremos escolhidos pelo algoritmo em destaque. Em (d), a representação gerada pela segunda iteração comparada com o sinal original. Em (e) e (f), as frequências que compõem o sinal original e a primeira e a segunda aproximações, respectivamente. 


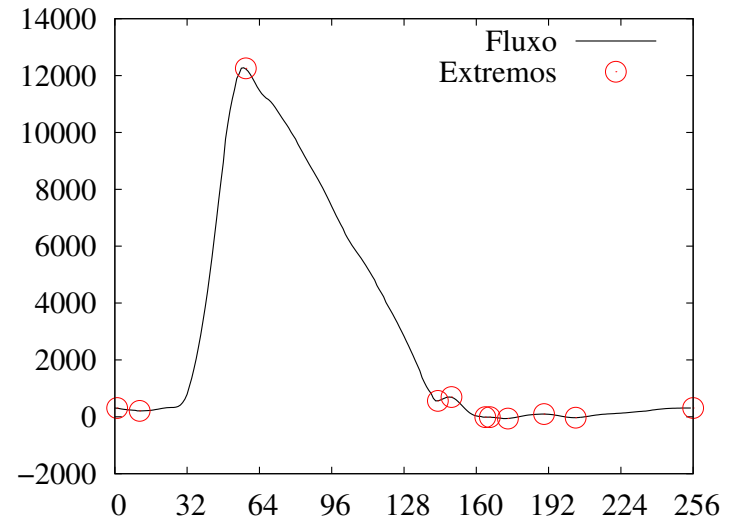

(a) Sinal original

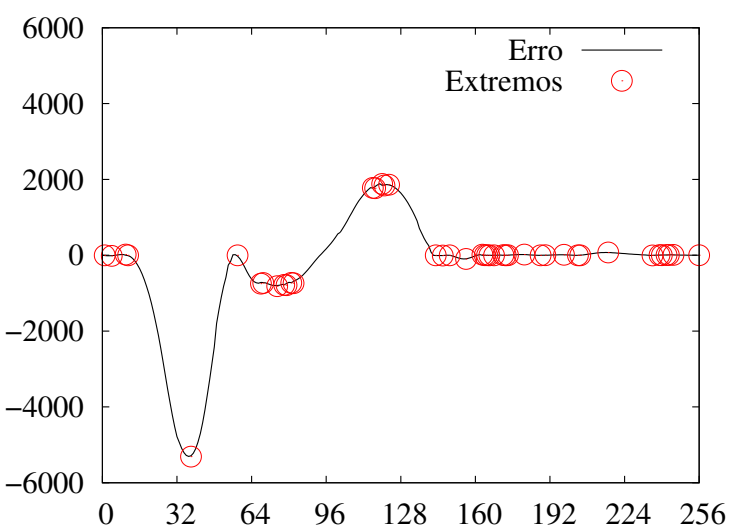

(c) Erro da primeira aproximação

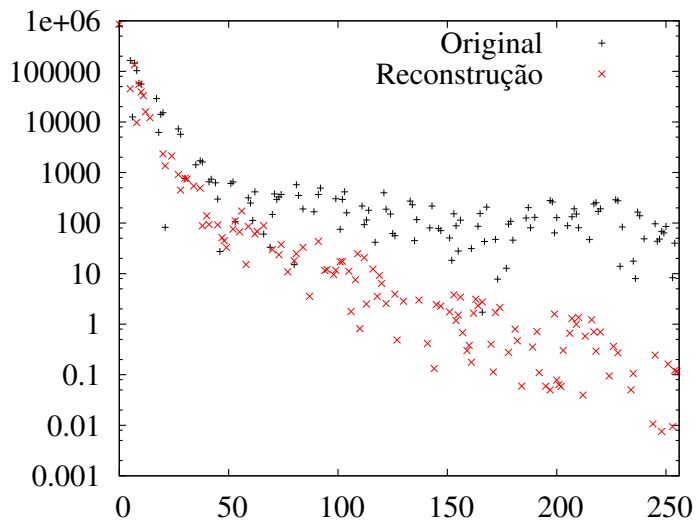

(e) Frequências da primeira aproximação

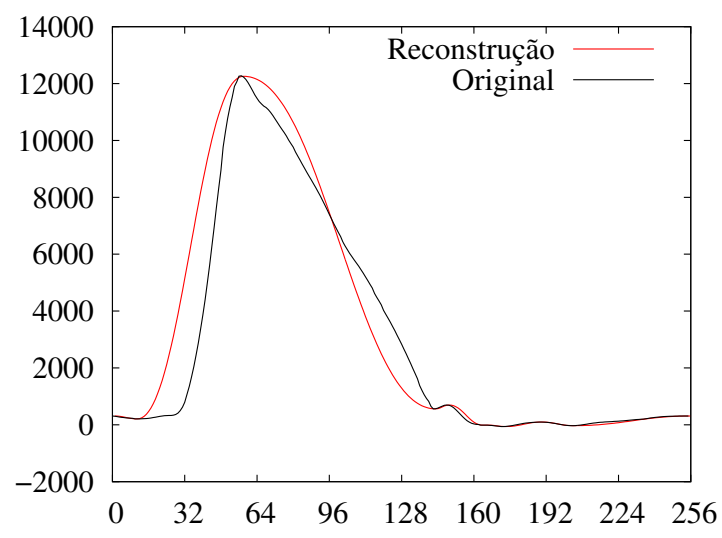

(b) Primeira aproximação

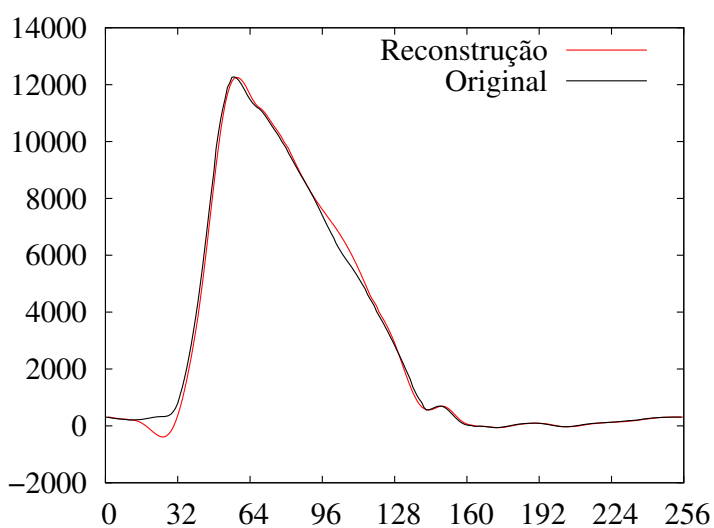

(d) Segunda aproximação

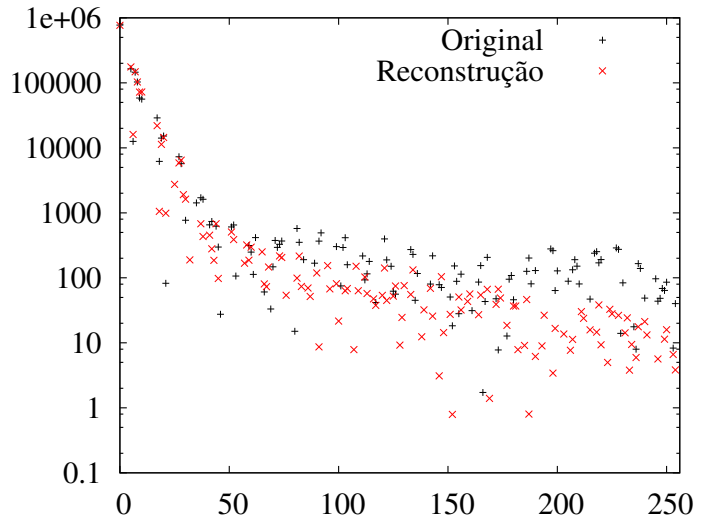

(f) Frequências da segunda aproximação

Figura 4.6: Aplicação da segunda metodologia descrita para o sinal de variação de fluxo sanguíneo (figura 3.9b). Em (a), o sinal original com os pontos extremos escolhidos pelo algoritmo em destaque. Em (b), a representação gerada pela primeira iteração comparada com o sinal original. Em (c), o erro entre a primeira iteração do algoritmo e o sinal original com os pontos extremos escolhidos pelo algoritmo em destaque. Em (d), a representação gerada pela segunda iteração comparada com o sinal original. Em (e) e (f), as frequências que compõem o sinal original e a primeira e a segunda aproximações, respectivamente. 


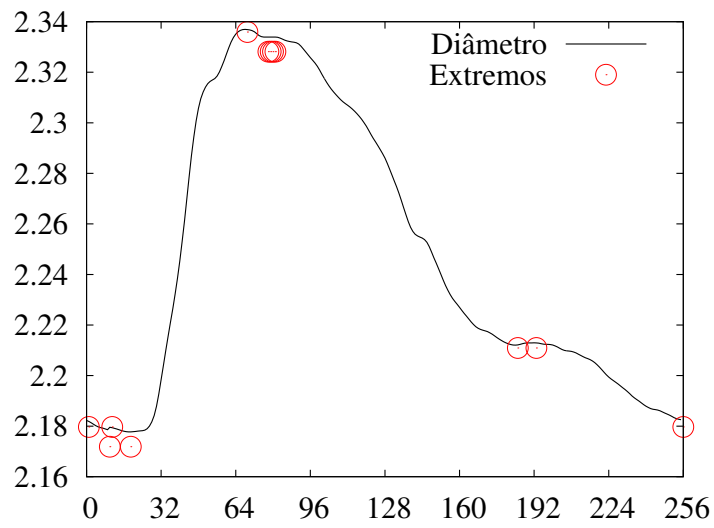

(a) Sinal original

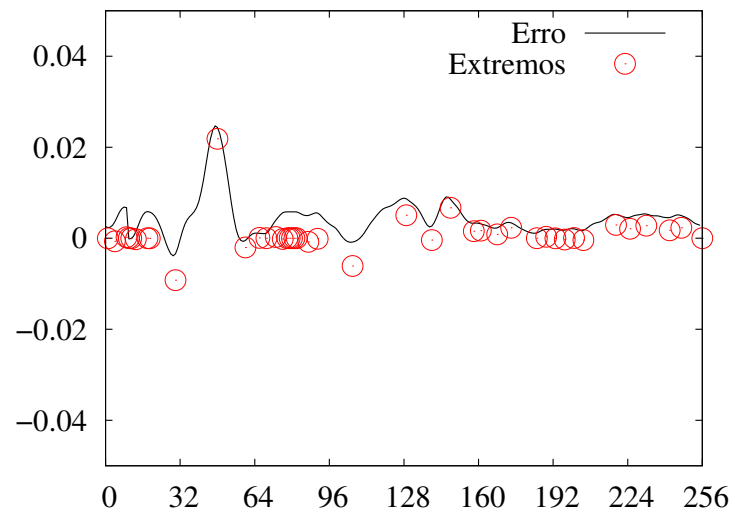

(c) Erro da primeira aproximação

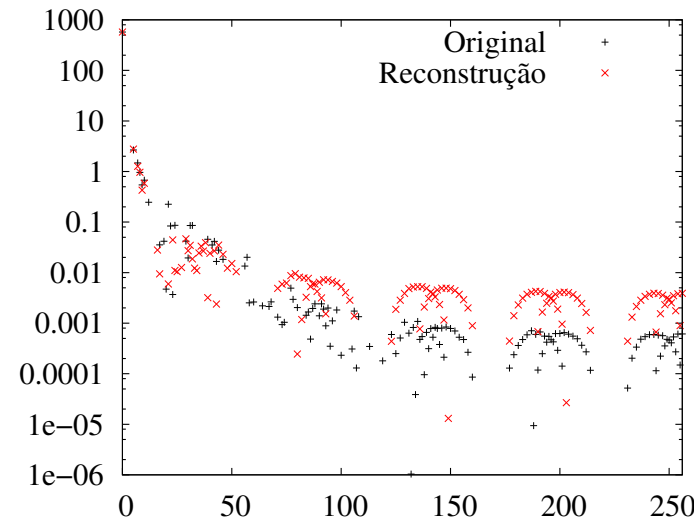

(e) Frequências da primeira aproximação

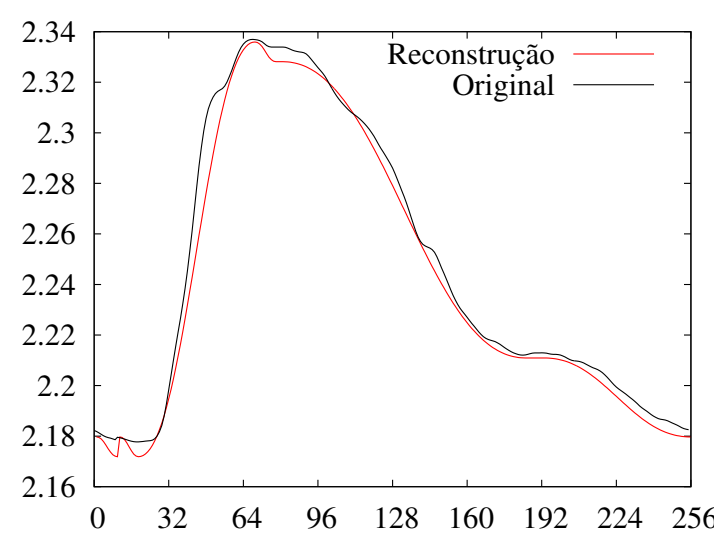

(b) Primeira aproximação

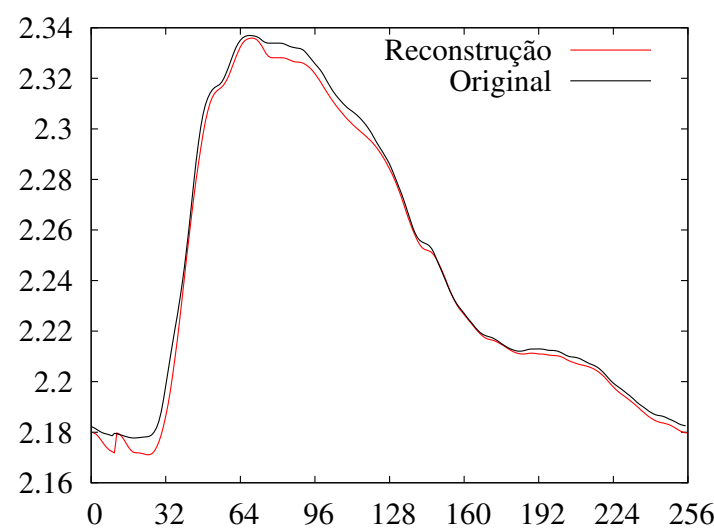

(d) Segunda aproximação

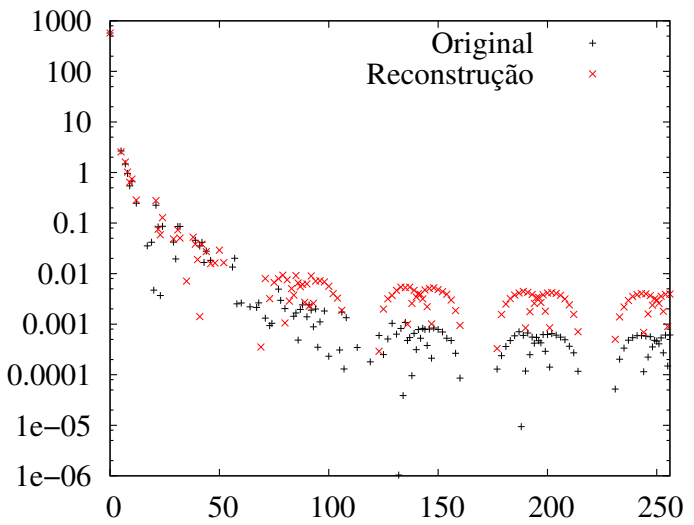

(f) Frequências da segunda aproximação

Figura 4.7: Aplicação da segunda metodologia descrita para o sinal de variação de diâmetro arterial (figura 3.9c). Em (a), o sinal original com os pontos extremos escolhidos pelo algoritmo em destaque. Em (b), a representação gerada pela primeira iteração comparada com o sinal original. Em (c), o erro entre a primeira iteração do algoritmo e o sinal original com os pontos extremos escolhidos pelo algoritmo em destaque. Em (d), a representação gerada pela segunda iteração comparada com o sinal original. Em (e) e (f), as frequências que compõem o sinal original e a primeira e a segunda aproximações, respectivamente. 


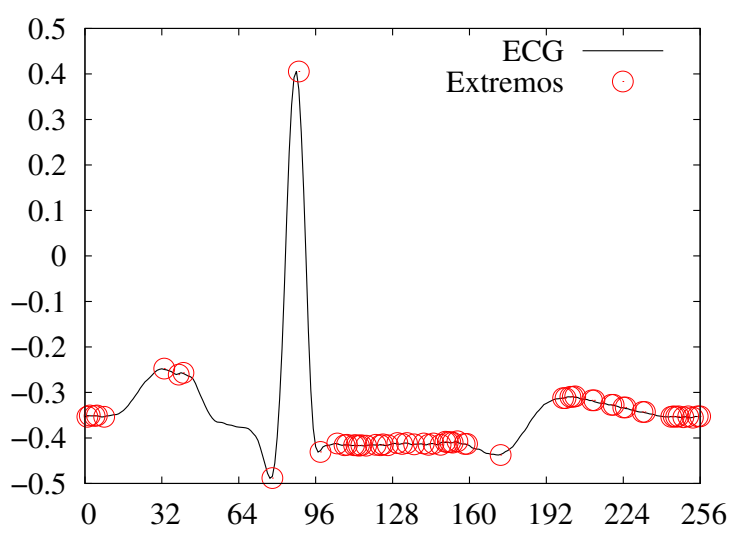

(a) Sinal original

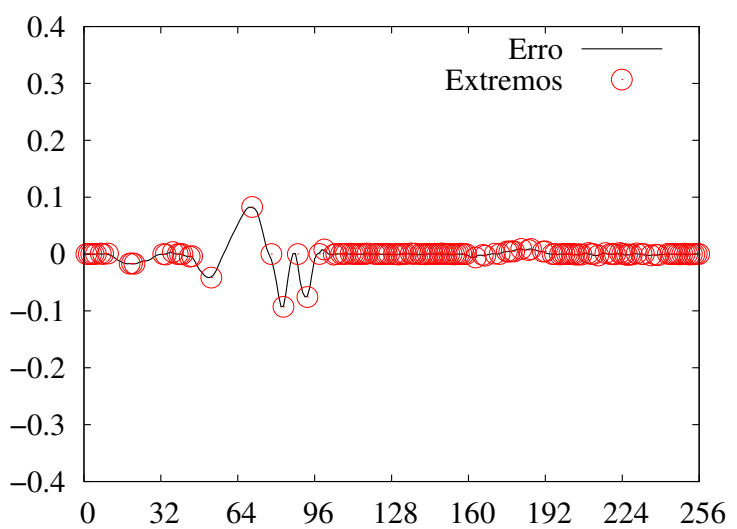

(c) Erro da primeira iteração

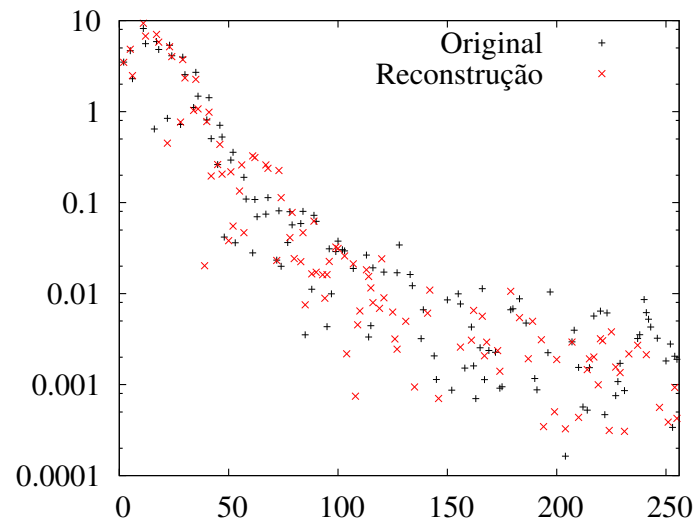

(e) Frequências da primeira aproximação

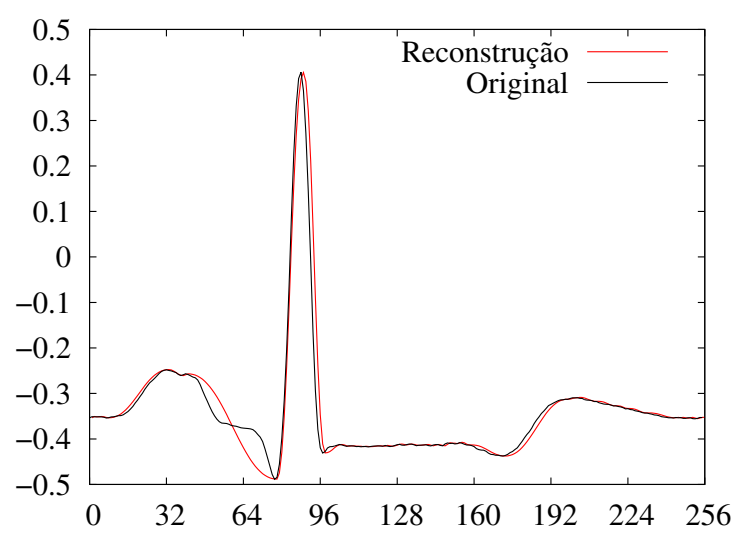

(b) Primeira iteração

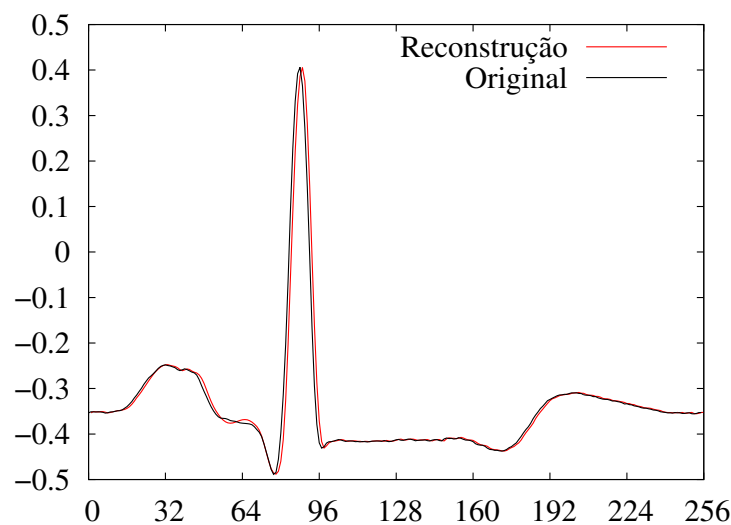

(d) Segunda iteração

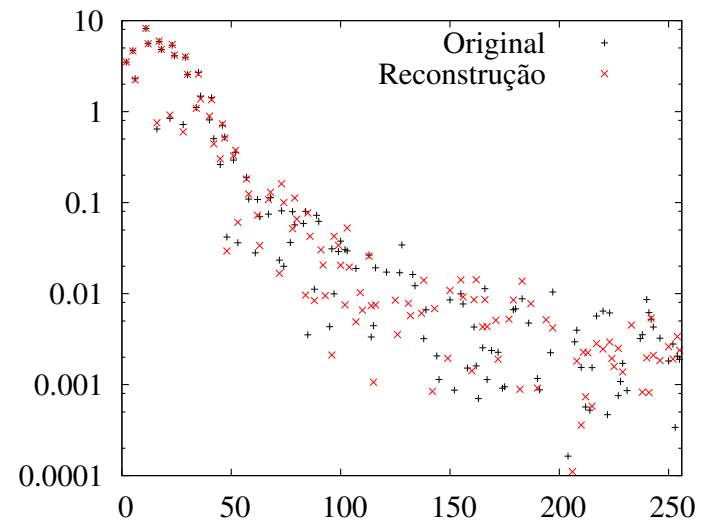

(f) Frequências da segunda aproximação

Figura 4.8: Aplicação da segunda metodologia descrita para o sinal de ECG (figura 3.9d). Em (a), o sinal original com os pontos extremos selecionados pela codificação em destaque. Em (b), o resultado da primeira iteração. Em (c), o erro entre o resultado da primeira iteração e o sinal original, com os pontos selecionados pelo algoritmo para a segunda iteração. Em (d), o resultado da segunda iteração. Em (e) e (f), as frequências que compõem o sinal original e a primeira e a segunda aproximações, respectivamente. 


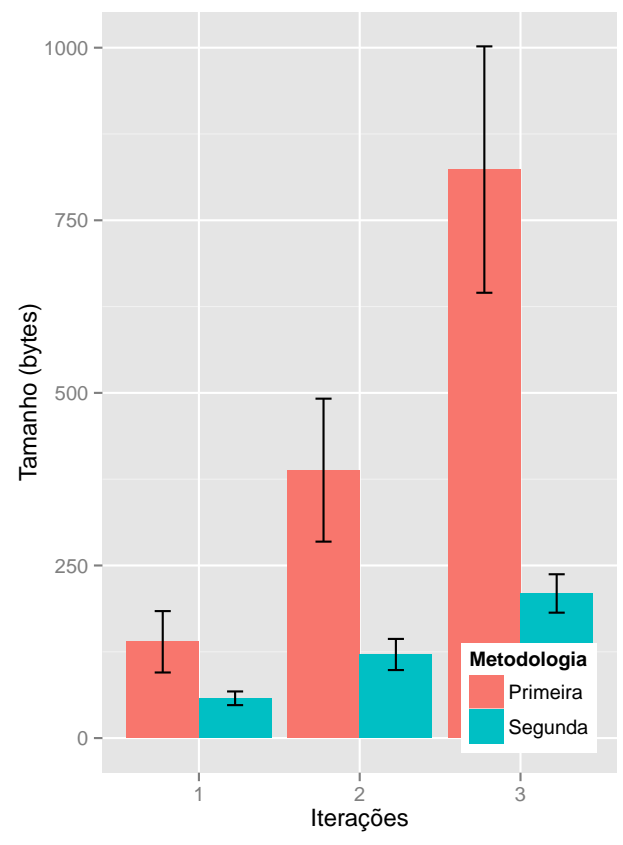

(a) Tamanho

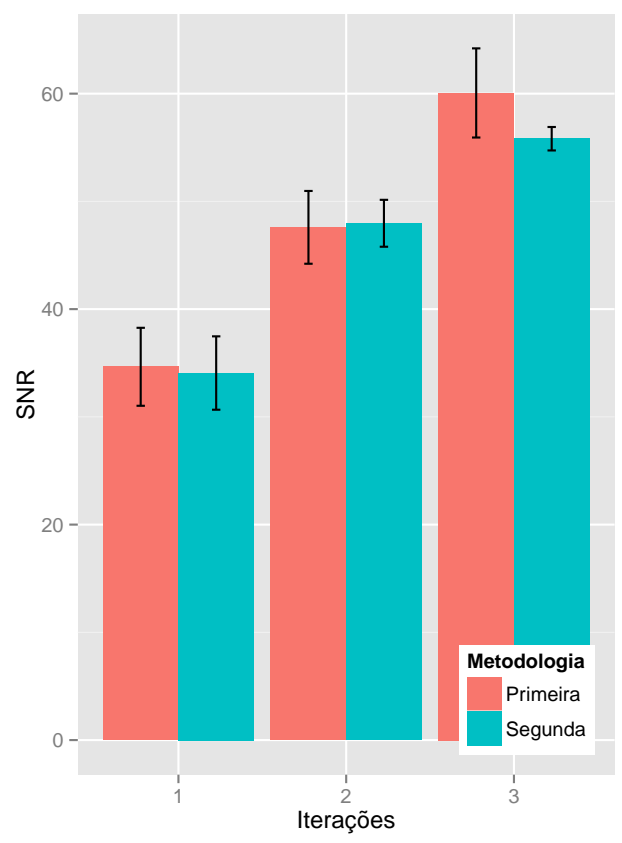

(b) $S N R$

Figura 4.9: Evolução dos tamanhos finais e do SNR dos arquivos dos sinais de 256 amostras comprimidos com uma, duas e três iterações por ambas as metodologias descritas.

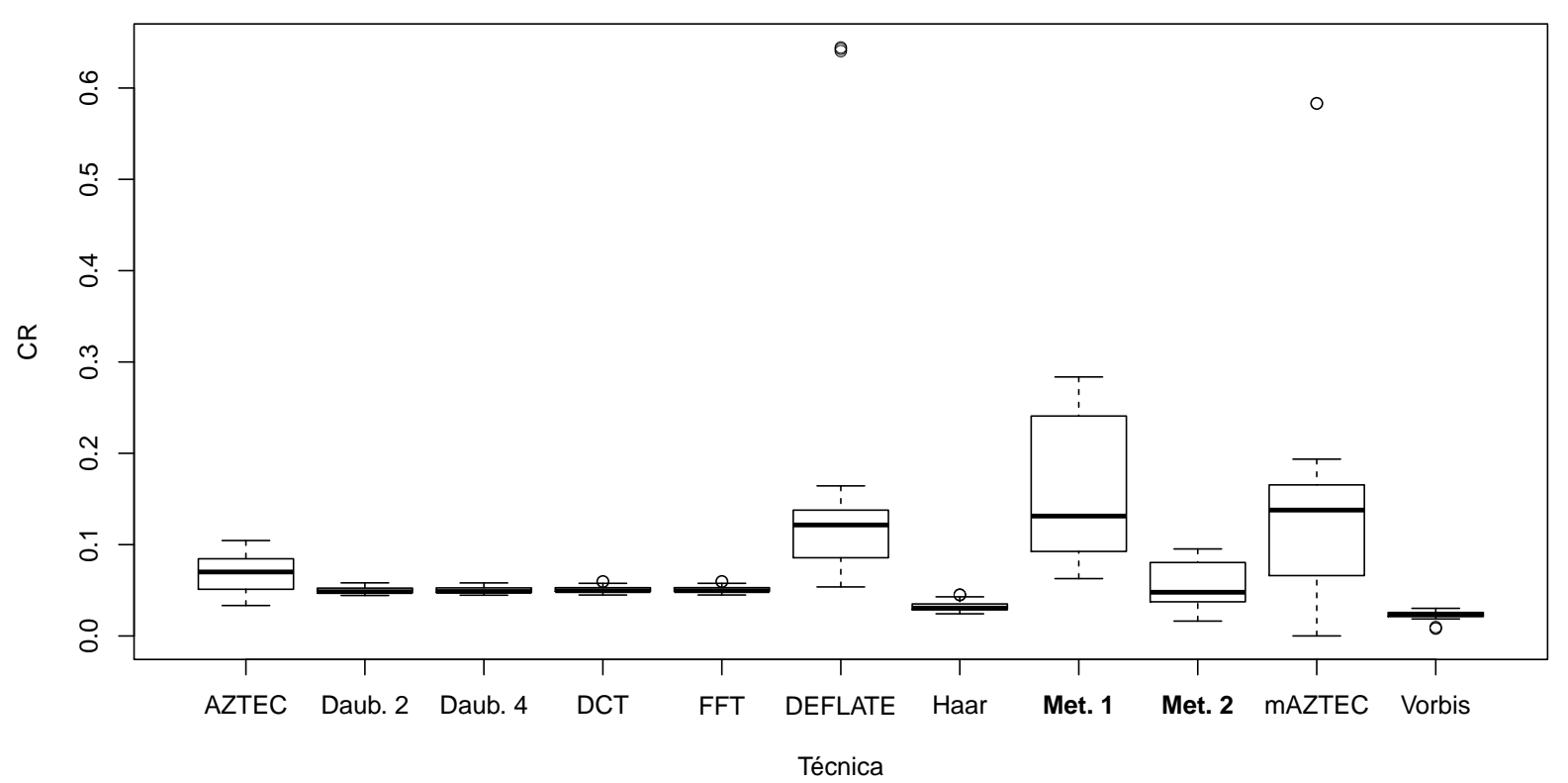

Figura 4.10: Boxplots das razões de compressão das técnicas estudadas para os sinais com mais de 256 amostras. 


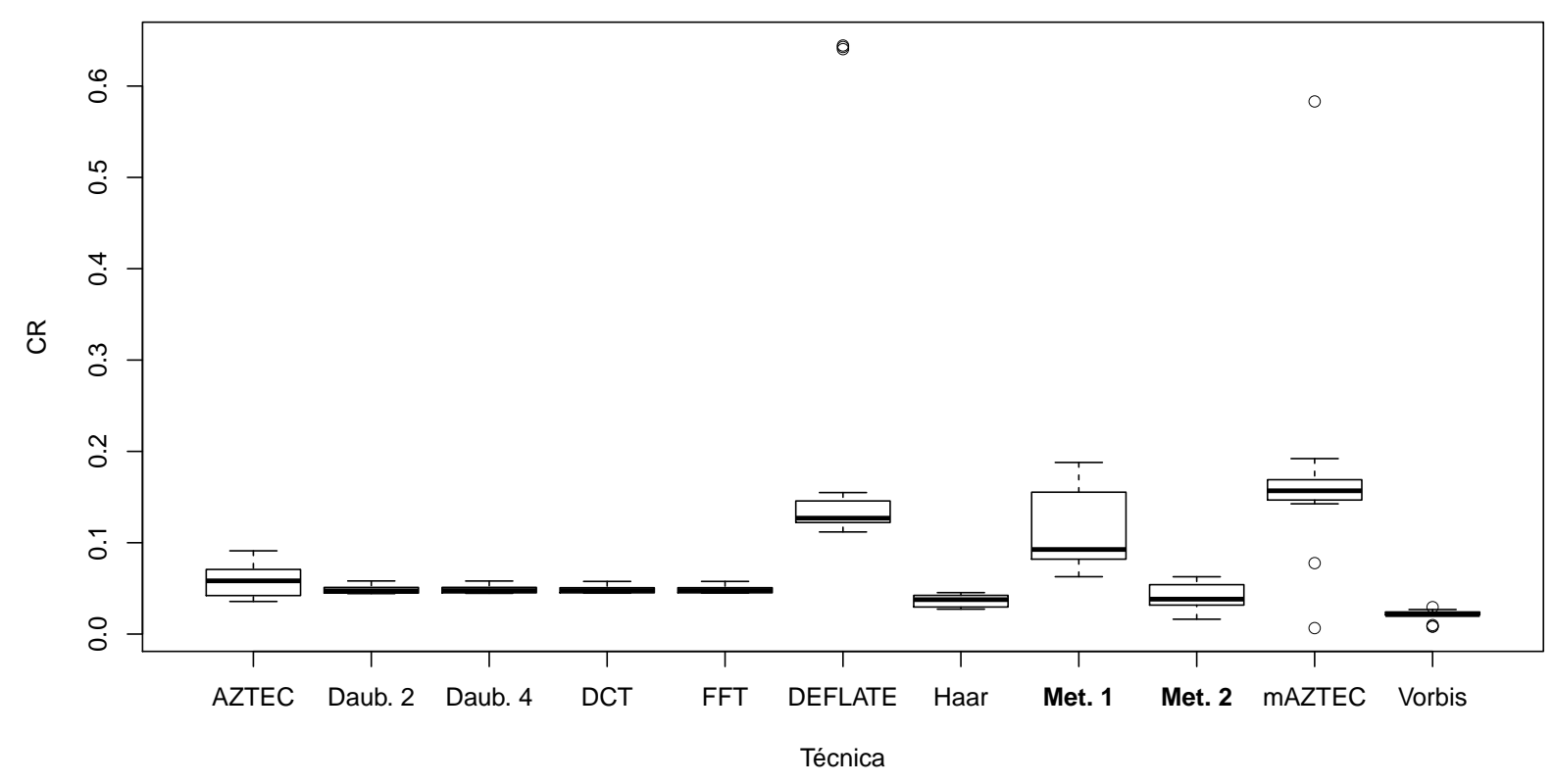

(a) $E C G$

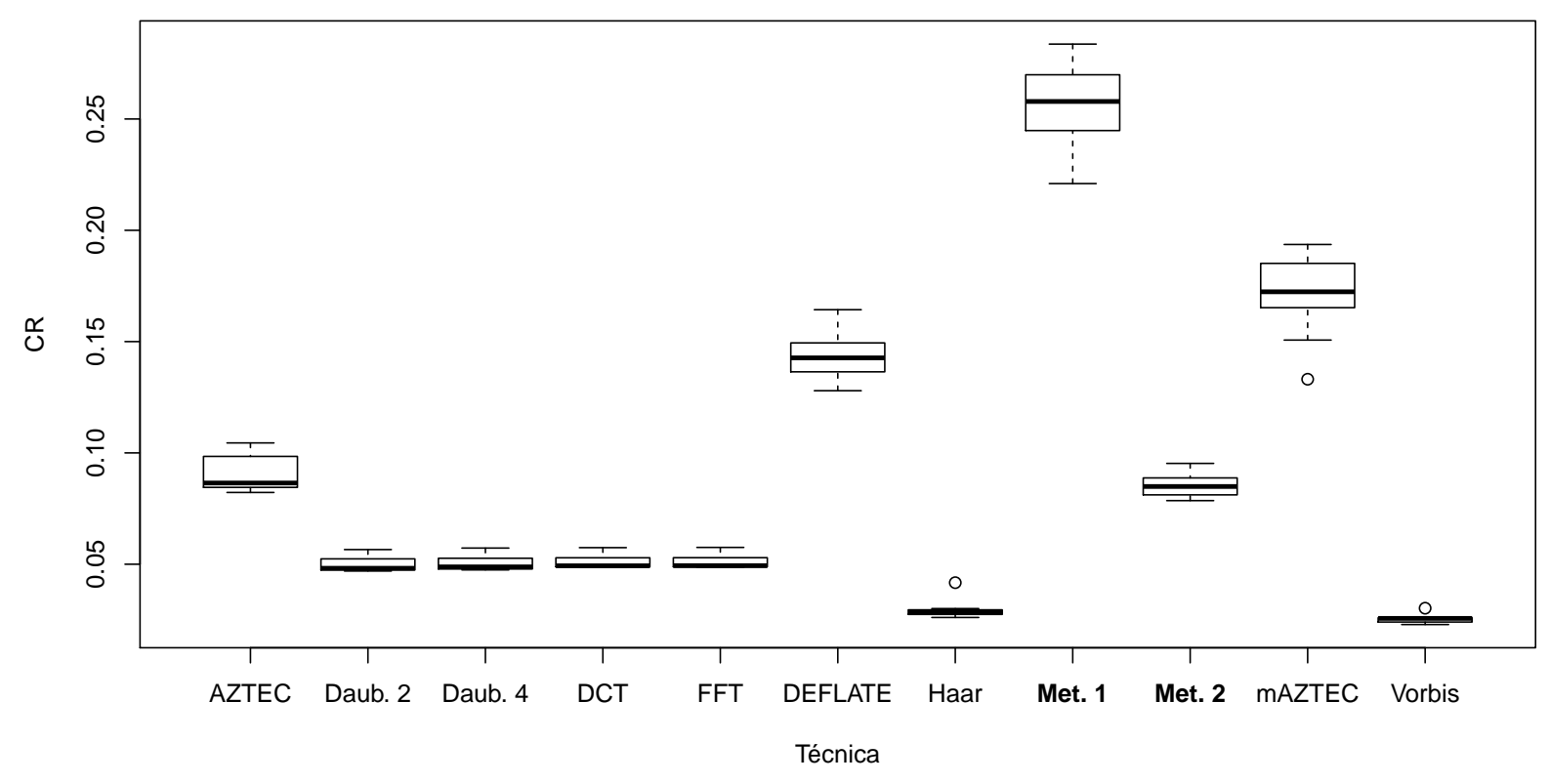

(b) Pressão de via aérea 


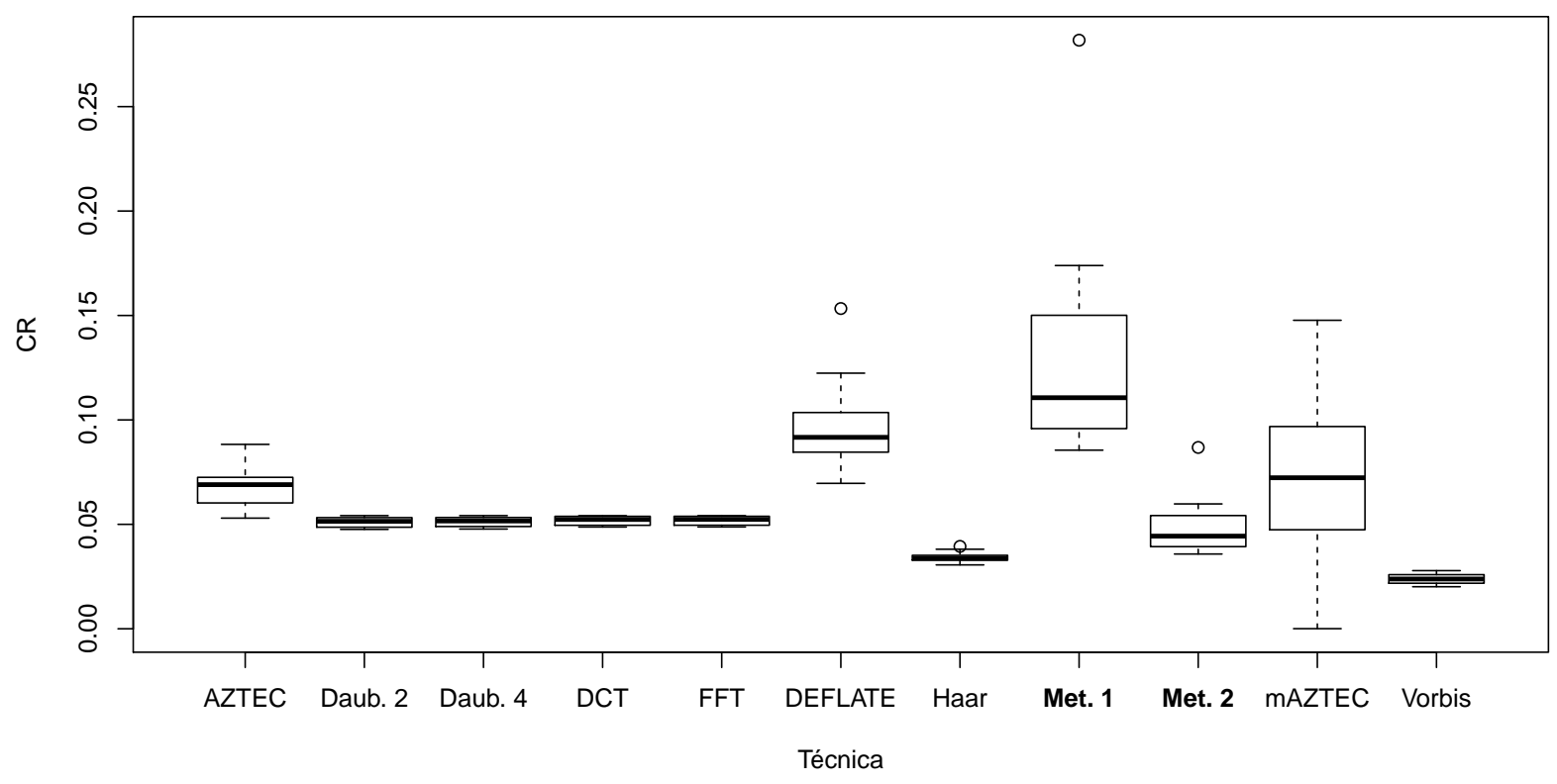

(c) Pressão venosa central



(d) Pressão intraesofágica

Figura 4.11: Boxplots das razões de compressão das técnicas estudadas para os sinais com mais de 256 amostras, discriminando a natureza dos sinais. 


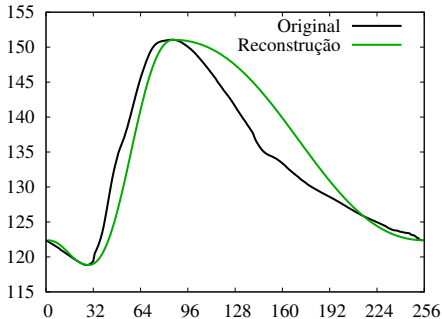

(a) Primeira metodologia descrita

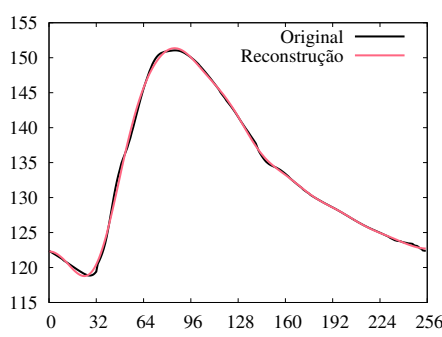

(d) $D C T$

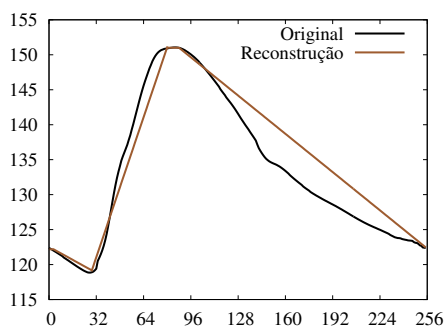

(g) $A Z T E C$
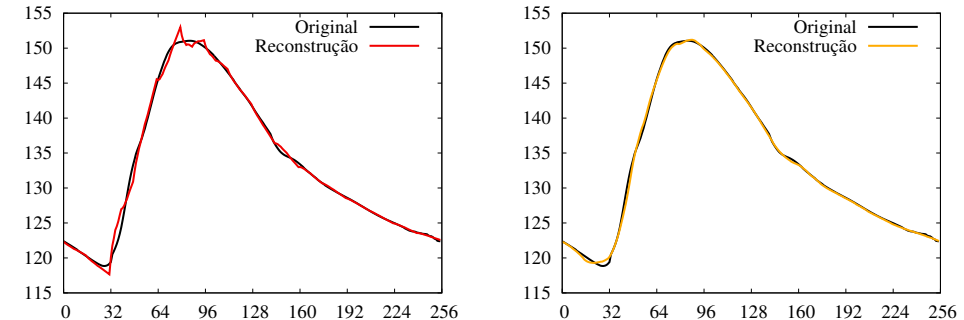

(b) Daubechies com 2 momentos nulos

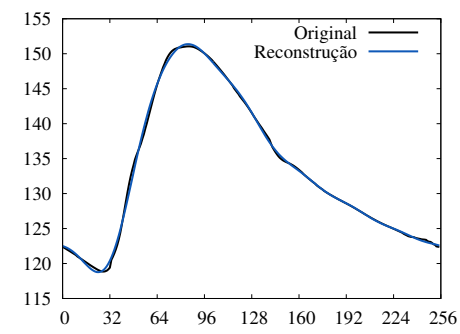

(e) FFT



(h) $m A Z T E C$ (c) Daubechies com 4 momentos nulos



(f) Haar

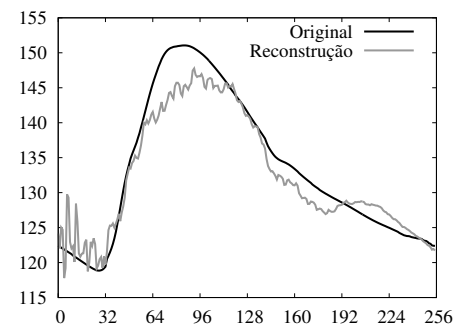

(i) Vorbis

Figura 4.12: Resultado da codificação do sinal de variação de pressão (figura 3.9a) usando a primeira metodologia descrita, o algoritmo AZTEC, o algoritmo mAZTEC, o algoritmo Vorbis e as transformadas estudadas. 


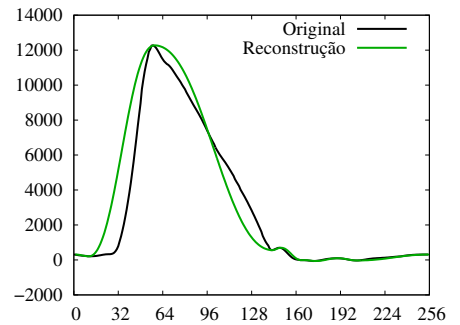

(a) Primeira metodologia descrita

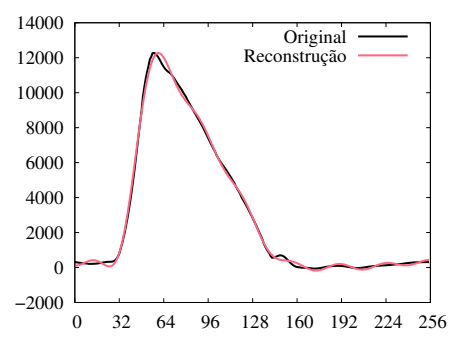

(d) $D C T$

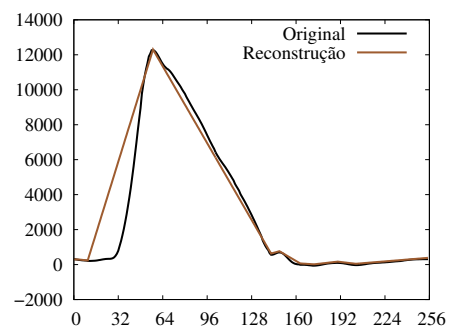

(g) $A Z T E C$

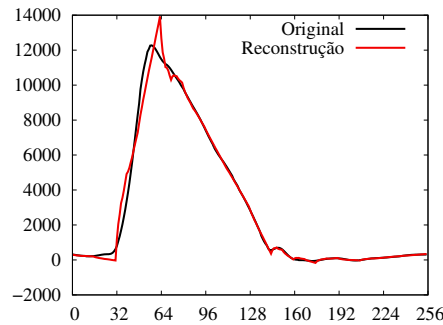

(b) Daubechies com 2 momentos nulos

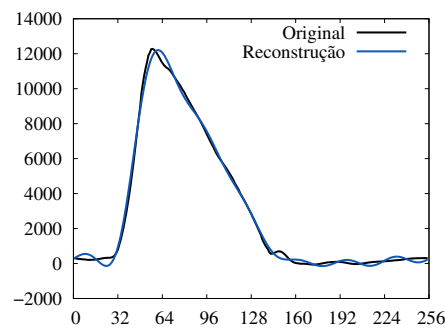

(e) FFT

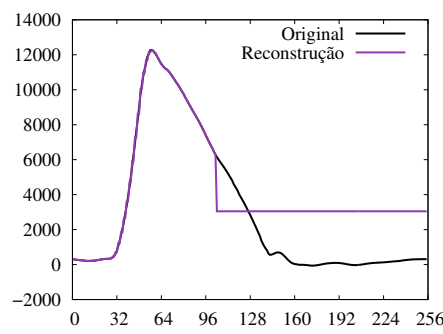

(h) $\mathrm{mAZTEC}$

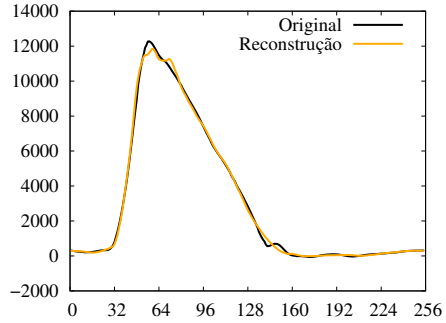

(c) Daubechies com 4 momentos nulos

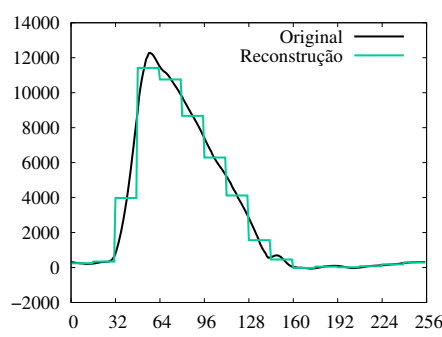

(f) Haar

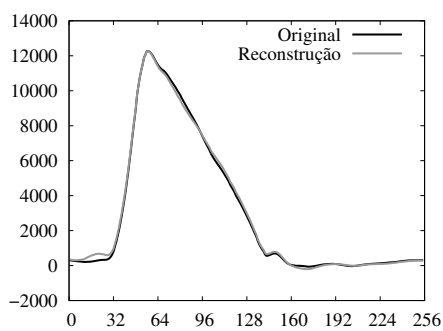

(i) Vorbis

Figura 4.13: Resultado da codificação do sinal de variação de fluxo sanguíneo (figura 3.9b) usando a primeira metodologia descrita, o algoritmo AZTEC, o algoritmo mAZTEC, o algoritmo Vorbis e as transformadas estudadas. 


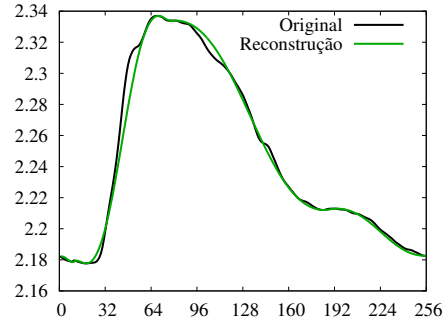

(a) Primeira metodologia descrita

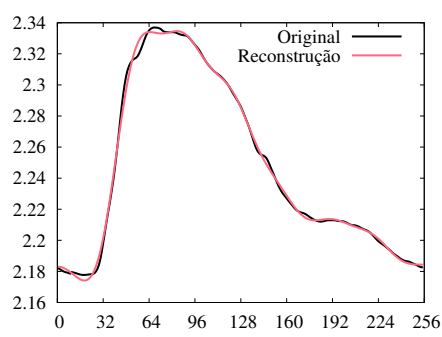

(d) $D C T$

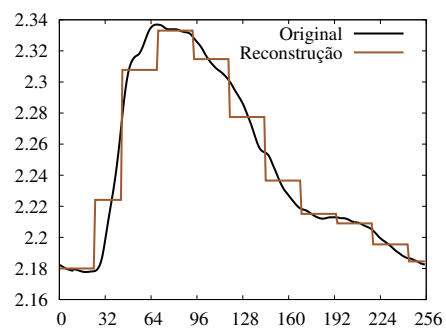

(g) $A Z T E C$

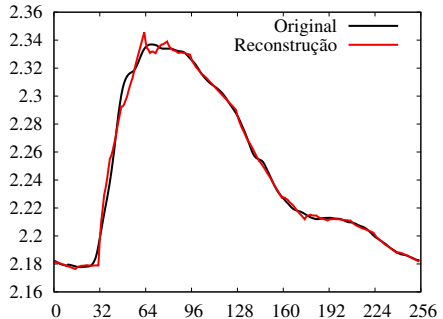

(b) Daubechies com 2 momentos nulos

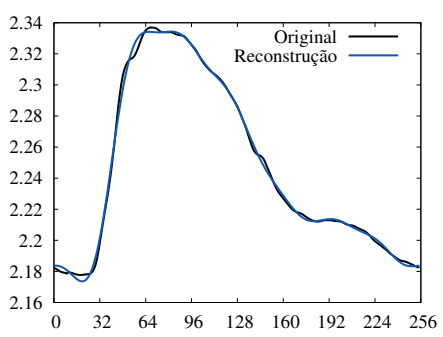

(e) FFT

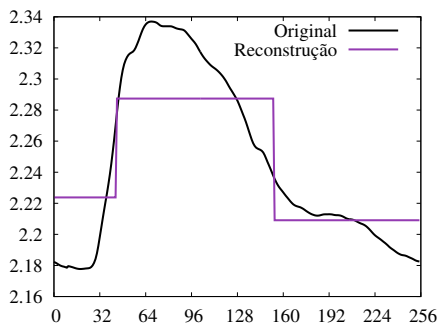

(h) $m A Z T E C$

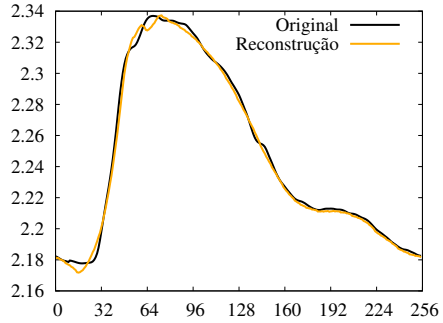

(c) Daubechies com 4 momentos nulos

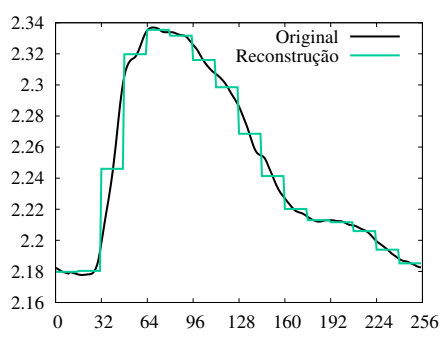

(f) Haar

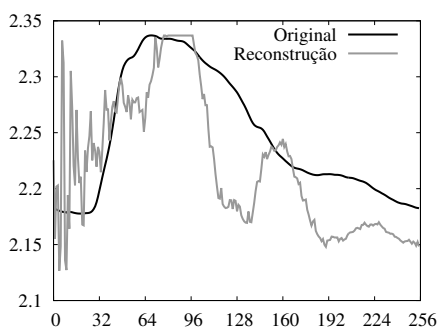

(i) Vorbis

Figura 4.14: Resultado da codificação do sinal de variação de diâmetro arterial (figura 3.9c) usando a primeira metodologia descrita, o algoritmo AZTEC, o algoritmo mAZTEC, o algoritmo Vorbis e as transformadas estudadas. 


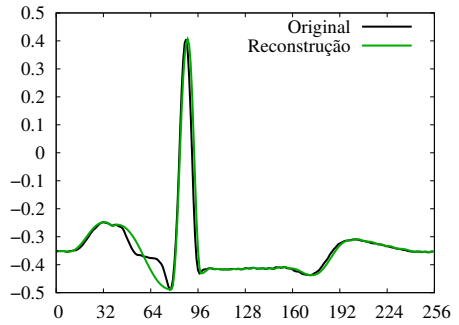

(a) Primeira metodologia descrita

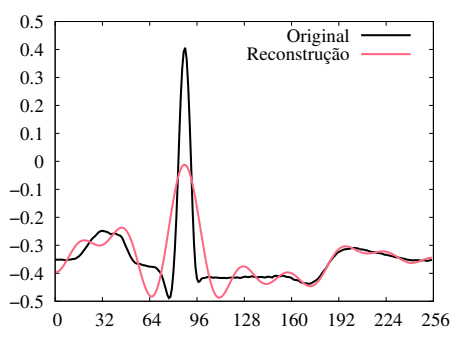

(d) $D C T$

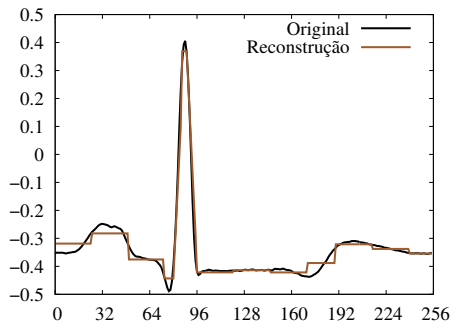

(g) AZTEC
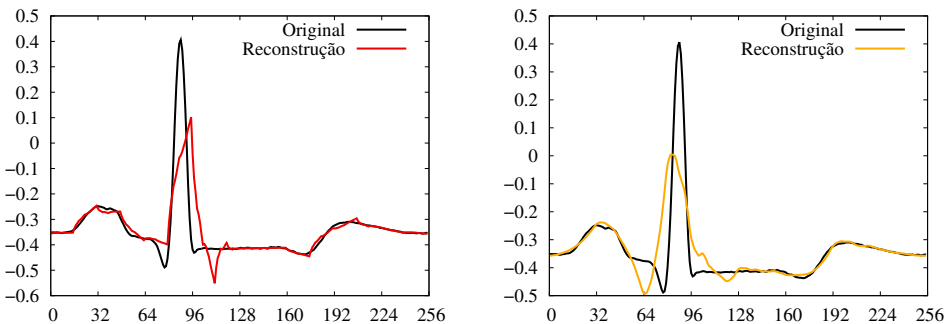

(c) Daubechies com 4 momentos nulos

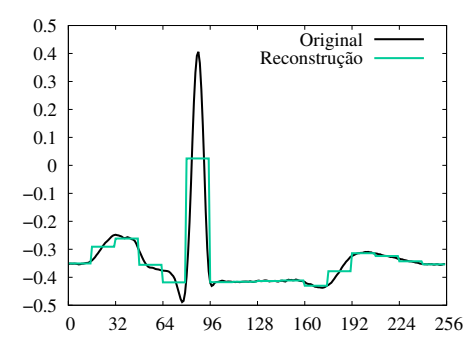

(f) Haar

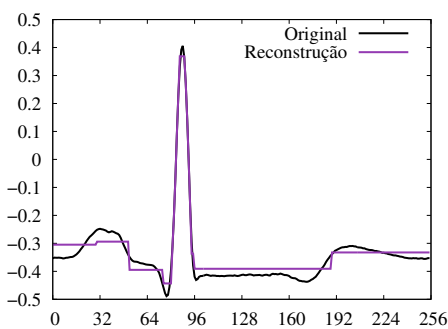

(h) $\mathrm{mAZTEC}$

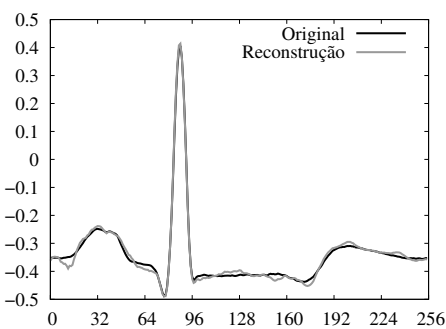

(i) Vorbis

Figura 4.15: Resultado da codificação do sinal de ECG (figura 3.9d) usando a primeira metodologia descrita, o algoritmo AZTEC, o algoritmo mAZTEC, o algoritmo Vorbis e as transformadas estudadas. 


\section{SNR para ECG}

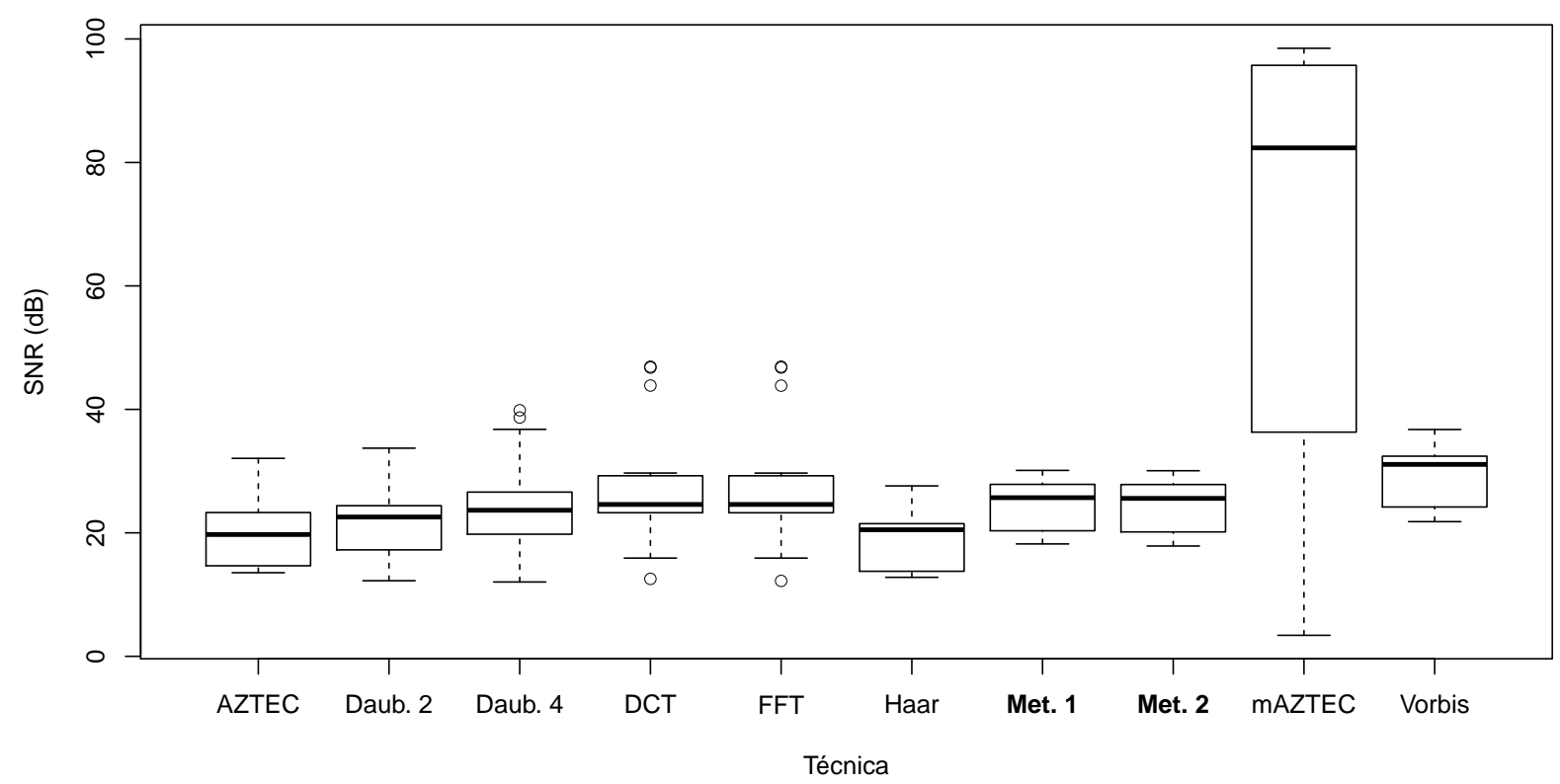

Figura 4.16: Boxplot das razões sinal-ruído para a codificação dos sinais de ECG descritos na seção 3.6 usando as técnicas estudadas.

A figura 4.23 mostra um comparativo entre a razão de compressão e a razão sinal-ruído para cada técnica de compressão com perdas avaliada, considerando os resultados obtidos com todos os sinais descritos na seção 3.6.

\subsection{Imagens}

As figuras 4.24, 4.25, 4.26, 4.27, 4.28 e 4.29 mostram o resultado da compressão das imagens descritas na seção 3.4 com a segunda metodologia descrita usando a ordenação de pixels em espiral para transformar as imagens em sinais unidimensionais. Também é mostrado o resultado da compressão de cada uma das imagens utilizando o algoritmo JPEG com 90\% de qualidade. 


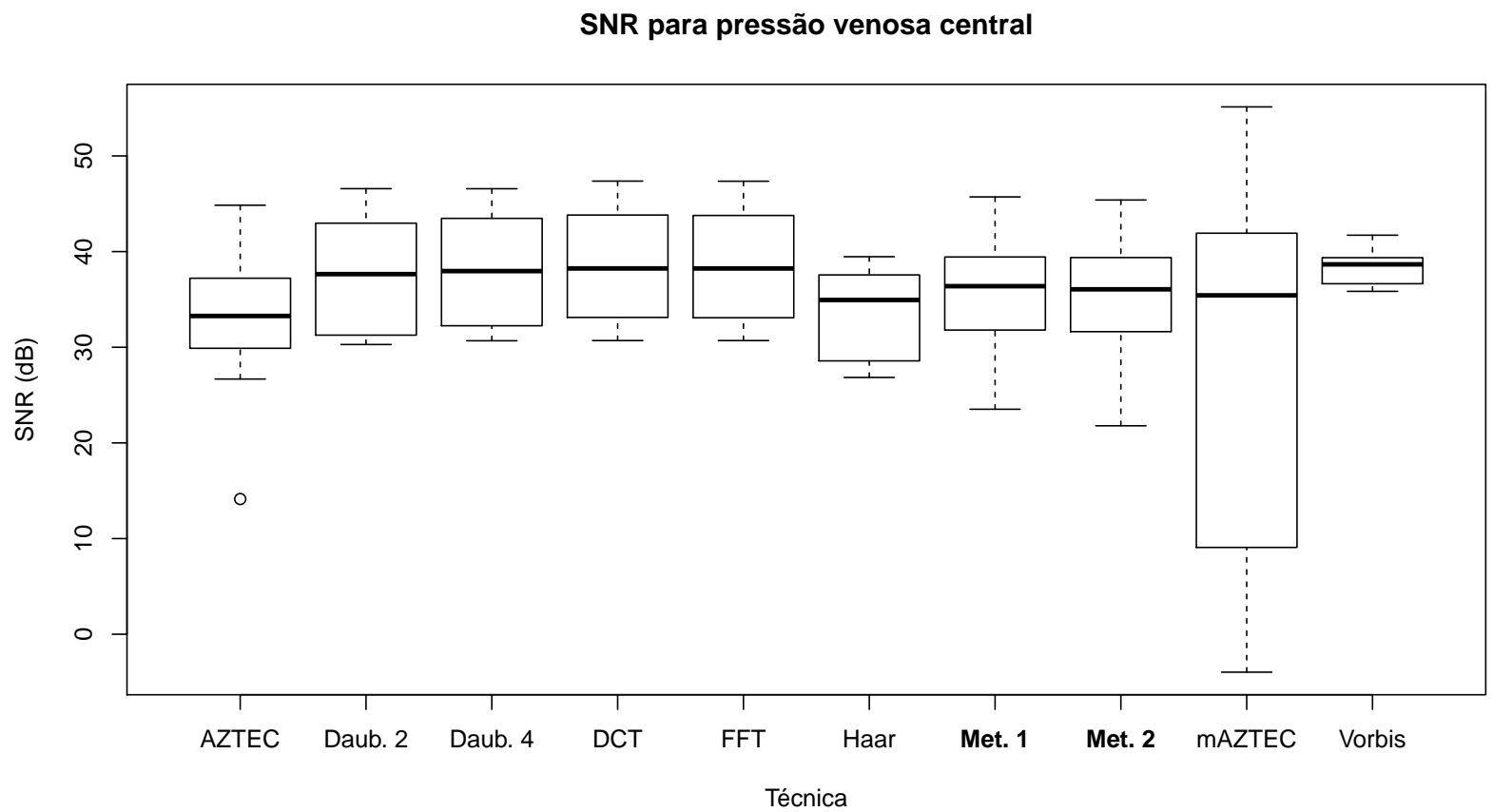

Figura 4.17: Boxplot das razões sinal-ruído para a codificação dos sinais de pressão venosa central descritos na seção 3.6 usando as técnicas estudadas.

SNR para pressão intraesofágica

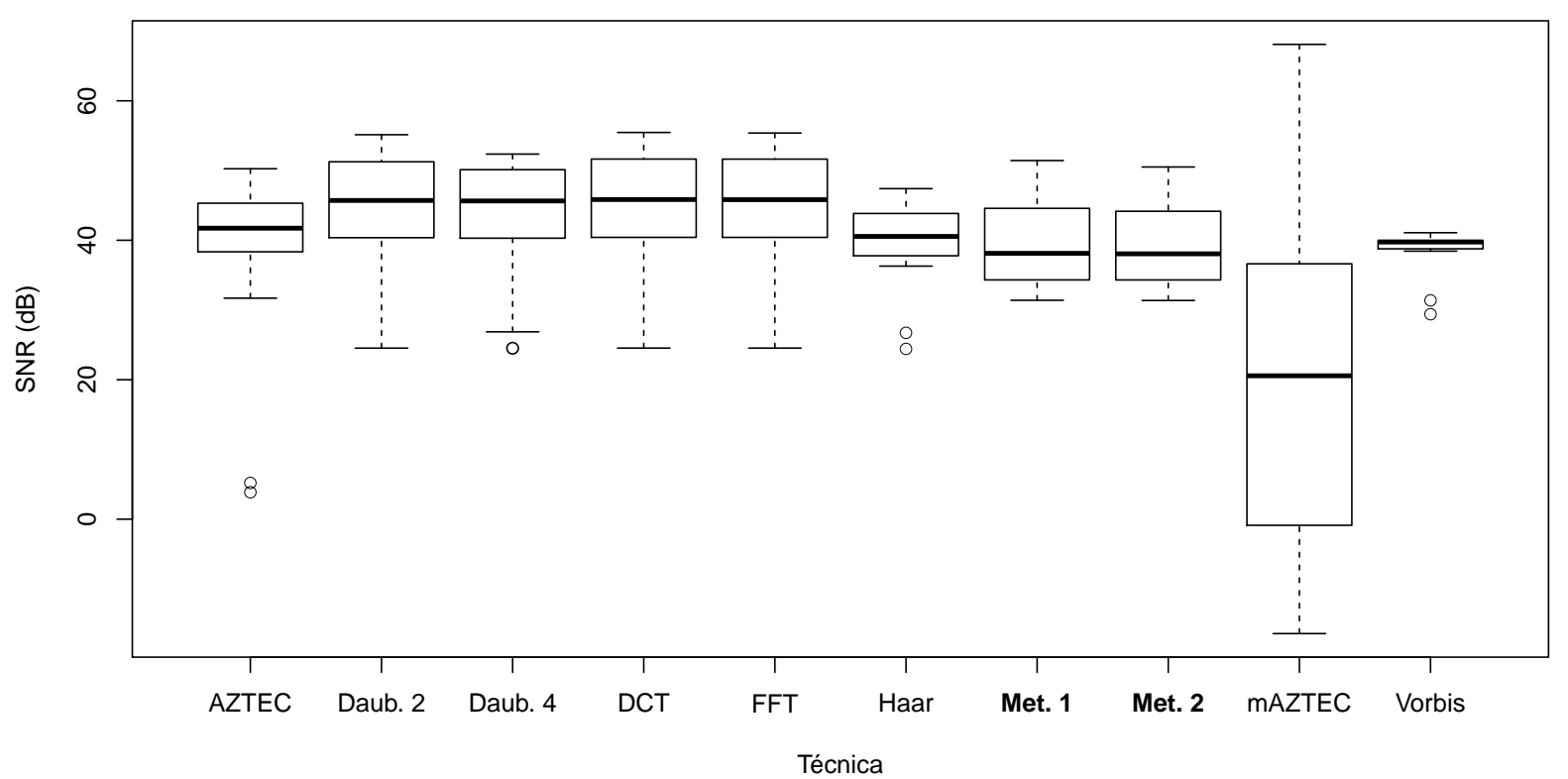

Figura 4.18: Boxplot das razões sinal-ruído para a codificação dos sinais de pressão intraesofágica descritos na seção 3.6 usando as técnicas estudadas. 


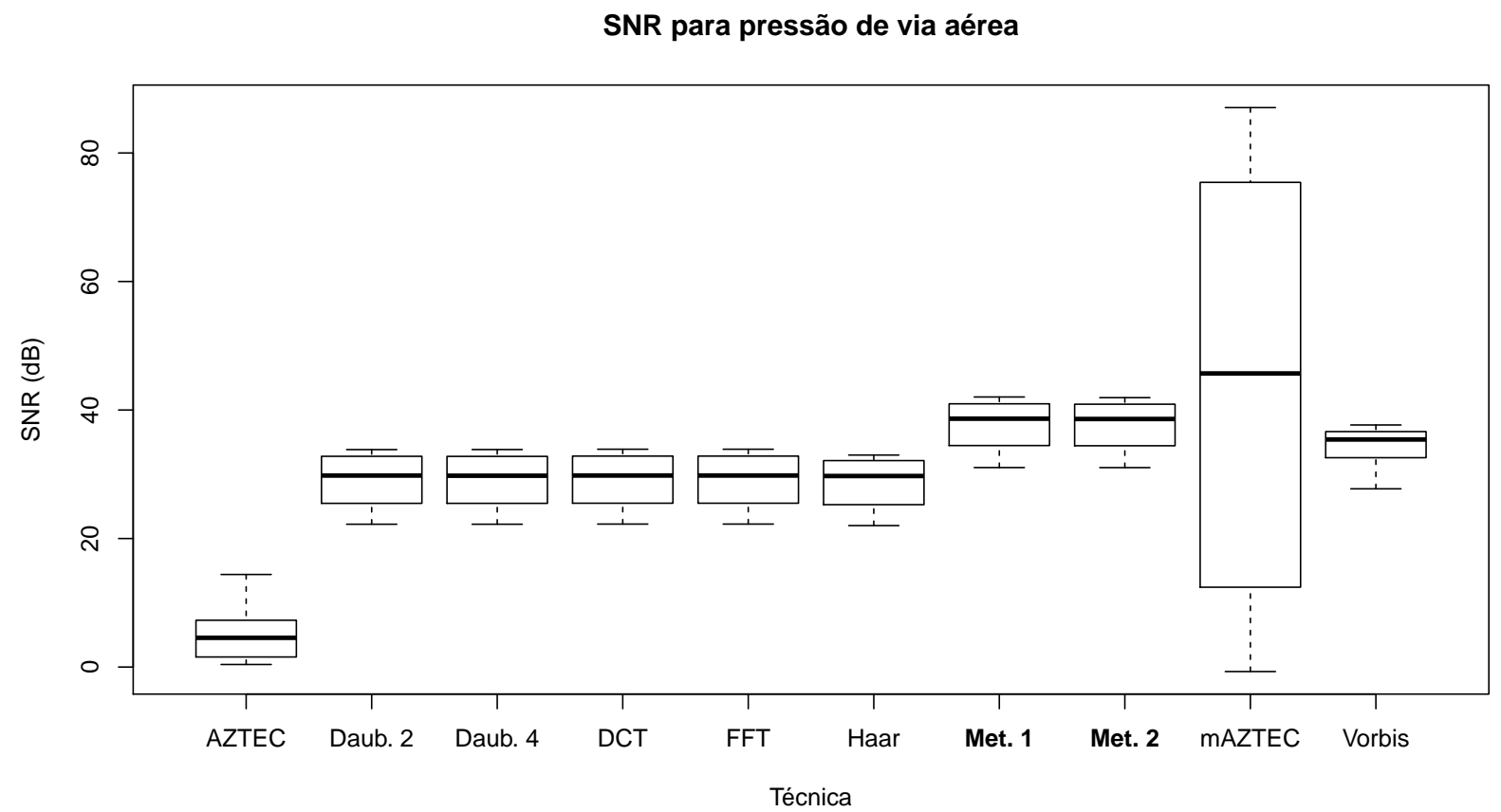

Figura 4.19: Boxplot das razões sinal-ruído para a codificação dos sinais de pressão de via aérea descritos na seção 3.6 usando as técnicas estudadas.

SNR para pressão arterial de um suíno

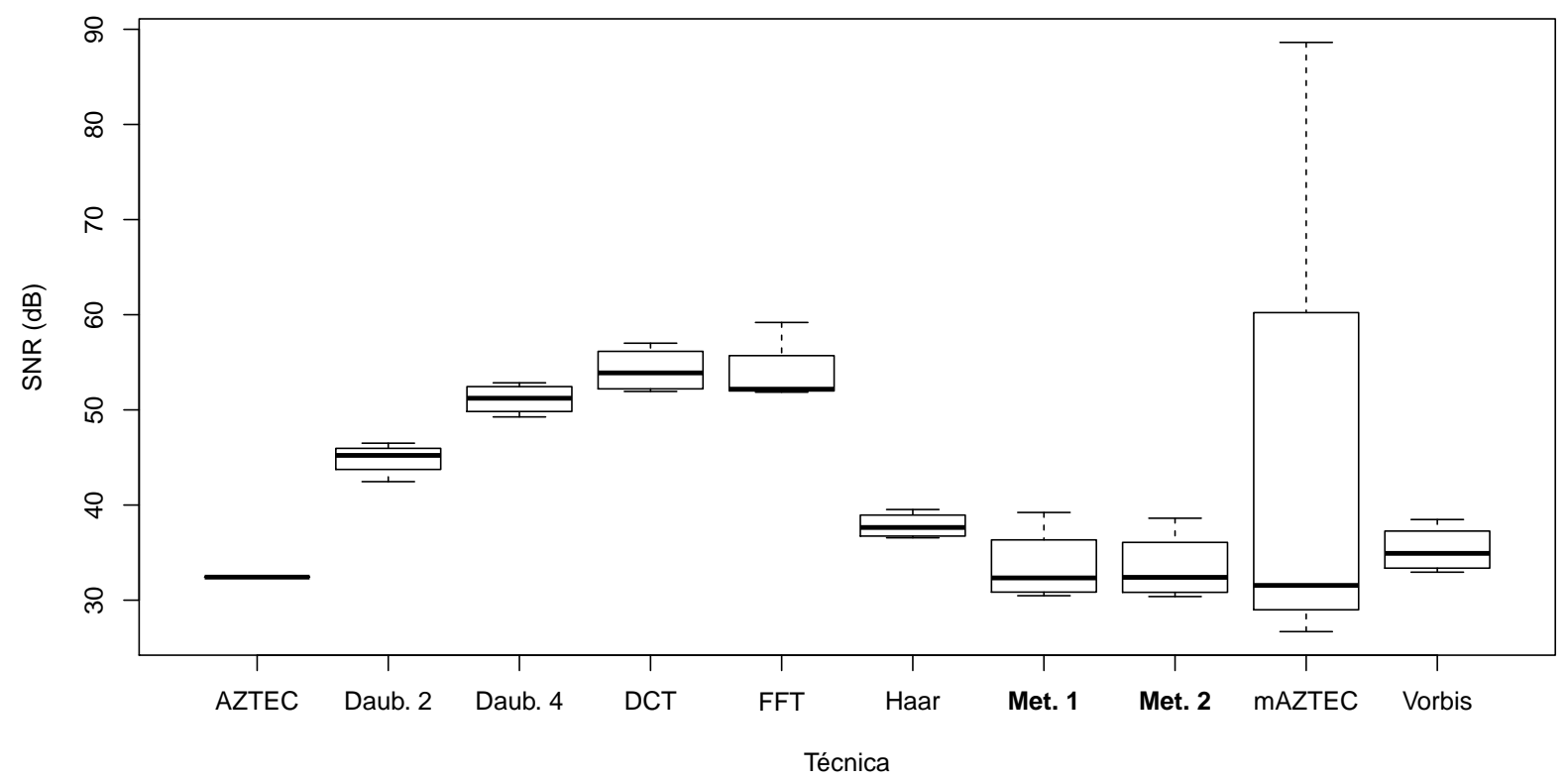

Figura 4.20: Boxplot das razões sinal-ruído para a codificação dos sinais de pressão arterial de um suíno descritos na seção 3.6 usando as técnicas estudadas. 
SNR para fluxo sanguíneo na artéria de um suíno

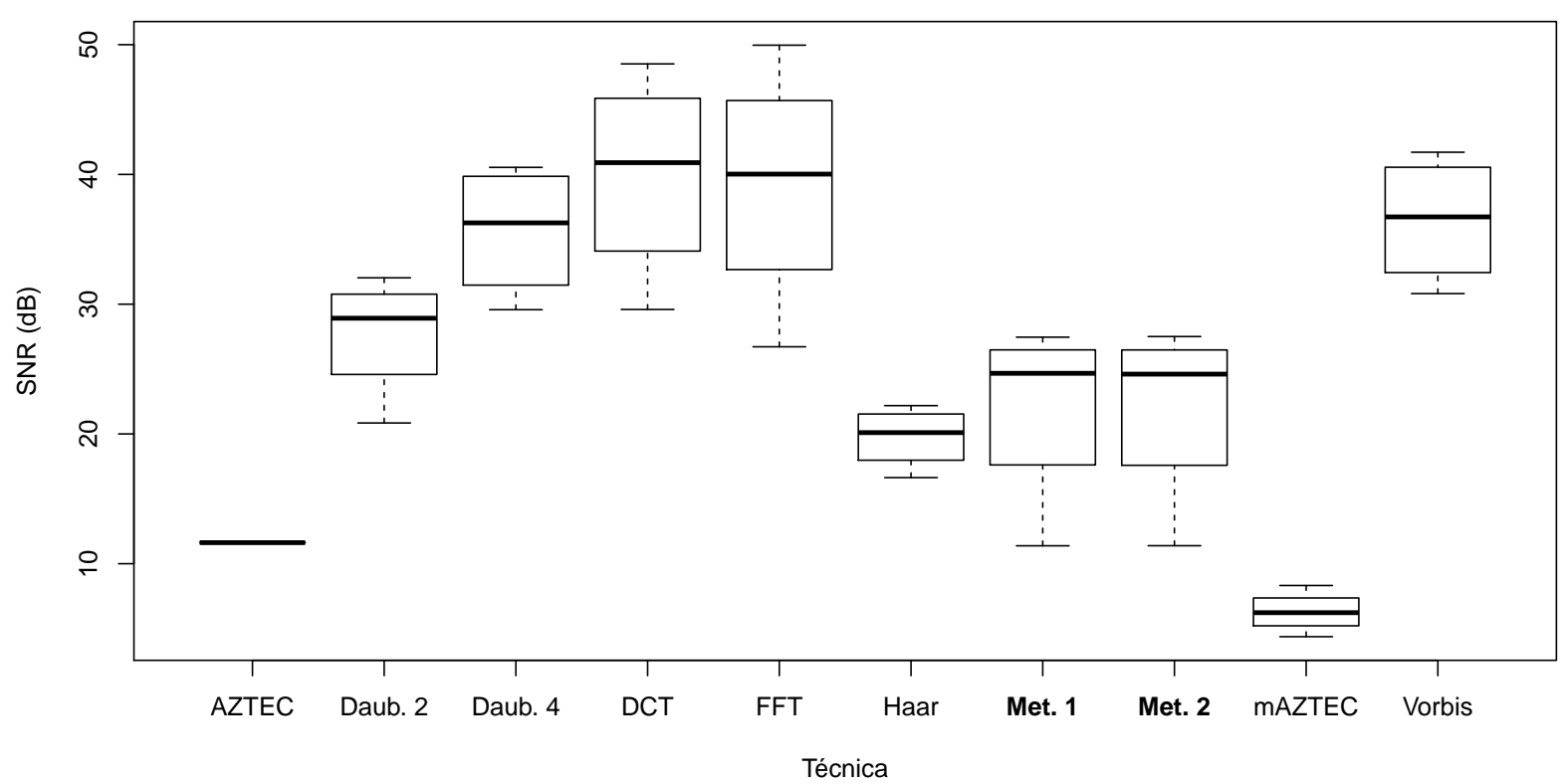

Figura 4.21: Boxplot das razões sinal-ruído para a codificação dos sinais de fluxo de sangue na artéria de um suíno descritos na seção 3.6 usando as técnicas estudadas.

\section{SNR para diâmetro arterial de um suíno}

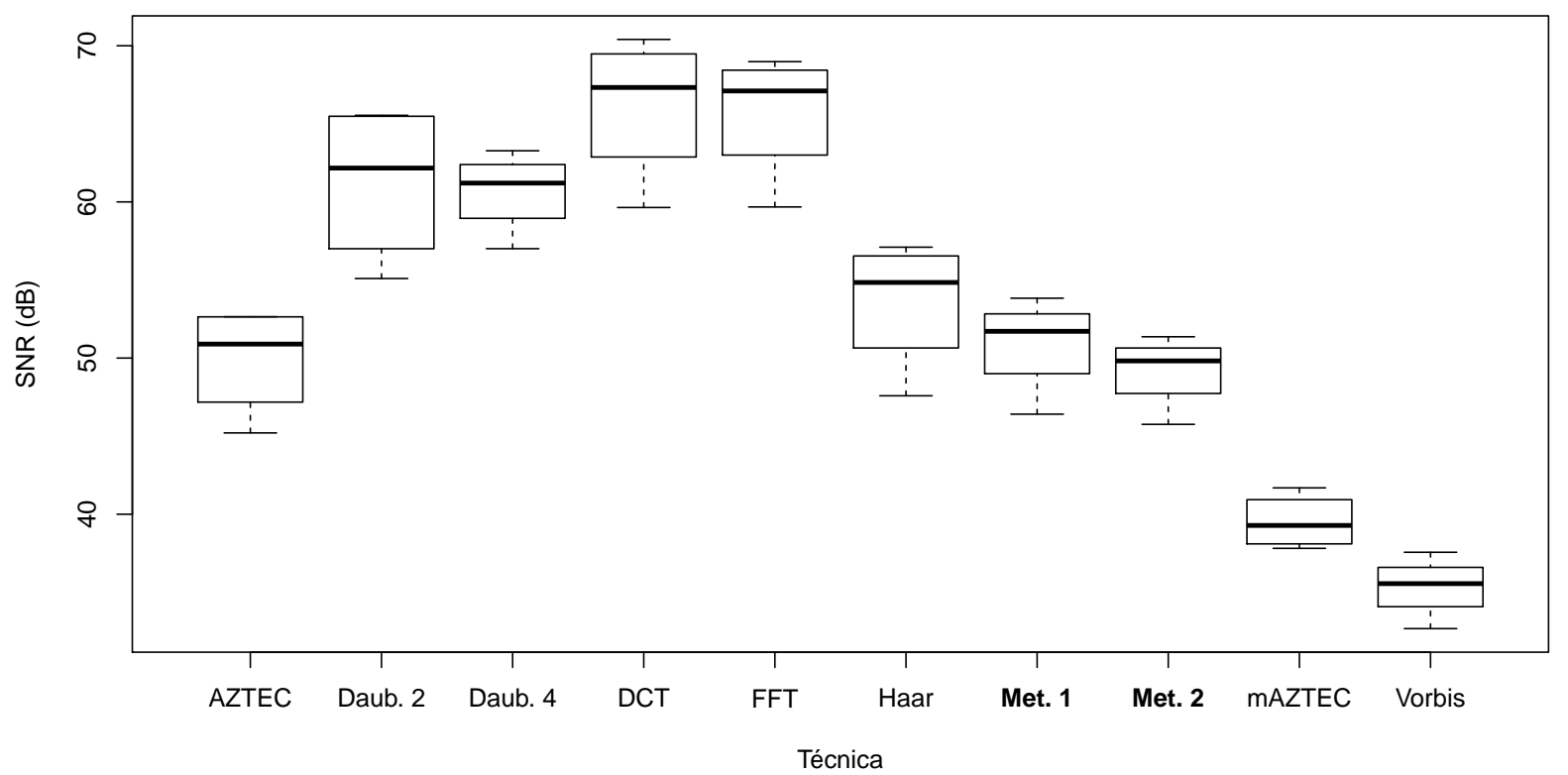

Figura 4.22: Boxplot das razões sinal-ruído para a codificação dos sinais de variação de diâmetro da artéria de um suíno descritos na seção 3.6 usando as técnicas estudadas. 




(a) Primeira metodologia

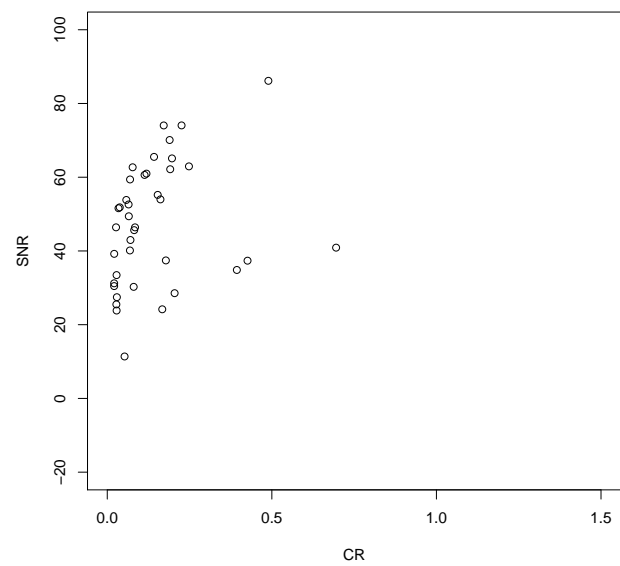

(c) Primeira metodologia (2 iterações apenas sinais de 256 amostras)

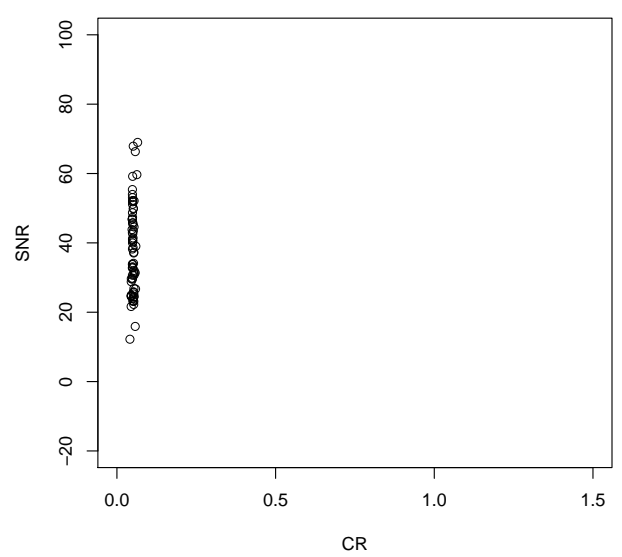

(e) FFT

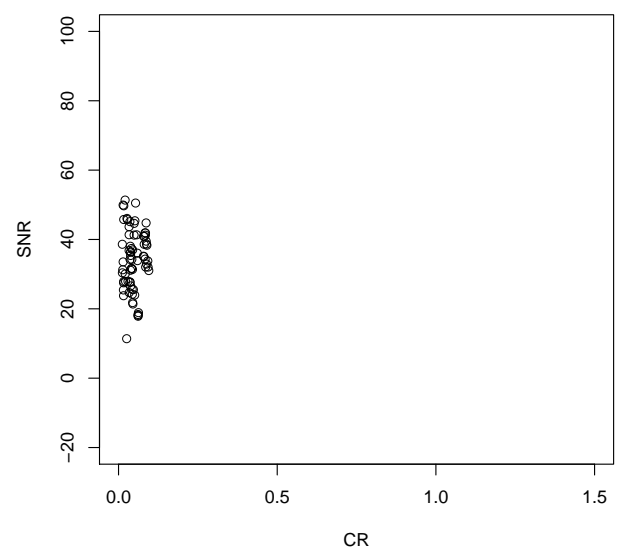

(b) Segunda metodologia

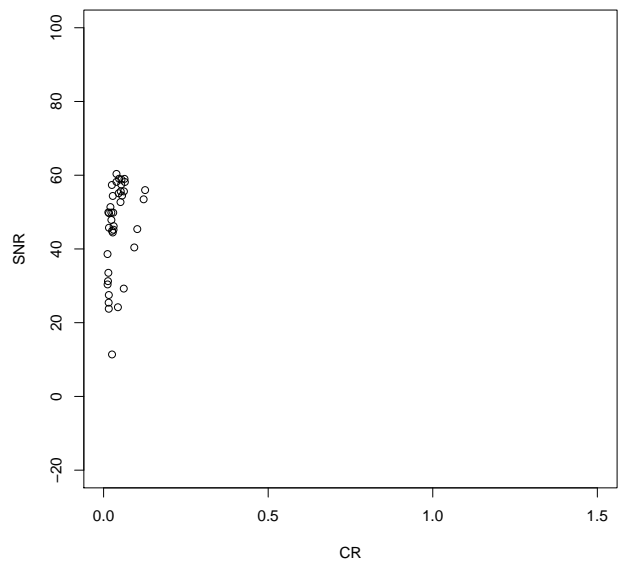

(d) Segunda metodologia (2 iterações - apenas sinais de 256 amostras)



(f) $D C T$ 


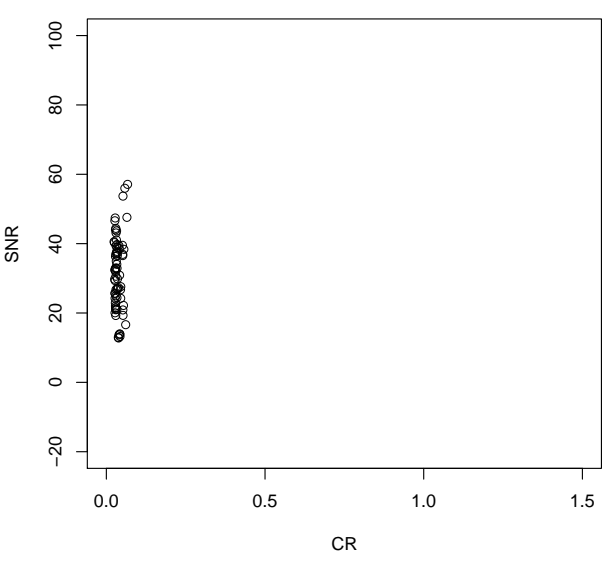

(g) Haar

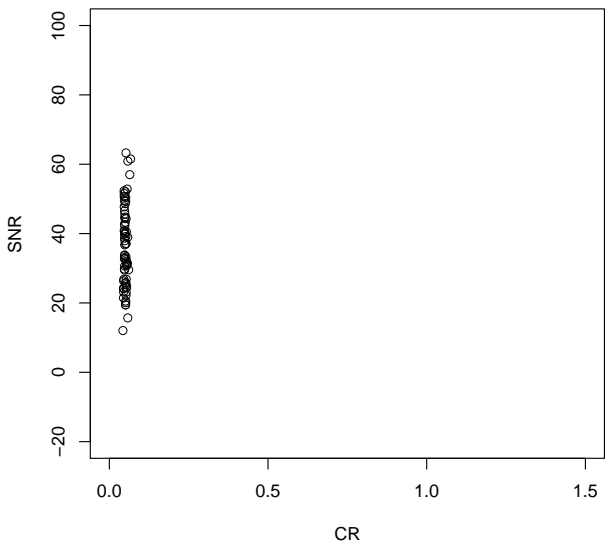

(i) Daubechies com 4 momentos nulos

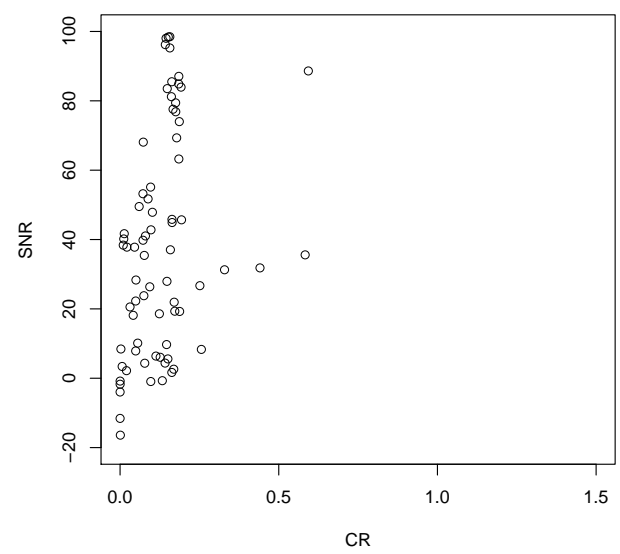

(k) $m A Z T E C$

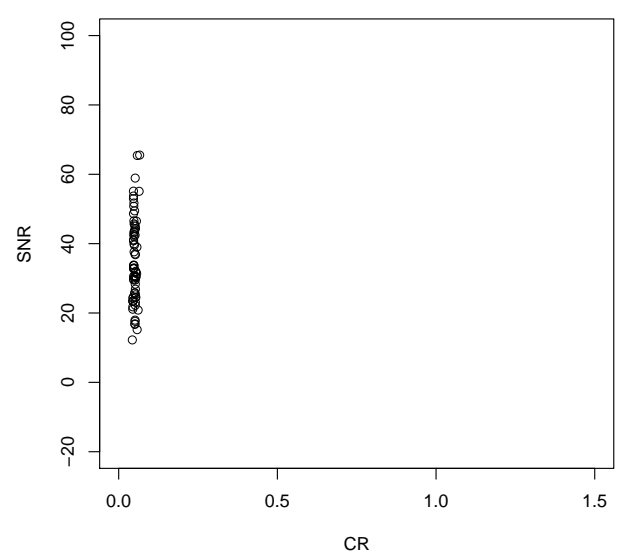

(h) Daubechies com 2 momentos nulos

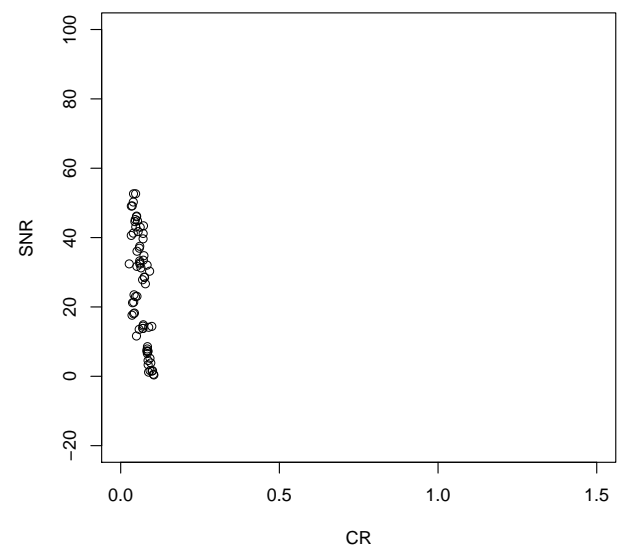

(j) AZTEC

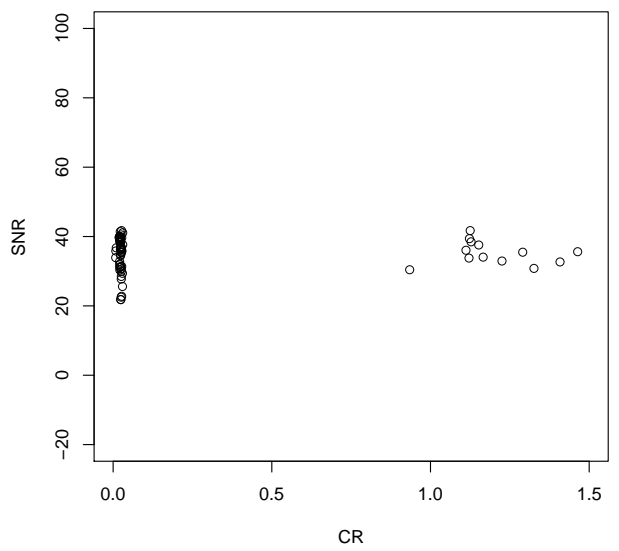

(1) Vorbis

Figura 4.23: Comparativo entre razão de compressão e razão sinal-ruído para as técnicas de compressão com perdas estudadas considerando os sinais descritos na seção 3.6. Quanto maior a concentração de pontos no canto superior esquerdo do gráfico, melhor é a relação compressão/qualidade da técnica. 


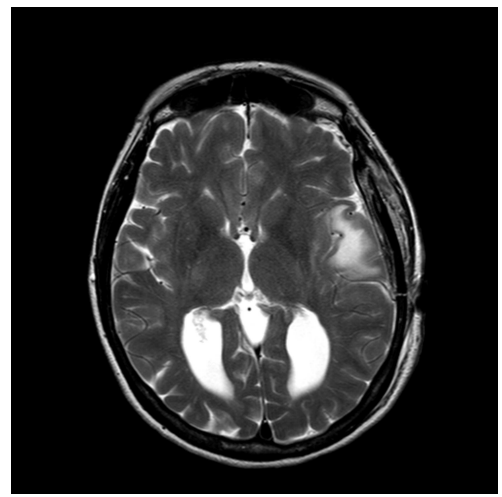

(a) Imagem original

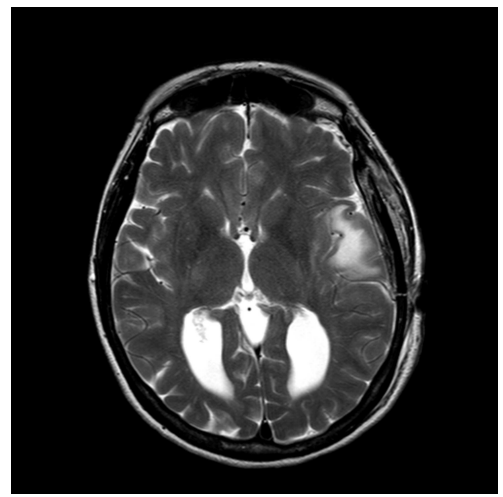

(b) JPEG

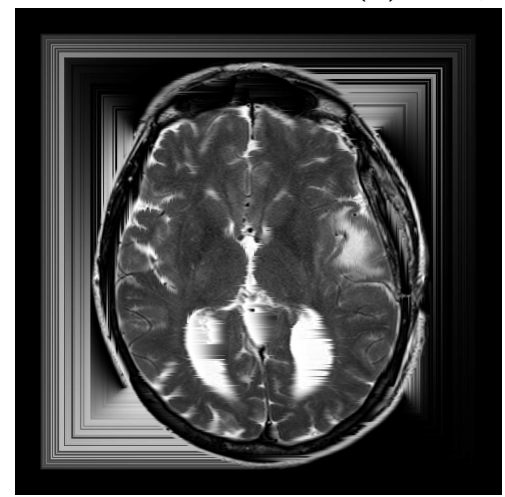

(c) Primeira iteração

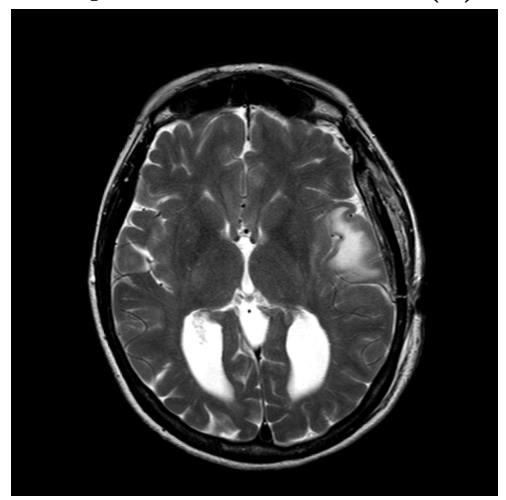

(d) Segunda iteração

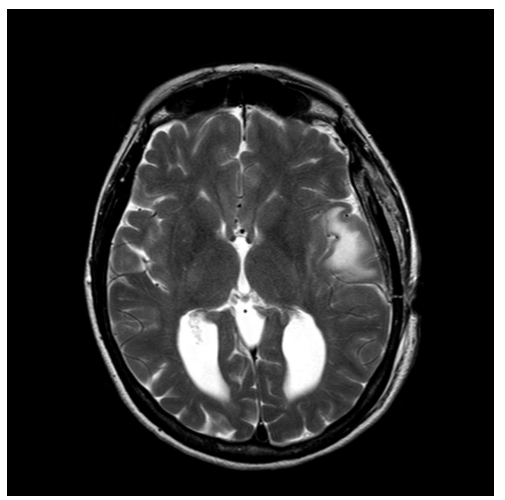

(e) Terceira iteração

Figura 4.24: Codificação de uma imagem de RM com a segunda metodologia descrita usando a ordenação de pixels em espiral

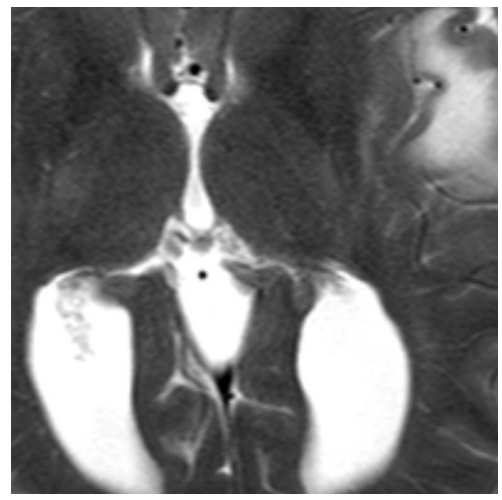

(a) Imagem original

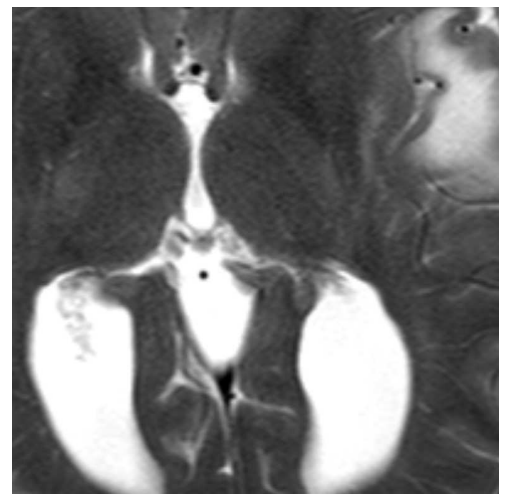

(b) $J P E G$

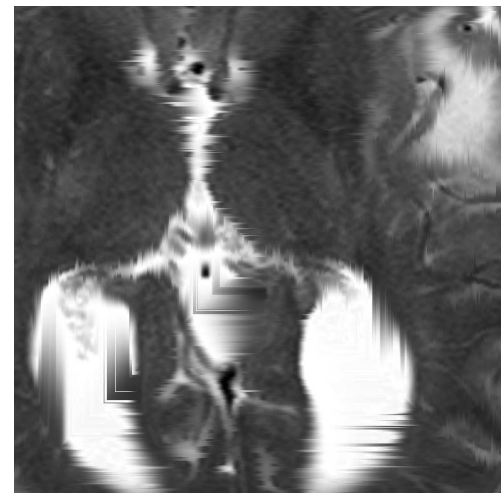

(c) Primeira iteração

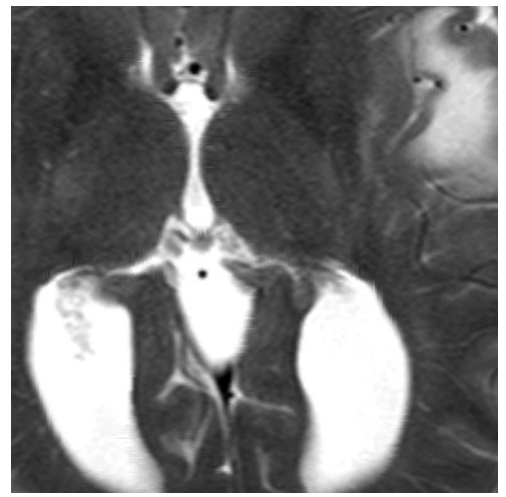

(d) Segunda iteração

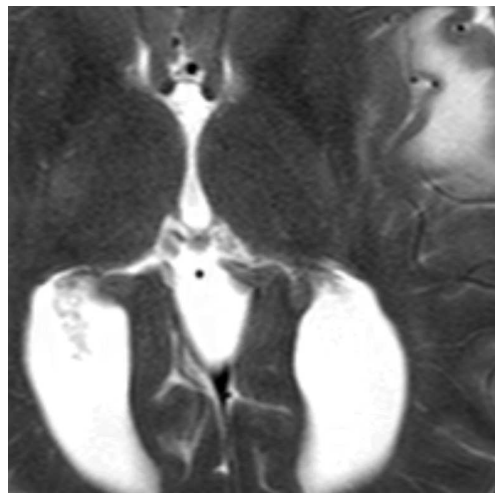

(e) Terceira iteração

Figura 4.25: Codificação de uma região de uma imagem de RM com a segunda metodologia descrita usando a ordenação de pixels em espiral 


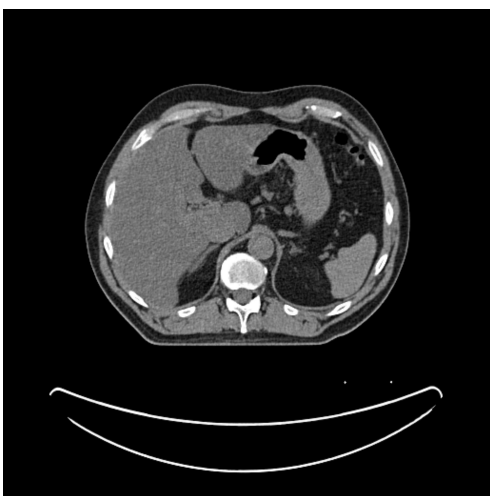

(a) Imagem original

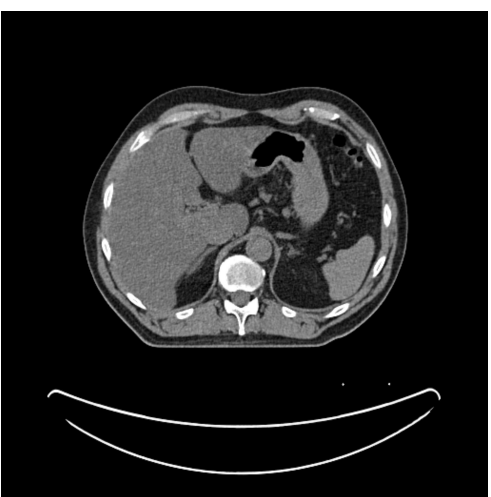

(b) $J P E G$

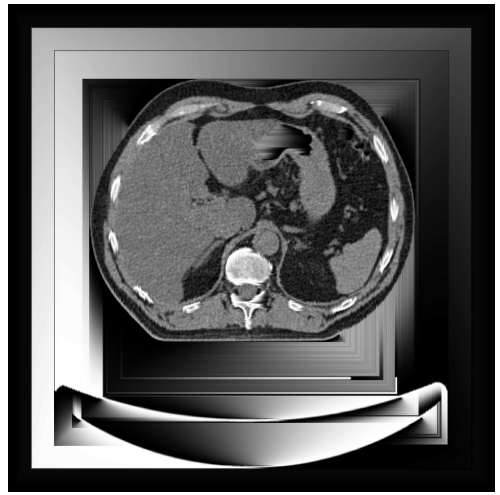

(c) Primeira iteração



(d) Segunda iteração

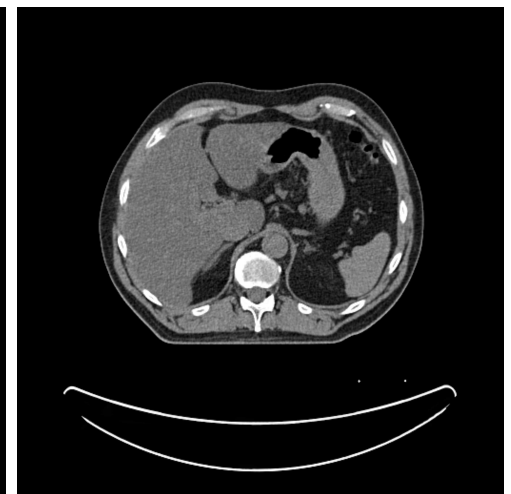

(e) Terceira iteração

Figura 4.26: Codificação de uma imagem de tomografia com a segunda metodologia descrita usando a ordenação de pixels em espiral

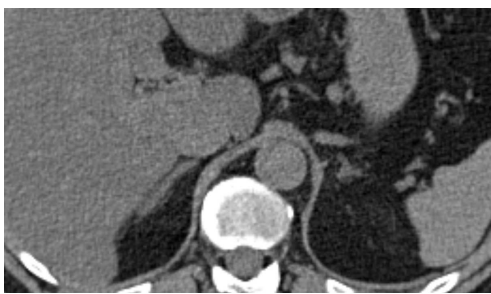

(a) Imagem original

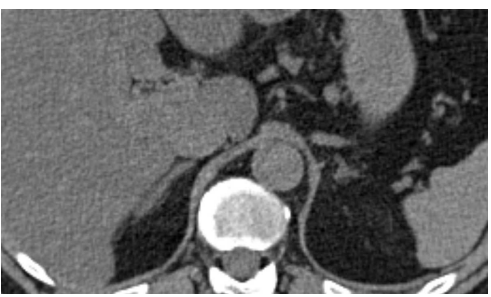

(b) $J P E G$

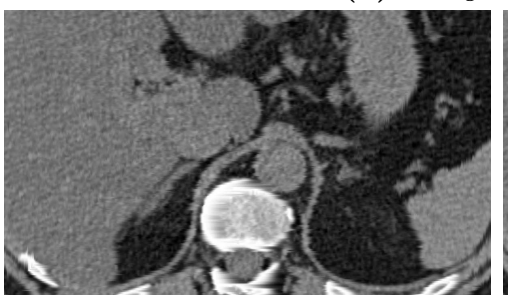

(c) Primeira iteração

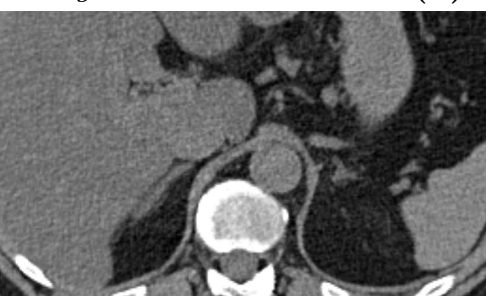

(d) Segunda iteração

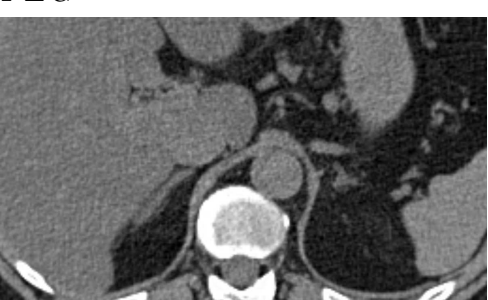

(e) Terceira iteração

Figura 4.27: Codificação de uma região de uma imagem de tomografia com a segunda metodologia descrita usando a ordenação de pixels em espiral 


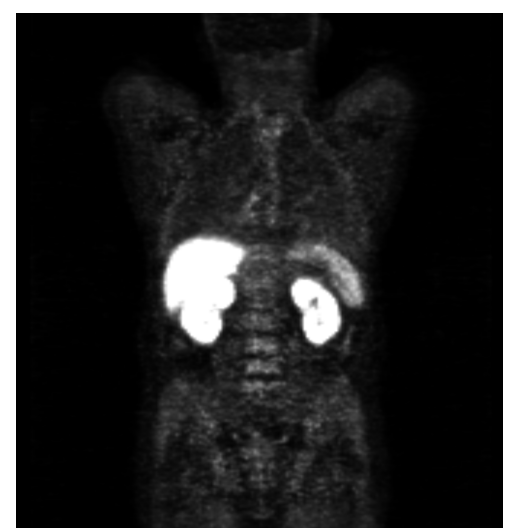

(a) Imagem original

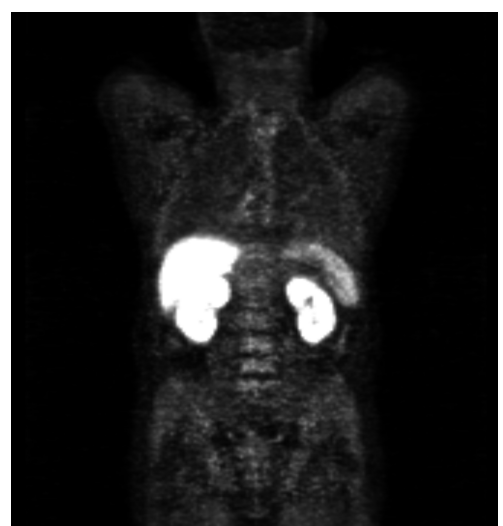

(b) JPEG

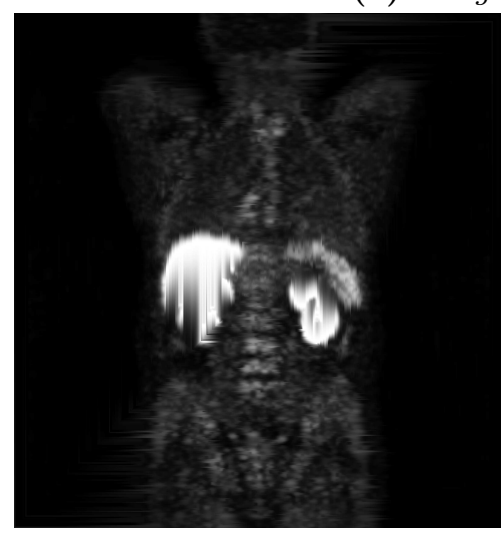

(c) Primeira iteração

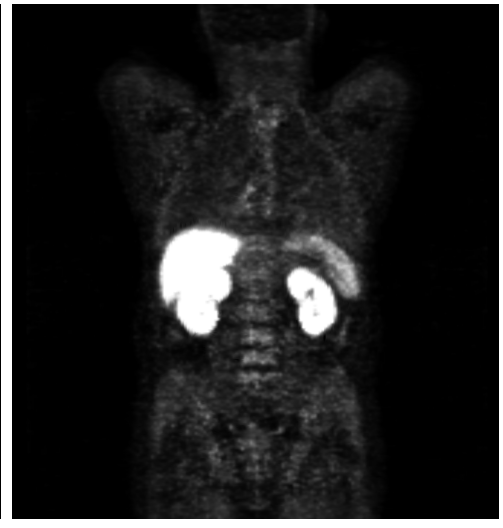

(d) Segunda iteração

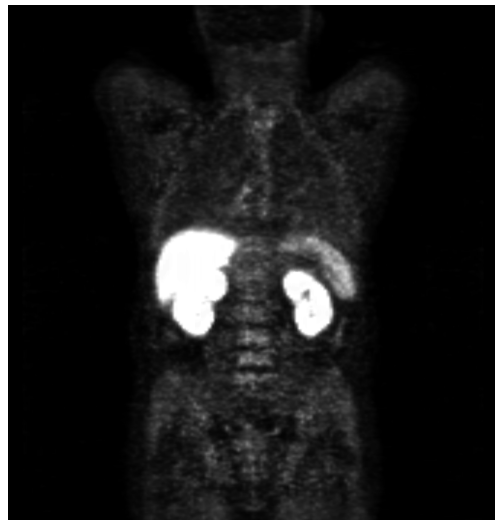

(e) Terceira iteração

Figura 4.28: Codificação de uma imagem de PET com a segunda metodologia descrita usando a ordenação de pixels em espiral 


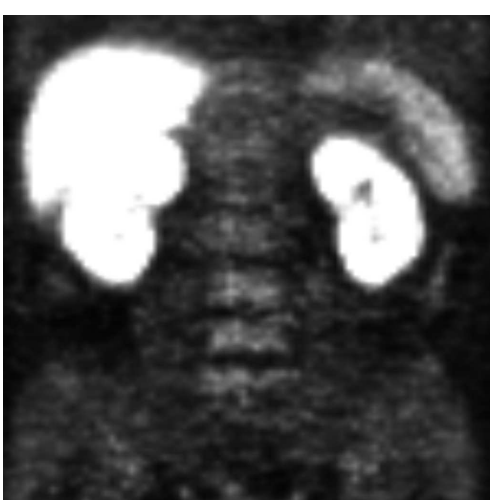

(a) Imagem original

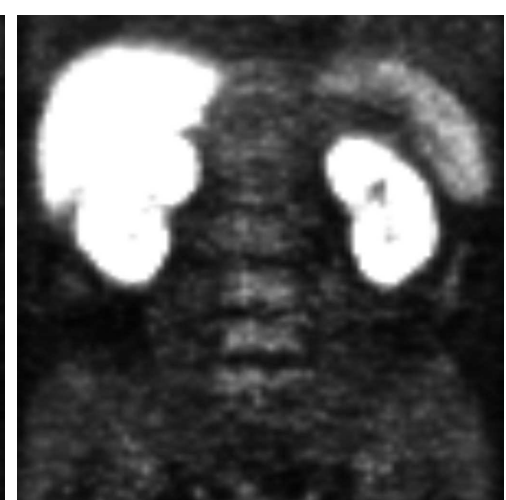

(b) $J P E G$

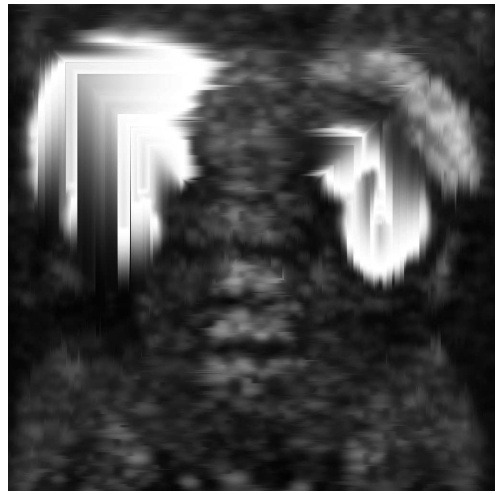

(c) Primeira iteração

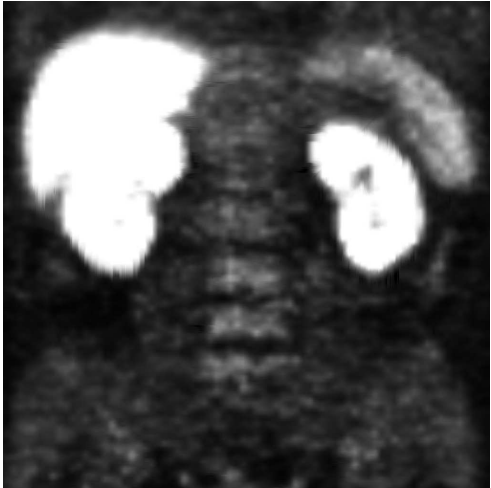

(d) Segunda iteração

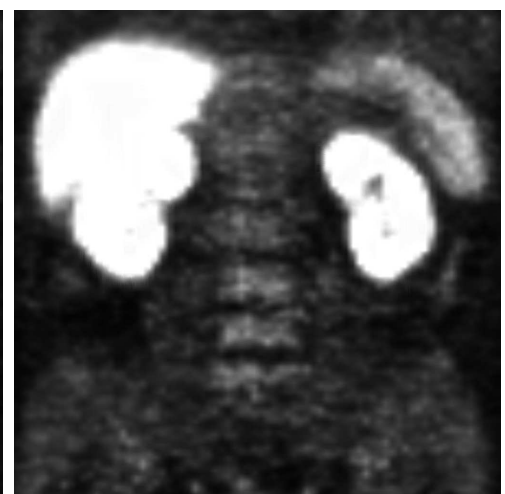

(e) Terceira iteração

Figura 4.29: Codificação de uma região de uma imagem de PET com a segunda metodologia descrita usando a ordenação de pixels em espiral 


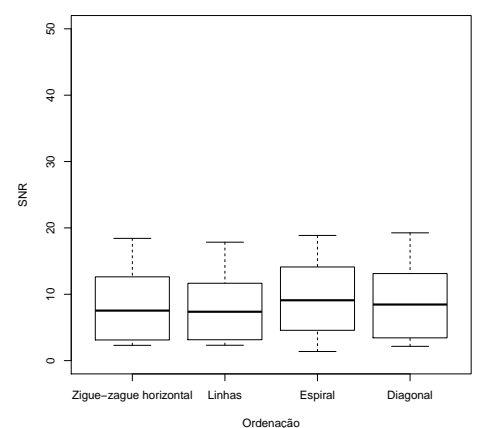

(a) Primeira iteração

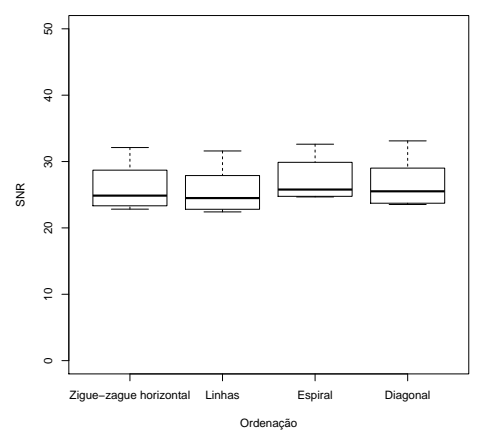

(b) Segunda iteração

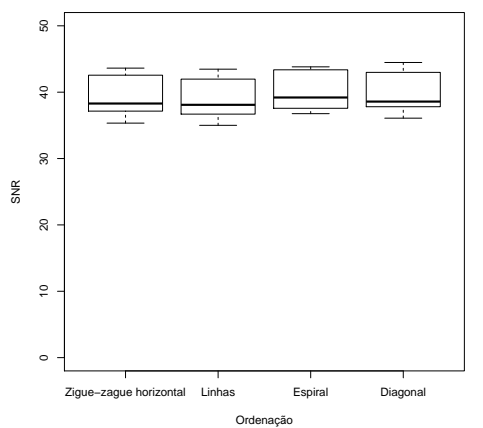

(c) Terceira iteração

Figura 4.30: Razão sinal-ruído das imagens comprimidas de acordo com a ordenação de pixels escolhida.

As figuras 4.30a, 4.30b e 4.30c mostram a razão sinal-ruído das imagens comprimidas de acordo com a ordenação de pixels escolhida. A figura 4.31a mostra a evolução da razão sinal-ruído de acordo com o número de iterações e a imagem para a ordenação em espiral. Por fim, a figura 4.31b mostra a evolução da razão entre a relação sinal-ruído da segunda metodologia descrita e a relação sinal-ruído do algoritmo JPEG para a ordenação em espiral.

As figuras 4.32, 4.33, 4.34, 4.35, 4.36 e 4.37 mostram o resultado da aplicação do filtro Sobel após a compressão das imagens descritas na seção $3.4 \mathrm{com}$ a segunda metodologia descrita usando a ordenação de pixels em espiral para transformar as imagens em sinais unidimensionais. Também é mostrado o resultado da aplicação do mesmo filtro após a compressão de cada uma das imagens utilizando o algoritmo JPEG com 90\% de qualidade. 




(a) SNR absoluto

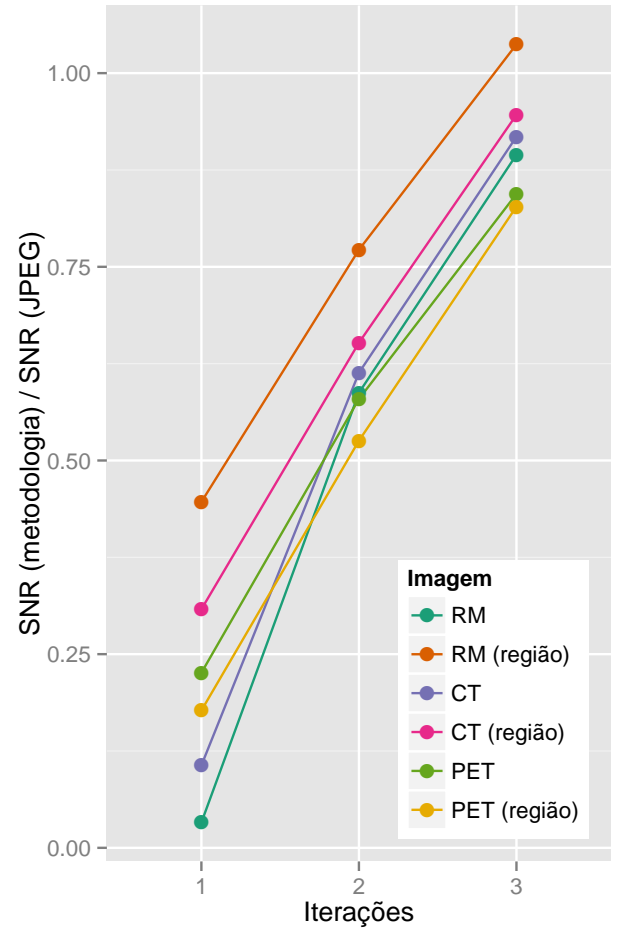

(b) Comparativo com JPEG

Figura 4.31: Evolução da razão sinal-ruído para cada imagem codificada de acordo com o número de iterações usando a ordenação em espiral.

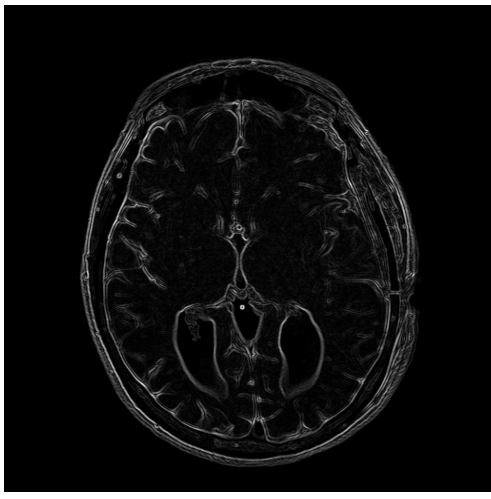

(a) Imagem original

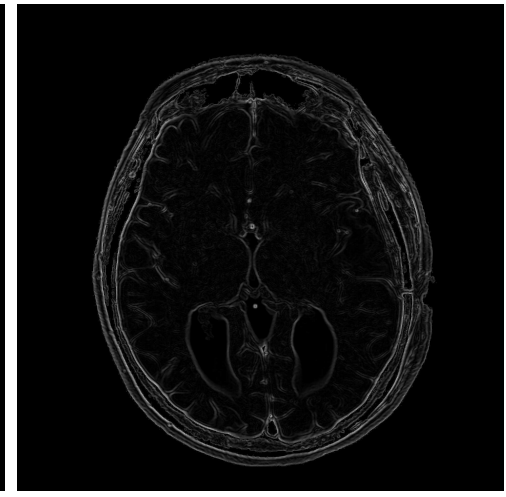

(b) JPEG

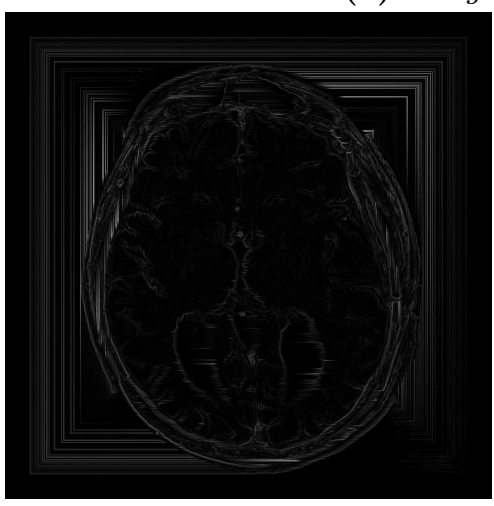

(c) Primeira iteração

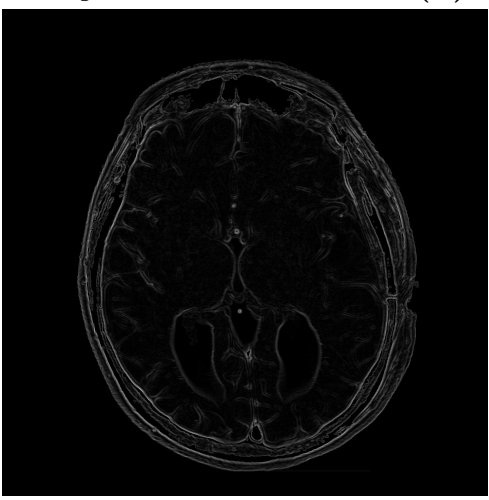

(d) Segunda iteração

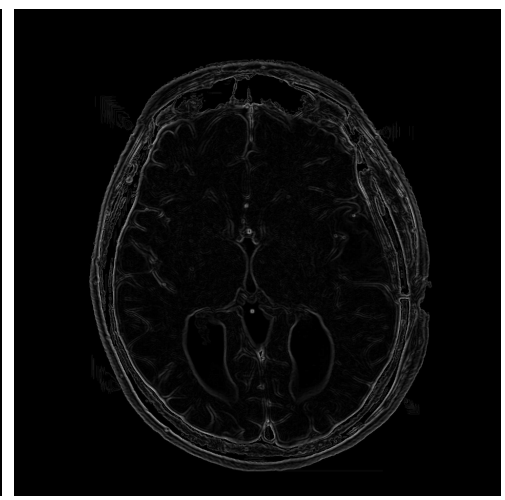

(e) Terceira iteração

Figura 4.32: Resultado da aplicação do filtro Sobel na imagem de RM original e nas imagens comprimidas com o algoritmo JPEG e a segunda metodologia descrita usando uma, duas e três iterações e a ordenação de pixels em espiral. 


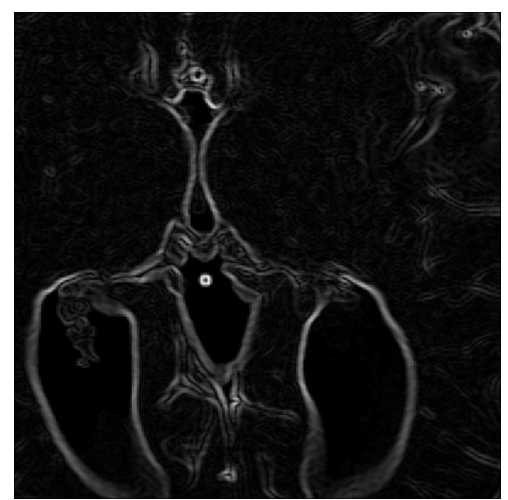

(a) Imagem original

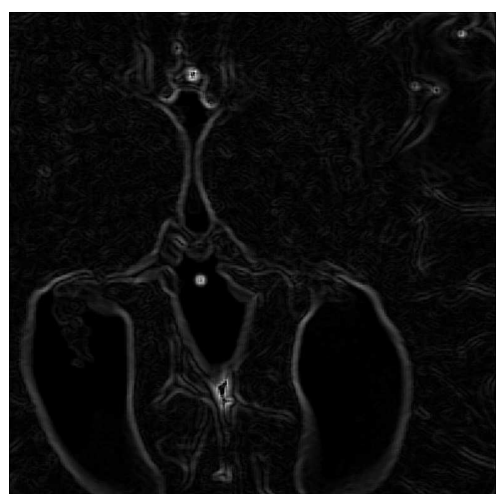

(b) $J P E G$

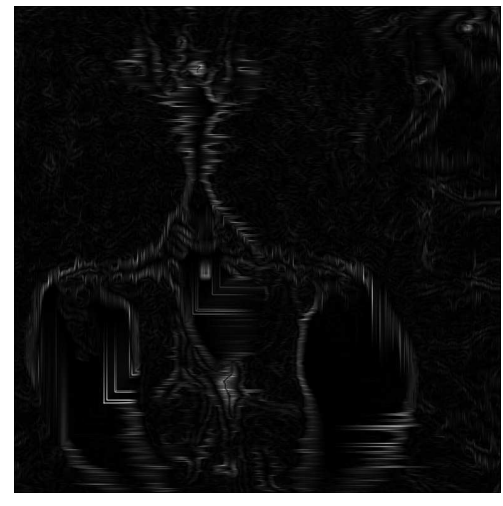

(c) Primeira iteração

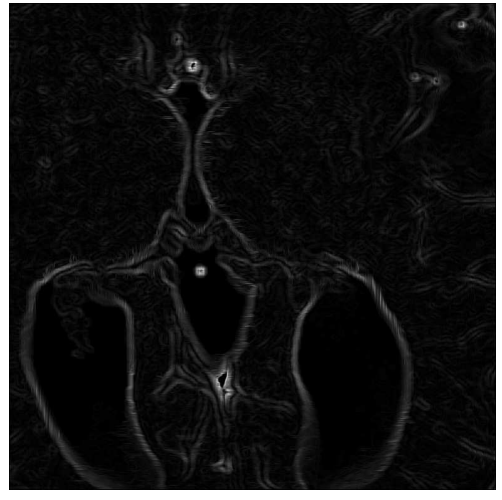

(d) Segunda iteração

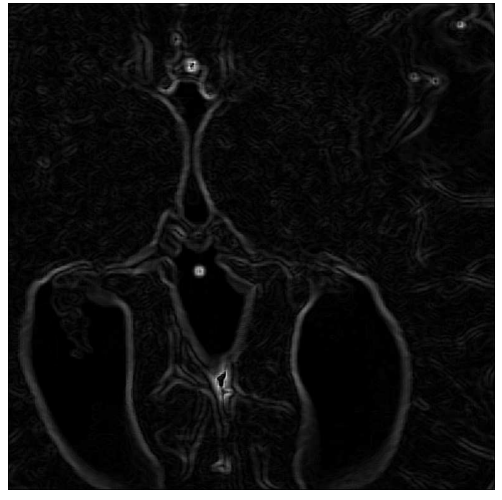

(e) Terceira iteração

Figura 4.33: Resultado da aplicação do filtro Sobel na região da imagem de RM original e nas imagens comprimidas com o algoritmo JPEG e a segunda metodologia descrita usando uma, duas e três iterações e a ordenação de pixels em espiral. 




(a) Imagem original

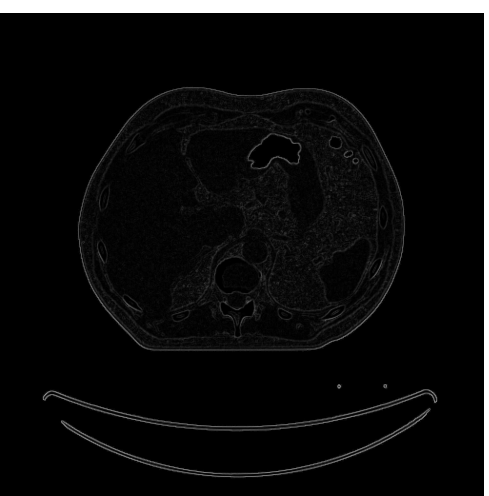

(b) $J P E G$

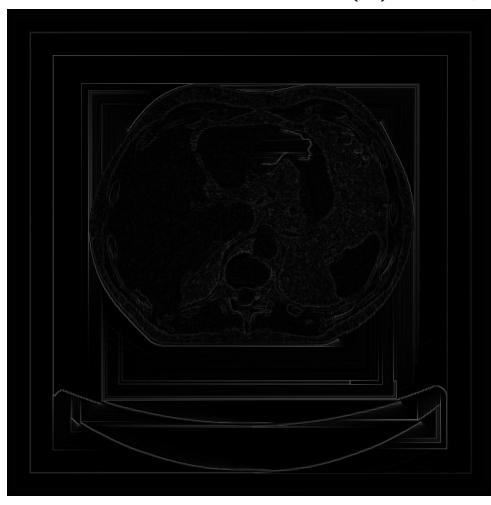

(c) Primeira iteração



(d) Segunda iteração

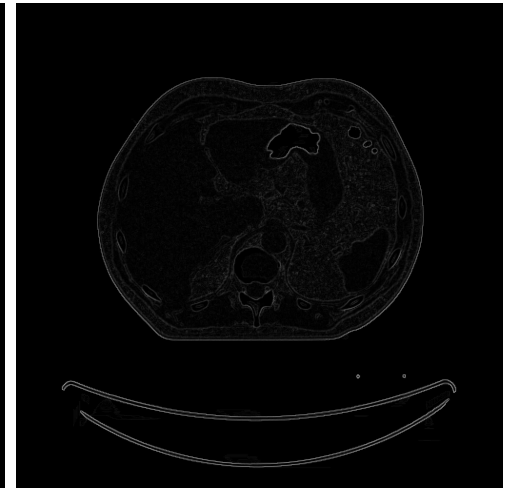

(e) Terceira iteração

Figura 4.34: Resultado da aplicação do filtro Sobel na imagem de CT original e nas imagens comprimidas com o algoritmo JPEG e a segunda metodologia descrita usando uma, duas e três iterações e a ordenação de pixels em espiral.

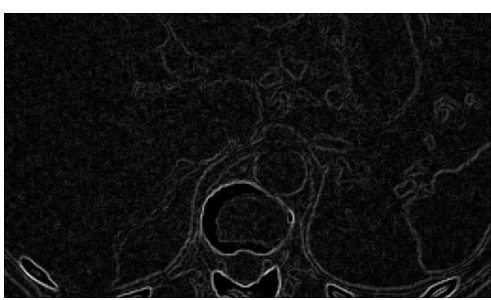

(a) Imagem original

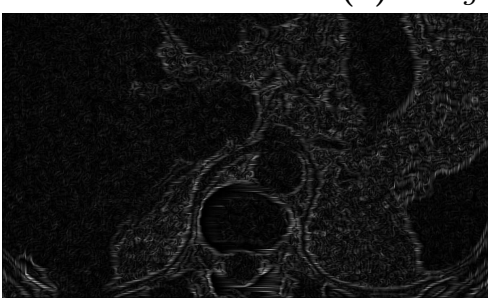

(c) Primeira iteração

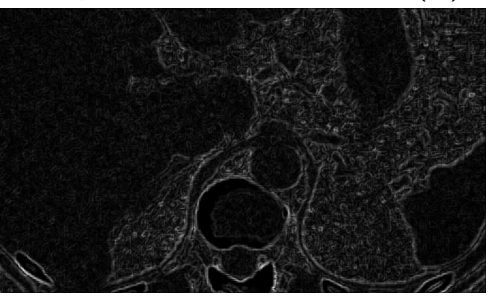

(d) Segunda iteração

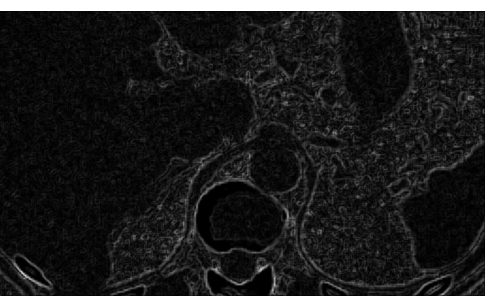

(b) $J P E G$

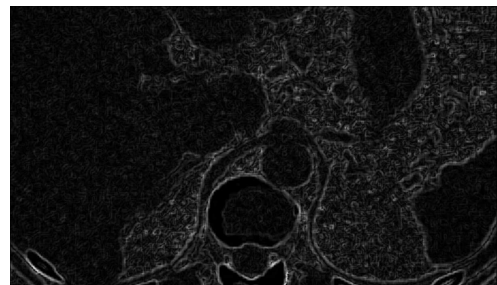

(e) Terceira iteração

Figura 4.35: Resultado da aplicação do filtro Sobel na região da imagem de CT original e nas imagens comprimidas com o algoritmo JPEG e a segunda metodologia descrita usando uma, duas e três iterações e a ordenação de pixels em espiral. 


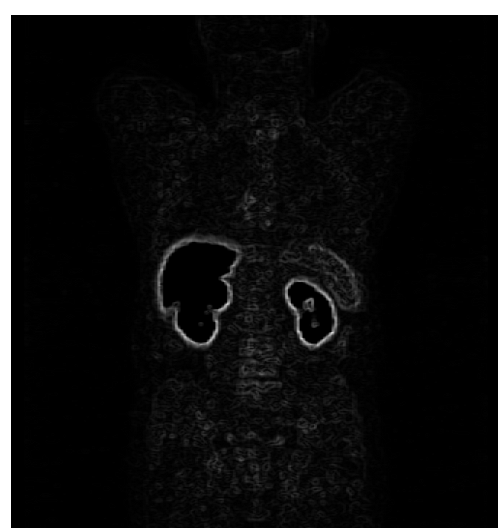

(a) Imagem original

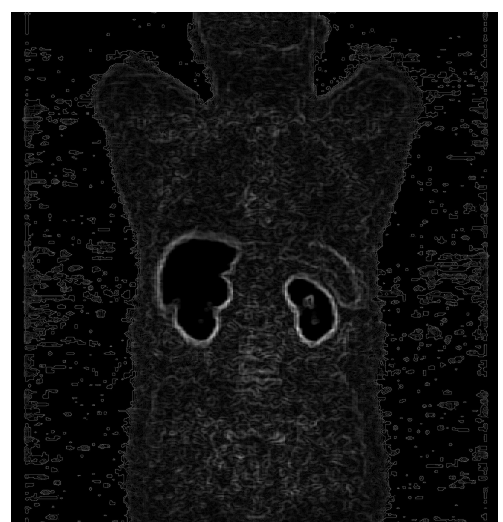

(b) JPEG

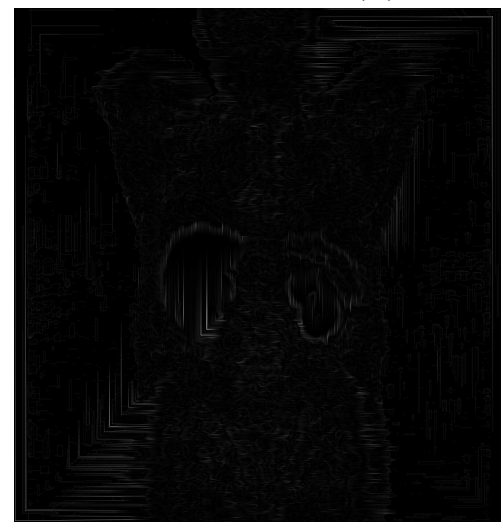

(c) Primeira iteração

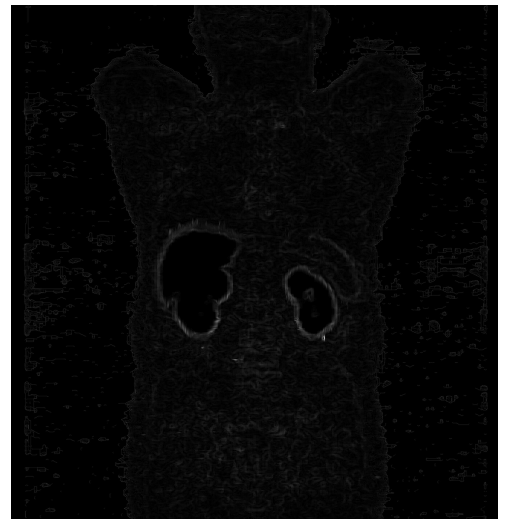

(d) Segunda iteração

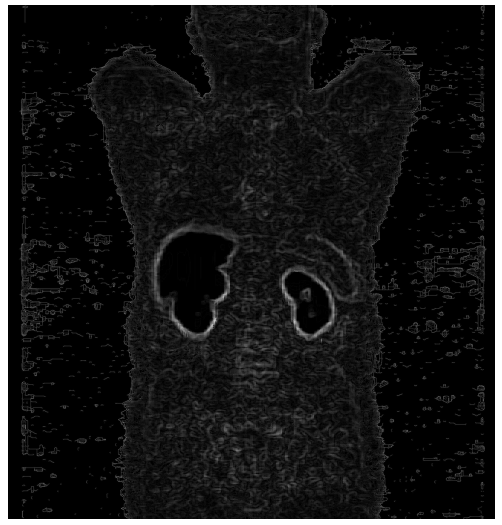

(e) Terceira iteração

Figura 4.36: Resultado da aplicação do filtro Sobel na imagem de PET original e nas imagens comprimidas com o algoritmo JPEG e a segunda metodologia descrita usando uma, duas e três iterações e a ordenação de pixels em espiral. 


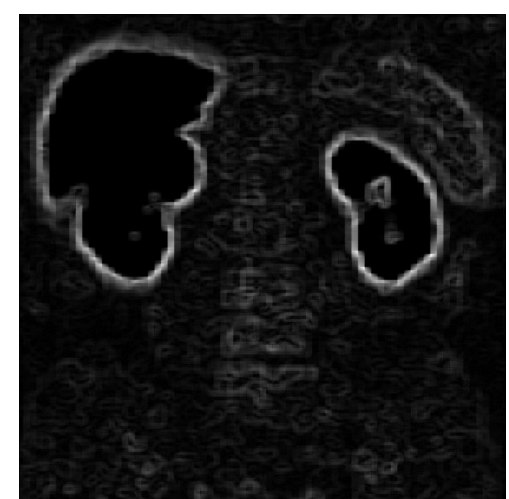

(a) Imagem original

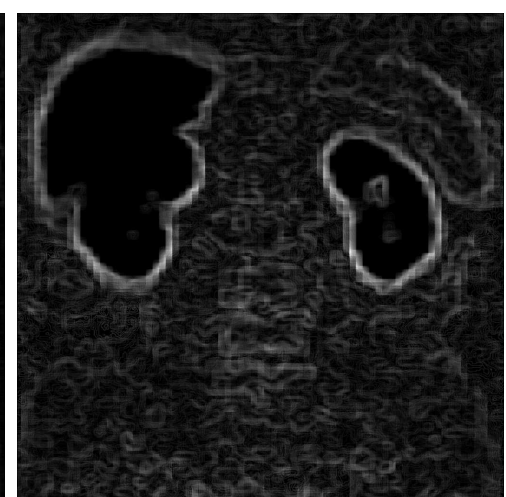

(b) $J P E G$

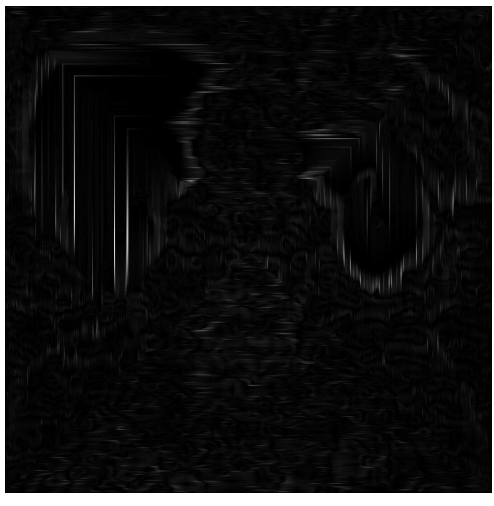

(c) Primeira iteração

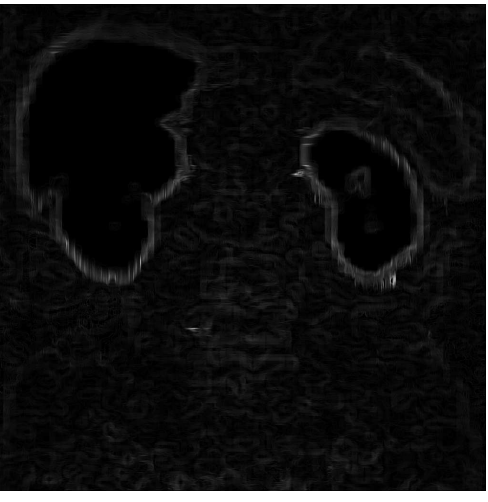

(d) Segunda iteração

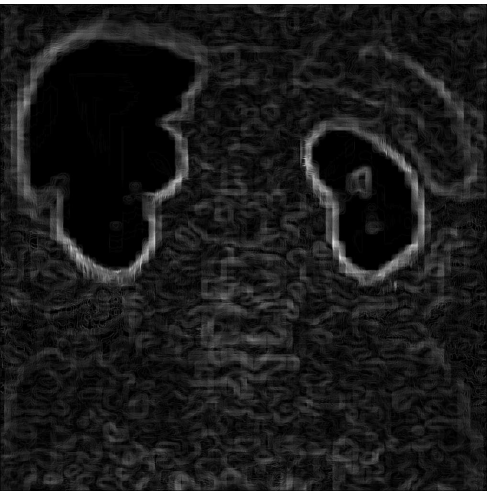

(e) Terceira iteração

Figura 4.37: Resultado da aplicação do filtro Sobel na região da imagem de PET original e nas imagens comprimidas com o algoritmo JPEG e a segunda metodologia descrita usando uma, duas e três iterações e a ordenação de pixels em espiral. 


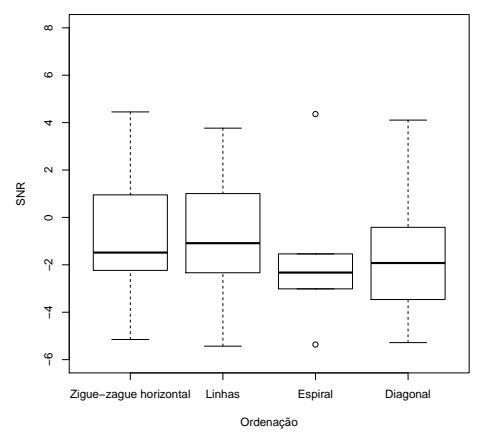

(a) Primeira iteração

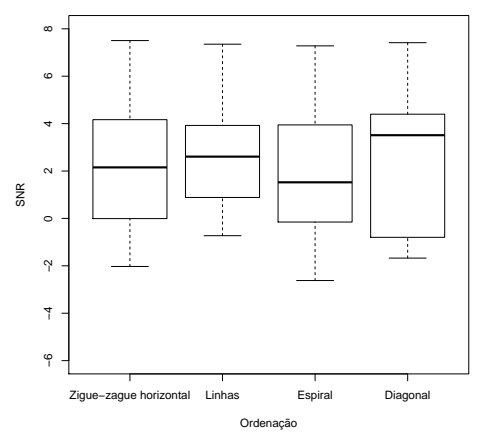

(b) Segunda iteração

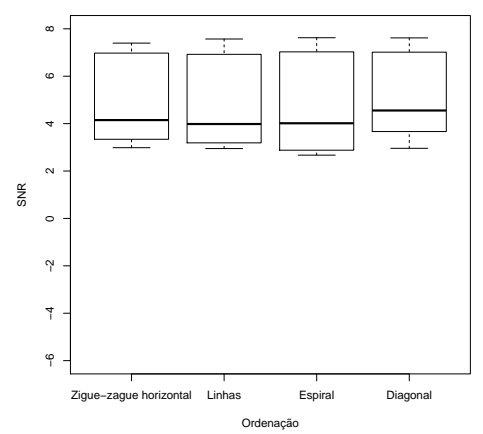

(c) Terceira iteração

Figura 4.38: Razão sinal-ruído das imagens comprimidas após a aplicação do filtro Sobel de acordo com a ordenação de pixels escolhida e o número de iterações.

A figura 4.38 mostra a razão sinal-ruído entre as aplicações do filtro Sobel nas imagens comprimidas de acordo com a ordenação de pixels escolhida e o número de iterações utilizado na codificação. A figura 4.39a mostra a evolução da razão sinal-ruído das imagens após a aplicação do filtro Sobel de acordo com o número de iterações e a imagem para a ordenação em espiral. Por fim, a figura 4.39b mostra a evolução da razão entre a relação sinal-ruído da segunda metodologia descrita e do algoritmo JPEG após a aplicação do filtro Sobel para a ordenação em espiral.

A figura 4.40 mostra a taxa de compressão obtida pela segunda metodologia descrita de acordo com o número de iterações e a ordenação de pixels escolhida. A figura 4.41 mostra um boxplot comparativo das taxas de compressão obtidas com a segunda metodologia descrita e a ordenação dos pixels em espiral e os algoritmos PNG e JPEG.

\subsection{Análise}

As figuras 4.42a, 4.42b, 4.42c e 4.42d mostram a distribuição de valores dos parâmetros das sigmoides geradas na codificação dos cortes axiais das regiões extraídas da imagem de RM do dataset BRAINIX.

\subsection{Desempenho}

Os gráficos 4.43a e 4.43b mostram boxplots dos tempos gastos para comprimir e descomprimir um sinal de ECG com 1048576 amostras usando as técnicas estudadas.

\subsection{Comentários}

Como é possível observar nas figuras 4.1, 4.2, 4.3, 4.4, 4.5, 4.6, 4.7 e 4.8, as metodologias descritas conseguem aproximar bem sinais biomédicos diversos em poucas iterações. Nelas, também é possível notar que diversos pontos extremos são selecionados possivelmente sem necessidade. O fator de tolerância a erro da implementação talvez possa ser utilizado para otimizar a seleção de pontos. Além disso, é possível notar que o sinal, após a reconstrução, apresenta magnitudes menores de frequências mais altas, ou seja, as metodologias descritas suavizam ligeiramente o sinal modelado. 


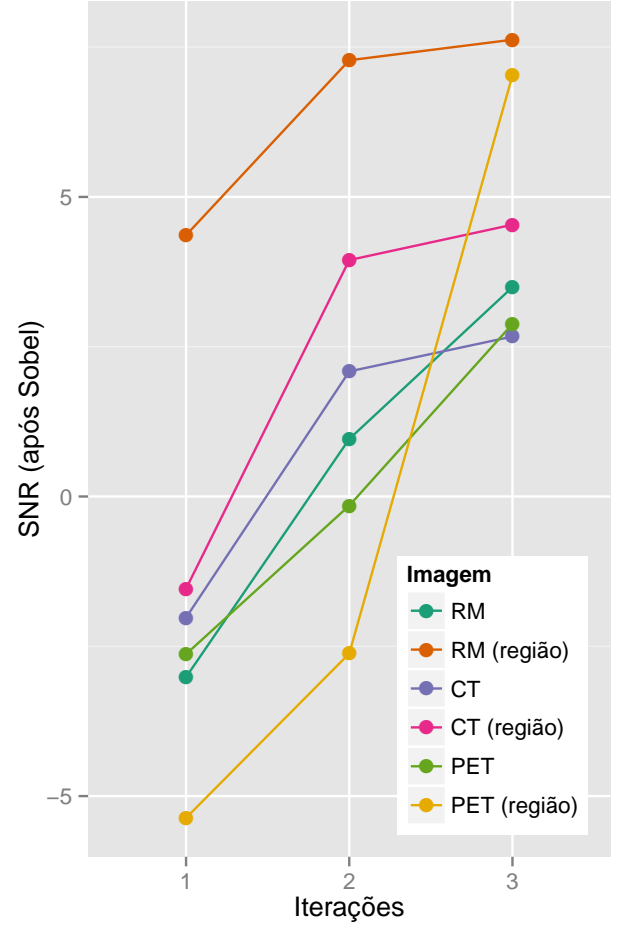

(a) SNR absoluto

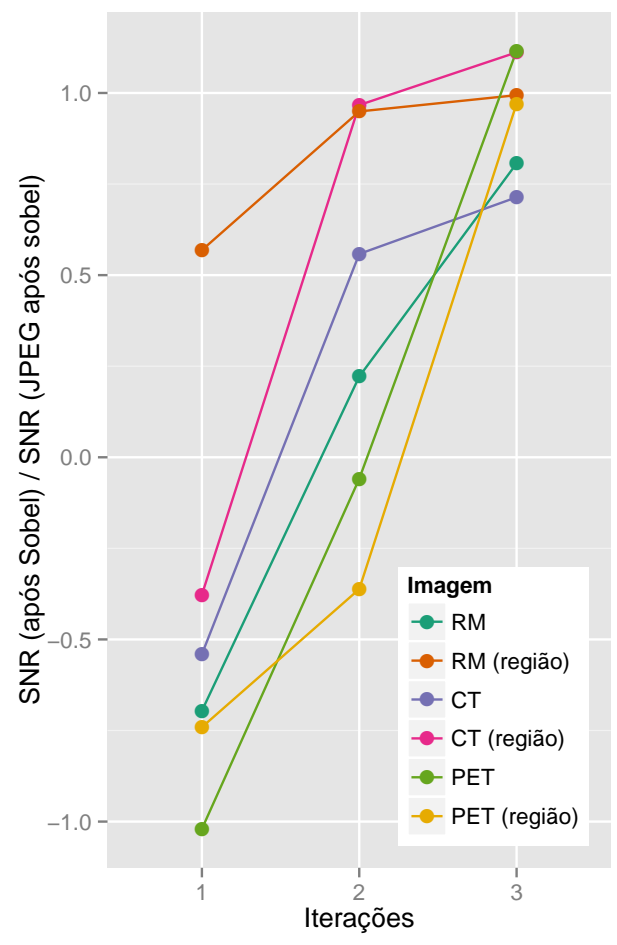

(b) Comparativo com JPEG

Figura 4.39: Evolução da razão sinal-ruído para cada imagem codificada e filtrada com Sobel de acordo com o número de iterações usando a ordenação em espiral.

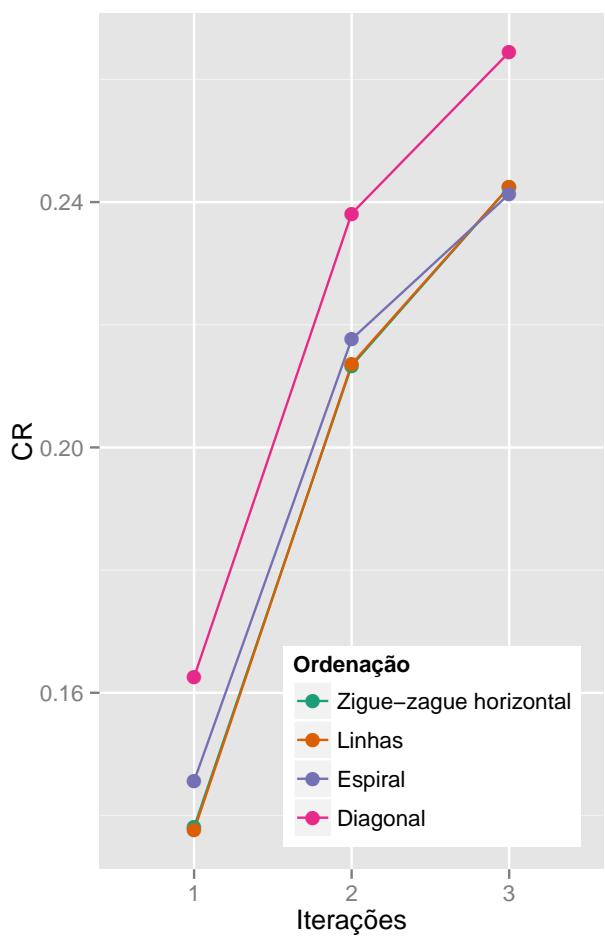

Figura 4.40: Evolução da taxa de compressão obtida de acordo com o número de iterações e a ordenação de pixels escolhida. 


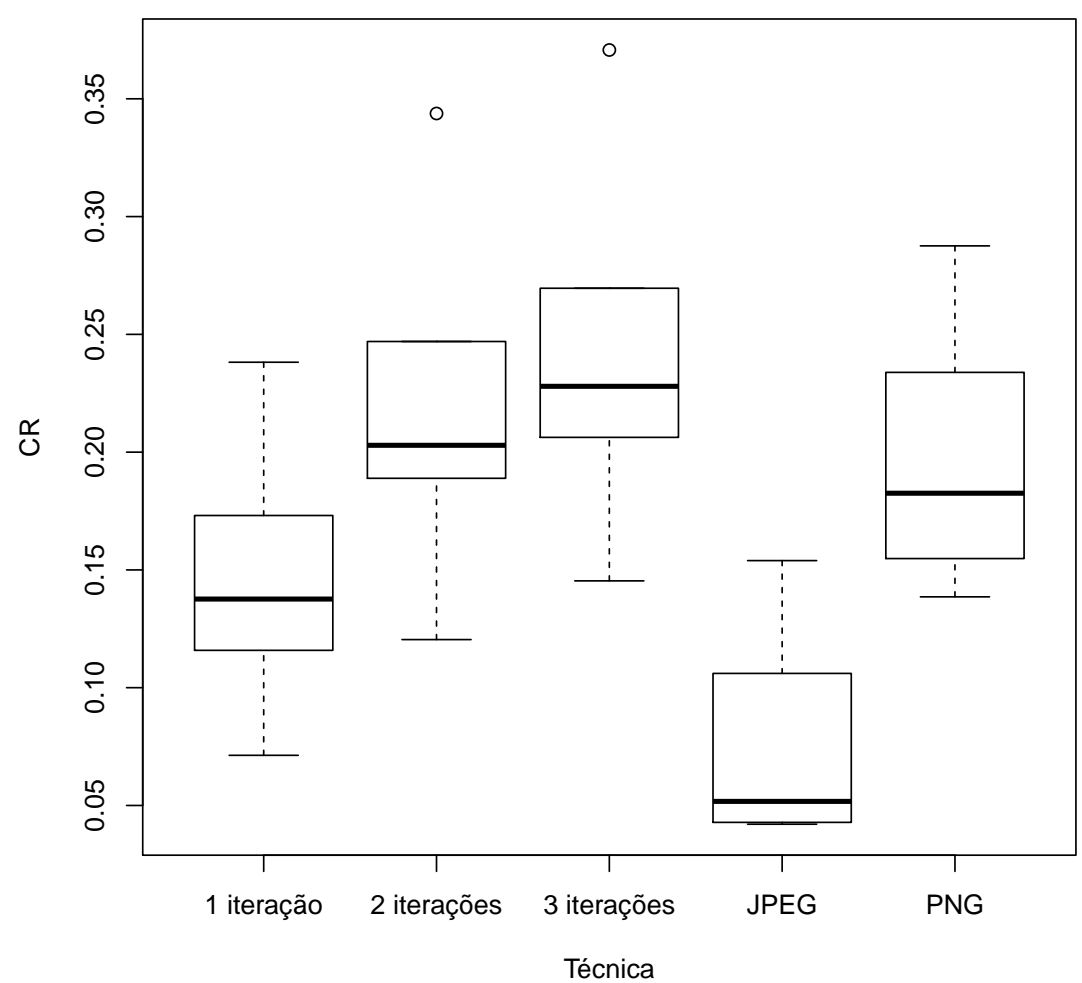

Figura 4.41: Boxplot da taxa de compressão da segunda metodologia descrita com uma, duas e três iterações, usando a ordenação de pixels em espiral, e das taxas de compressão dos algoritmos JPEG e PNG. 


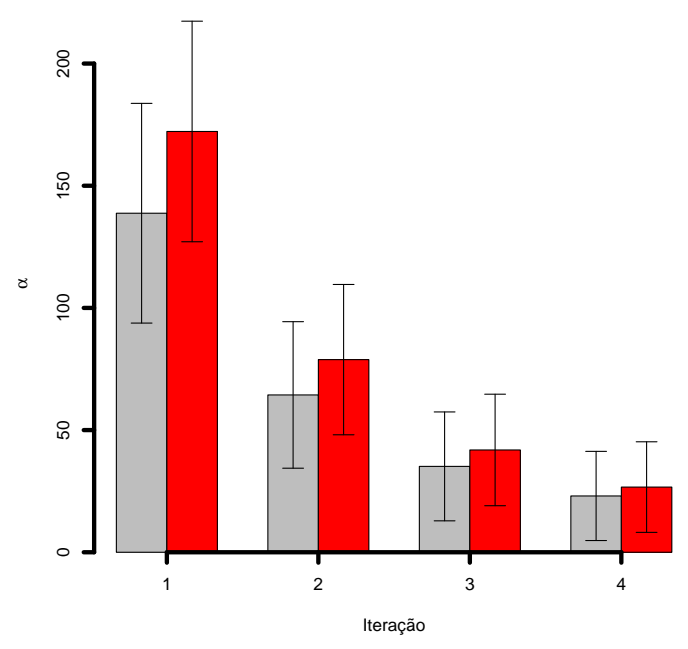

(a) Número de iterações vs. $\alpha$

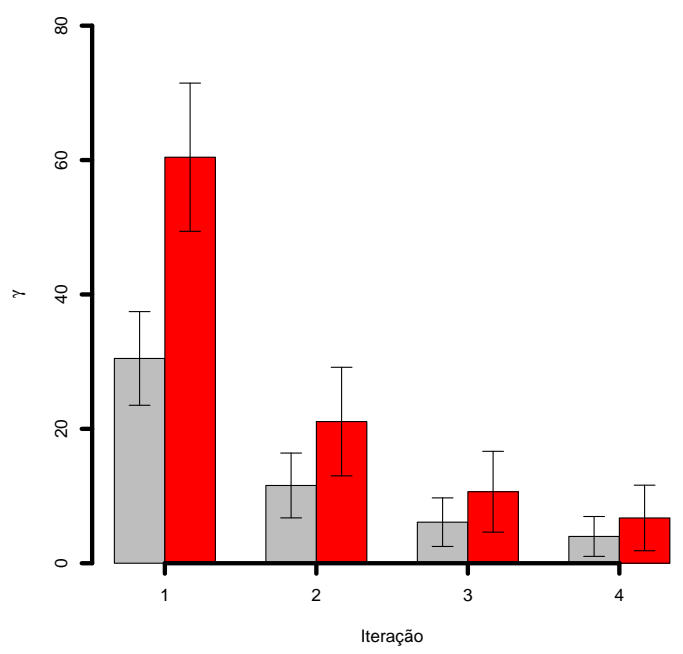

(c) Número de iterações vs. $\gamma$

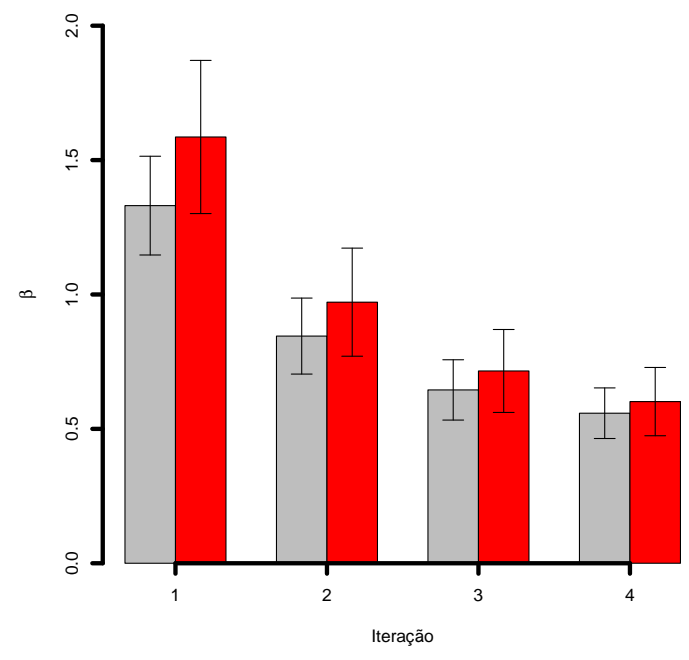

(b) Número de iterações vs. $\beta$

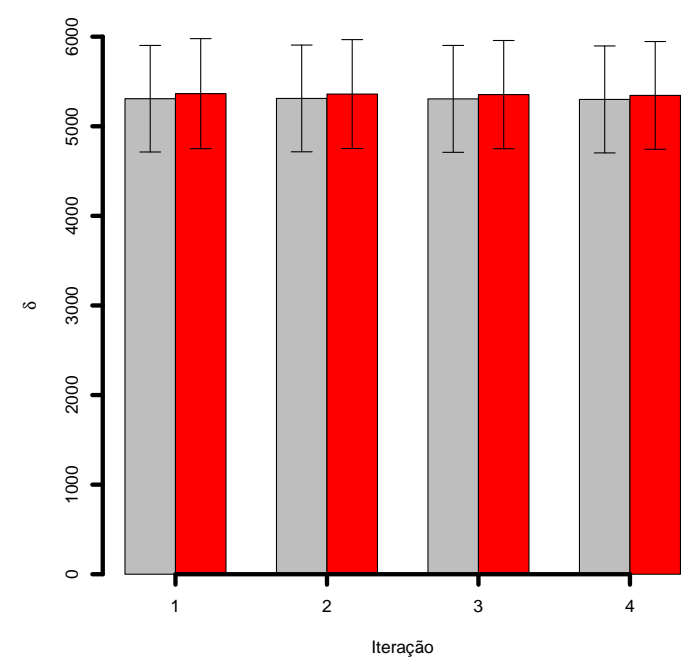

(d) Número de iterações vs. $\delta$

Figura 4.42: Comparativo da distribuição dos parâmetros (média e desvio padrão) para os cortes axiais dos volumes com e sem tumor extraídos do dataset BRAINIX, de acordo com o número de iterações utilizado na codificação da imagem. 


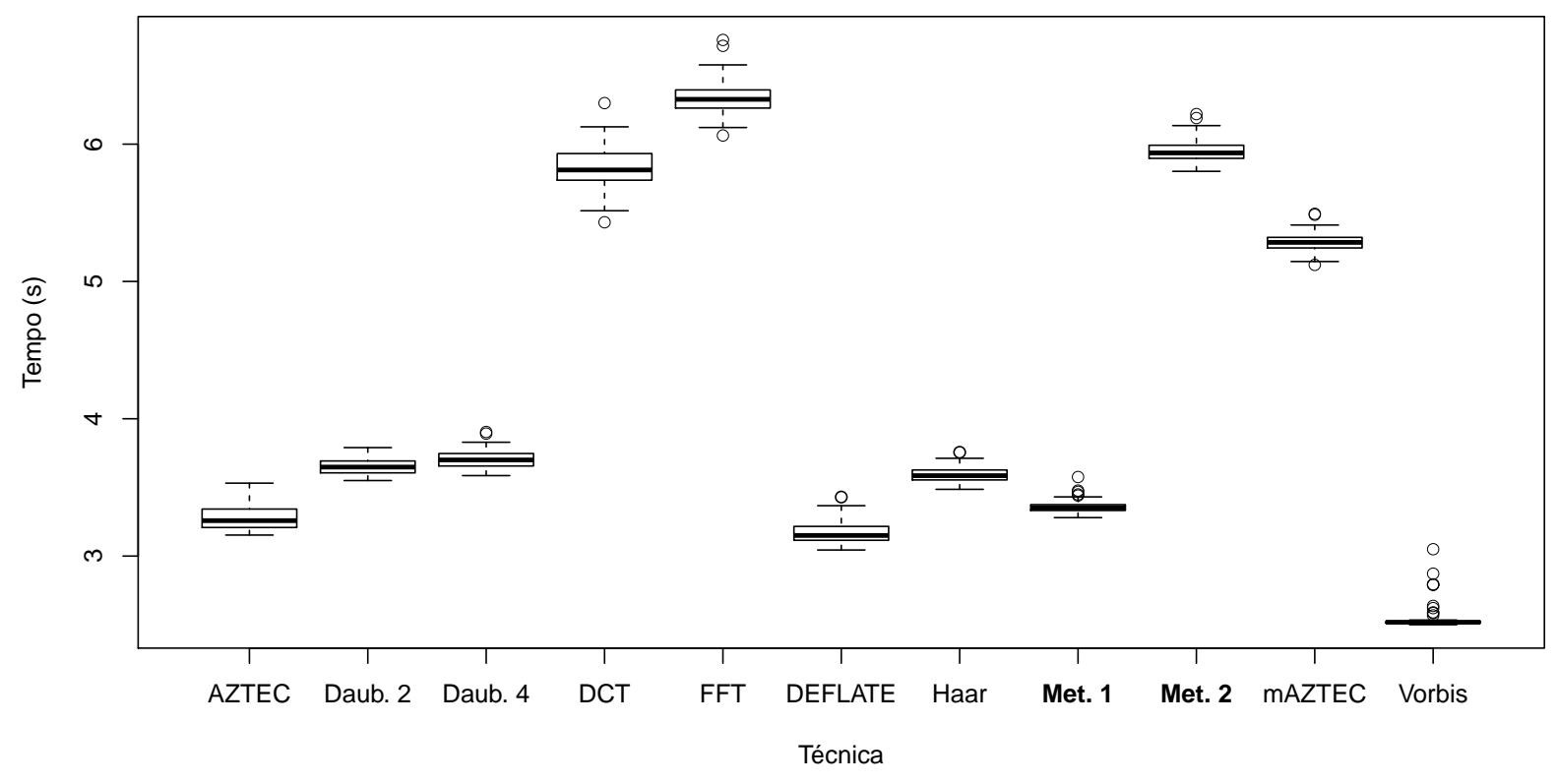

(a) Compressão

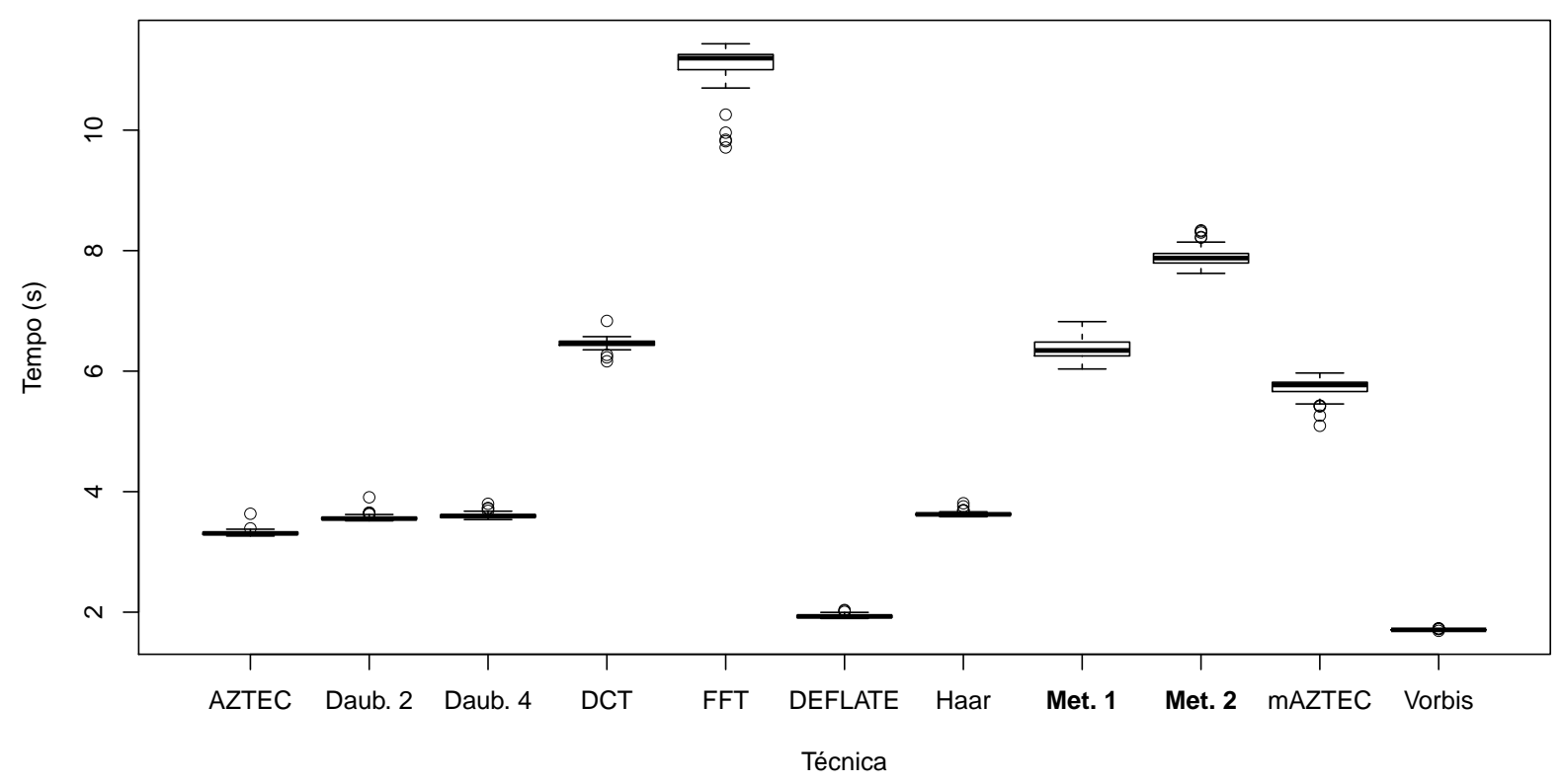

(b) Descompressão

Figura 4.43: Comparativo de desempenho entre as técnicas estudadas. Os tempos são a média de 10 execuções e estão em milissegundos. 
Na figura 4.7, é possível notar artefatos no início do sinal. Também é possível notar que os extremos escolhidos, sobretudo na segunda iteração, estão ligeiramente deslocados com relação ao sinal de erro. Por fim, é possível notar que esses desvios influenciaram no comportamento das frequências do sinal reconstruído, aumentando a magnitude de frequências mais altas. Esse comportamento, aparentemente, está relacionado à codificação dos valores usando os bits menos significativos da representação binária dos valores em ponto flutuante para armazenar a iteração correspondente ao ponto. No entanto, uma investigação mais profunda ainda é necessária.

Na figura 4.9a, é possível notar que a segunda metodologia descrita é, de fato, mais eficiente na compressão de sinais comparada à primeira metodologia descrita. Também é possível notar que a diferença entre as duas metodologias aparentemente aumenta junto com o número de iterações, ou seja, o armazenamento das iterações aparenta ser mais eficiente na segunda metodologia descrita.

Com base na figura 4.10, é possível afirmar que a segunda metodologia descrita, quando usada com apenas uma iteração, apresenta uma taxa de compressão próxima às apresentadas pelas outras técnicas estudadas e melhor do que aquela apresentada pelo algoritmo DEFLATE. Ainda, com base na figura 4.11, é possível concluir que a segunda metodologia descrita não apresenta uma razão de compressão tão boa para sinais de pressão de via aérea mas, por outro lado, apresenta bons resultados na compressão de ECG, pressão venosa central e pressão intraesofágica. Também é possível notar que o algoritmo AZTEC, inicialmente projetado para comprimir sinais de ECG, também apresenta um bom desempenho em compressão para sinais de pressão intraesofágica e pressão venosa central. Por outro lado, o algoritmo mAZTEC, baseado nele, não obteve um bom desempenho se comparado ao AZTEC, e apresentou uma grande variação na taxa de compressão. Por fim, ainda com base nessas figuras, é possível notar que a compressão baseada em wavelets de Haar é bastante eficiente mesmo com um processo de quantização simples, apresentando um desempenho comparável ao obtido pelo algoritmo Vorbis, que apresentou as melhores taxas de compressão.

Analisando as figuras 4.12, 4.13, 4.14 e 4.15, é possível notar que, já na primeira iteração, a primeira metodologia descrita (e consequentemente a segunda, uma vez que os resultados são semelhantes) é capaz de aproximar razoavelmente bem um sinal já na primeira iteração. É possível notar, ainda, que a codificação com wavelets de Daubechies de 4 momentos nulos, com a transformada de cossenos e com a transformada de Fourier aproximam muito bem os sinais de pressão, fluxo e diâmetro mesmo com poucos coeficientes não zerados. No entanto, o mesmo não ocorre para o sinal de ECG, onde é possível observar que a eliminação dos coeficientes correspondentes às altas frequências resultou em perda de informação do complexo QRS do sinal. Ainda no caso do ECG, é possível observar que os algoritmos AZTEC e mAZTEC apresentam um desempenho melhor do que o apresentado para os outros tipos de sinais.

A partir da figura 4.9b, é possível notar que ambas as metodologias descritas apresentam uma razão sinal-ruído aceitável já na primeira iteração. Também é possível notar que, da primeira para a segunda iteração, a segunda metodologia descrita apresenta uma melhoria de qualidade na representação ligeiramente maior do que a primeira metodologia. É possível concluir que o método de aproximar iterativamente o sinal por sigmoides é bastante eficiente, com um ganho de qualidade considerável de uma iteração para outra. Também é possível notar, mais uma vez, que a codificação utilizada na segunda metodologia descrita introduz uma limitação na qualidade da reconstrução do sinal. 
Observando as figuras 4.16, 4.17, 4.18, 4.19, 4.20, 4.21 e 4.22, é possível observar que as metodologias descritas apresentam bons resultados, comparados à maioria das técnicas estudadas, em todos os tipos de sinais utilizados, em particular para sinais pressão de via aérea e ECG. Também é possível notar que as transformadas de cossenos, de Fourier e de wavelets baseadas na wavelet de Daubechies apresentam resultados muito bons para os sinais obtidos de um suíno.

Analisando os gráficos da figura 4.23, é possível observar que a segunda metodologia obtém um resultado comparável aos das técnicas estudadas, apenas com uma distribuição maior da taxa de compressão, tanto para a codificação de uma e duas iterações. É possível notar que o algoritmo mAZTEC apresenta resultados dos mais diversos, desde sinais bem comprimidos com boa qualidade até sinais mal comprimidos e com baixa qualidade; os piores resultados talvez melhorem com uma regulagem dos parâmetros. No algoritmo Vorbis, é possível notar alguns pontos representando taxas de compressão acima de 1.0, correspondentes aos sinais de 256 amostras; excluindo-se estes sinais, o algoritmo apresenta um desempenho bastante consistente. Por fim, as transformadas de cossenos e de Fourier parecem apresentar a melhor relação entre taxa de compressão e SNR.

As figuras 4.24, 4.25, 4.26, 4.27, 4.28 e 4.29 mostram que a segunda metodologia descrita consegue codificar imagens médicas com boa qualidade em apenas duas iterações: as imagens codificadas assim apresentam poucos artefatos visíveis. Nas imagens codificadas com três iterações, não se notam diferenças com a imagem original, bem como naquelas codificadas usando o algoritmo JPEG. No entanto, analisando as figuras 4.32, 4.33, 4.34, 4.35, 4.36 e 4.37, é possível notar que mesmo a codificação com três iterações e o algoritmo JPEG introduzem diferenças que influenciam o filtro Sobel.

Analisando os boxplots das figuras 4.30a, 4.30b e 4.30c, é possível notar que a ordenação dos pixels não influencia muito na qualidade da compressão mas, ainda assim, a ordenação em espiral parece dar resultados ligeiramente melhores enquanto que a ordenação em linhas parece dar resultados ligeiramente piores. Ainda nesses boxplots, é possível notar que essa tendência se mantém ao longo das iterações do algoritmo, e que, já na segunda iteração, o algoritmo apresenta valores de SNR aceitáveis. No entanto, após a aplicação do filtro Sobel, a ordenação em espiral não apresenta resultados tão bons; a ordenação em zigue-zague diagonal parece apresentar os melhores resultados nestas condições, como é possível notar na figura 4.38.

Pela figura 4.31a, é possível notar que a metodologia descrita apresenta melhores resultados na codificação das regiões internas das imagens de CT e RM. É possível notar essa mesma tendência no comparativo com o JPEG mostrado na figura 4.31b, na qual também é possível notar que a metodologia descrita apresenta resultados bem próximos aos obtidos pelo algoritmo JPEG na terceira iteração. No entanto, considerando os resultados após a aplicação do filtro Sobel, é possível notar que a metodologia descrita conseguiu preservar bem as bordas no comparativo com o algoritmo JPEG, como é possível observar na figura 4.39b, porém ambos os resultados divergem bastante do resultado da aplicação do filtro Sobel na imagem original, como é possível concluir com base nesta mesma figura e na figura 4.39a.

De acordo com o gráfico da figura 4.40, pode-se concluir que as ordenações por linhas (em sequência ou zigue-zague) são as mais eficientes para compressão, seguidas de perto pela ordenação em espiral, e que a taxa de compressão não diminui muito ao longo das iterações. Porém, observando os boxplots da figura 4.41, é possível notar que as taxas de compressão obtidas pela metodologia descrita ficam distantes daquelas apresentadas pelo algoritmo JPEG e próximas do algoritmo PNG, 
que comprime sem perdas.

Apesar de não gerar um arquivo de imagem comprimida com um tamanho tão pequeno como o JPEG, a metodologia descrita gera imagens de boa qualidade e ainda parece ser capaz de indicar a presença de um tumor cerebral numa imagem, como é possível concluir analisando os gráficos da figura 4.42. Os valores dos parâmetros $\alpha, \beta$ e, especialmente, $\gamma$ do modelo gerado para a compressão apresentam uma faixa de valores diferentes nas imagens com e sem tumor. Assim, analisando os valores de $\gamma$ na compressão de uma imagem, seria possível classificá-la. As faixas de valores para imagens com e sem tumor tendem a ficar mais próximas quando o número de iterações cresce, mas vale lembrar que é possível filtrar coeficientes de iterações mais avançadas facilmente.

Quanto ao desempenho das metodologias descritas, observando as figuras 4.43a e 4.43b, é possível notar que a primeira metodologia descrita apresenta um desempenho próximo ao das transformadas baseadas em wavelets e do algoritmo AZTEC, mas ainda inferior ao apresentado pelos algoritmos DEFLATE e Vorbis. Na descompressão, o desempenho cai um pouco, ficando próximo daqueles apresentados pela DCT e pela FFT; a segunda metodologia fica próxima dessas transformadas tanto na compressão como na descompressão. 


\section{Capítulo 5}

\section{Conclusão}

Neste trabalho, foram apresentadas uma análise de técnicas de compressão de sinais e duas novas técnicas iterativas, uma derivada da outra, baseadas na aproximação de um sinal por sigmoides. Ambas as técnicas codificam um sinal com perdas, isto é, distorcem o sinal original, porém é possível reduzir o quanto se desejar essa distorção usando mais iterações para modelar o sinal.

Experimentos foram realizados com sinais biomédicos diversos, incluindo sinais ECG, pressão vascular e imagens de ressonância magnética. Estes experimentos demonstram que as técnicas desenvolvidas são capazes de atingir uma taxa de compressão bastante aceitável. Em particular, a segunda metodologia descrita foi capaz de comprimir a taxas comparáveis àquelas obtidas pelas outras técnicas estudadas. Além disso, a qualidade da compressão é bastante aceitável e preserva informações importantes do sinal original, mesmo usando poucas iterações para codificar o sinal.

Para imagens, a taxa de compressão ficou um pouco atrás das apresentadas pelos algoritmos mais popularmente utilizados atualmente. No entanto, vale destacar que a qualidade da imagem comprimida após três iterações fica bem próxima à qualidade das imagens JPEG com 90\% de qualidade, sobretudo quando consideradas apenas as bordas da imagem comprimida. Com esquemas de quantização mais eficientes, a segunda metodologia descrita talvez apresente taxas de compressão ainda melhores.

Os experimentos também demonstram que as metodologias descritas são capazes de fornecer assinaturas que permitem diferenciar imagens representando tecidos saudáveis e com anomalias, uma outra vantagem sobre os métodos de compressão de imagem estudados. Por exemplo, os testes feitos com imagens de ressonância magnética mostram assinaturas diferentes para imagens com e sem tumor. Porém, faz-se necessário realizar mais experimentos com outras imagens e outros tipos de sinais. Além disso, é necessário avaliar o efeito de transformações como rotação, translação e escala nos coeficientes do modelo gerado. Caso essas transformações afetem a distribuição dos coeficientes, torna-se necessário registrar uma imagem para avaliá-la, o que pode ser um impeditivo para a aplicação da metodologia desenvolvida em larga escala.

O desempenho das implementações disponibilizadas juntamente com este trabalho é comparável ao da transformada de Fourier, bastante utilizada em diversas aplicações reais. Contudo, ainda é possível melhorar bastante os resultados com uma implementação mais eficiente e que explore o paralelismo dos processadores atuais.

Nos testes realizados, foram utilizadas codificações 12, 16 e 32 bits para a representação dos sinais modelados, sendo que as duas últimas são baseadas na representação de números de ponto flutuante. No entanto, é comum que um tipo de sinal tenha uma codificação otimizada para ele. Sinais de 
ECG, por exemplo, são comumente codificados usando uma representação de ponto fixo de 12 bits. Assim, para tornar a codificação ainda mais eficiente para compressão, pode ser interessante explorar tais codificações específicas, desenvolvendo formas de armazenar os valores dessas representações e suas respectivas iterações de forma eficiente. Para o caso do sinal de ECG, por exemplo, uma possibilidade é armazenar o número da iteração em 4 bits, logo após o valor de 12 bits do sinal.

Com base nos experimentos realizados, é possível concluir que as metodologias apresentadas têm potencial para serem aplicadas na redução do espaço ocupado por sinais biomédicos e, ao mesmo tempo, na análise e na deteç̧ão de anomalias nesses sinais. 


\section{Referências Bibliográficas}

[AB92] V.A. Allen e J. Belina. ECG data compression using the discrete cosine transform (DCT). Em Proceedings of Computers in Cardiology 1992, páginas 687-690, Durham, EUA, 10 1992. IEEE. 11

[Add05] P. S. Addison. Wavelet transforms and the ECG: a review. Physiological Measurement, 26(5):R155-R199, 2005. 16

[ANR74] N. Ahmed, T. Natarajan e K. R. Rao. Discrete cosine transfom. IEEE Transactions on Computers, 100(1):90-93, 1974. 10

[AT82] J. P. Abenstein e W. J. Tompkins. A new data-reduction algorithm for real-time ECG analysis. IEEE Transactions on Biomedical Engineering, (1):43-48, 1982. 14, 15

[BCNM95] F. Bartolini, V. Cappellini, S. Nerozzi e A. Mecocci. Recurrent neural network predictors for EEG signal compression. Em 1995 International Conference on Acoustics, Speech, and Signal Processing, 1995, volume 5, páginas 3395-3398, Detroit, EUA, 5 1995. IEEE. 18

[BJCO03] Ziv Bar-Joseph e Daniel Cohen-Or. Hierarchical context-based pixel ordering. Computer Graphics Forum, 22(3):349-358, 2003. 34

[BW94] M. Burrows e D. Wheeler. A block sorting lossless data compression algorithm. Relatório técnico, Digital Equipment Corporation, 1994. 6

[CBK09] Varun Chandola, Arindam Banerjee e Vipin Kumar. Anomaly detection: A survey. ACM Comput. Surv., 41(3):15:1-15:58, Julho 2009. 1

[CBLGRV04] J. L. Cárdenas-Barrera, J. V. Lorenzo-Ginori e E. Rodríguez-Valdivia. A waveletpackets based algorithm for EEG signal compression. Informatics for Health and Social Care, 29(1):15-27, 2004. 16

[Chu92] C. K. Chui. An introduction to wavelets. Wavelets analysis and its applications. Academic Press, Londres, Reino Unido, 1992. 35

[CK00] A. E. Cetin e H. Köymen. Compression of digital biomedical signals. Em J. D. Bronzino, editor, The Biomedical Engineering Handbook. CRC Press LLC, Boca Raton, EUA, 2 edição, 2000. 14, 17

[CNFO68] J. R. Cox, F. M. Nolle, H. A. Fozzard e G. C. Oliver. AZTEC, a preprocessing program for real-time ECG rhythm analysis. IEEE Transactions on Biomedical Engineering, (2):128-129, 1968. 13, 14, 15

[Dau92] I. Daubechies. Ten lectures on wavelets. SIAM, Filadélfia, EUA, 1992. 35

[Deu96] P. Deutsch. DEFLATE compressed data format specification version 1.3. RFC 1951, 5 1996. 3, 31, 37 
[Don00] R. D. Dony. Karhunen-Loève transform. Em K. R. Rao e P. Yip, editors, The Transform and Data Compression Handbook. CRC Press LLC, Boca Raton, EUA, 1 edição, 2000. 8, 9

[FP88] B. Furht e A. Perez. An adaptive real-time ECG compression algorithm with variable threshold. IEEE Transactions on Biomedical Engineering, 35(6):489-494, 6 1988. 15

$\left[\mathrm{GAG}^{+} 00\right]$ A. L. Goldberger, L. A. N. Amaral, L. Glass, J. M. Hausdorff, P. C. Ivanov, R. G. Mark, J. E. Mietus, G. B. Moody, C. K. Peng e H. E. Stanley. PhysioBank, PhysioToolkit, and PhysioNet: Components of a new research resource for complex physiologic signals. Circulation, 101(23):e215-e220, 2000. 36

[Gol66] S. W. Golomb. Run-length encodings. IEEE Transactions on Information Theory, 3(12):399-401, 1966. 5

[Gra84] R. Gray. Vector quantization. ASSP Magazine, IEEE, 1(2):4-29, 4 1984. 7

[HM04] J. B. Huber e B. Matschkal. Spherical logarithmic quantization and its application for DPCM. Em 5th International ITG Conference on Source and Channel Coding (SCC): January 14-16, 2004, Erlangen : conference record, ITG-Fachbericht, páginas 349-356. VDE-Verl., Erlangen, Alemanha, 2004. 7

[Huf52] D. A. Huffman. A method for the construction of minimum-redundancy codes. Proceedings of the IRE, 40(9):1098-1101, 1952. 5

[IEE08] IEEE. IEEE standard for floating-point arithmetic. IEEE Std 754-2008, páginas $1-58,8$ 2008. 31, 35

[INS90] A. Iwata, Y. Nagasaka e N. Suzumura. Data compression of the ECG using neural network for digital holter monitor. IEEE Engineering in Medicine and Biology Magazine, 9(3):53-57, 9 1990. 18

[ISO04a] ISO 15444-1. JPEG 2000 image coding system: Core coding system, 2004. 17

[ISO04b] ISO 15948. Portable Network Graphics (PNG): Functional specification, 2004. 3

[ISO06] ISO 12052. Digital imaging and communication in medicine (DICOM) including workflow and data management, 2006. 17

[KKV97] P. K. Kulkarni, V. Kumar e H. K. Verma. Direct data compression techniques for ECG signals: effect of sampling frequency on performance. International Journal of Systems Science, 28(3):217-228, 1997. 10, 13, 21

[KO95] T. Kalayci e O. Ozdamar. Wavelet preprocessing for automated neural network detection of EEG spikes. IEEE Engineering in Medicine and Biology Magazine, 14(2):160-166, 3-4 1995. 18

[KSGS05] V. Kumar, S. C. Saxena, V. K. Giri e D. Singh. Improved modified AZTEC technique for ECG data compression: Effect of length of parabolic filter on reconstructed signal. Computers \&3 Electrical Engineering, 31(4-5):334-344, 2005. 13, 15

[Mal99] S. G. Mallat. A Wavelet Tour of Signal Processing. Academic Press, Londres, Reino Unido, 2 edição, 1999. 9, 12

[MKC99] N. Memon, X. Kong e J. Cinkler. Context-based lossless and near-lossless compression of EEG signals. IEEE Transactions on Information Technology in Biomedicine, 3(3):231-238, 1999. 17, 18 
[MM01] G. B. Moody e R. G. Mark. The impact of the MIT-BIH arrhythmia database. IEEE Engineering in Medicine and Biology Magazine, 20(3):45-50, 2001. 36

$\left[\mathrm{MRF}^{+}\right.$03] C. Mekkaoui, P. H. Rolland, A. Friggi, M. Rasigni e T. G. Mesana. Pressure-flow loops and instantaneous input impedance in the thoracic aorta: Another way to assess the effect of aortic bypass graft implantation on myocardial, brain, and subdiaphragmatic perfusion. J Thorac Cardiovasc Surg, 125(3):699-710, 2003. 37

[MSM87] G. B. Moody, K. Soroushian e R. G. Mark. ECG data compression for tapeless ambulatory monitors. Computers in Cardiology, páginas 467-470, 1987. 13, 14, 34

[NC93] G. Nave e A. Cohen. ECG compression using long-term prediction. IEEE Transactions on Biomedical Engineering, 40(9):877-885, 9 1993. 17, 18

$\left[\mathrm{NKA}^{+}\right.$06] M. Nielsen, E. Kamavuako, M. Andersen, M. F. Lucas e D. Farina. Optimal wavelets for biomedical signal compression. Medical and Biological Engineering and Computing, 44:561-568, 2006. 10.1007/s11517-006-0062-0. 16, 17

[OMGL96] S. Olmos, M. Millan, J. Garcia e P. Laguna. ECG data compression with the Karhunen-Loève transform. Em Computers in Cardiology 1996, páginas 253-256, Indianapolis, EUA, 1996. IEEE. 8, 9

[Pfe03] S. Pfeiffer. The ogg encapsulation format version 0. RFC 3533, 5 2003. 35

[Pos03] Jef Poskanzer. PGM format specification, 2003. 3

[Raj02] B.A. Rajoub. An efficient coding algorithm for the compression of ECG signals using the wavelet transform. IEEE Transactions on Biomedical Engineering, 49(4):355-362, 4 2002. 16,17

[SM98] R. Silipo e C. Marchesi. Artificial neural networks for automatic ECG analysis. IEEE Transactions on Signal Processing, 46(5):1417-1425, 5 1998. 18

[Ste02] K. Sternickel. Automatic pattern recognition in ECG time series. Computer Methods and Programs in Biomedicine, 68(2):109-115, 2002. 19

[Tai93] S. C. Tai. AZTDIS - a two-phase real-time ECG data compressor. Journal of Biomedical Engineering, 15(6):510-515, 1993. 16

[UA96] M. Unser e A. Aldroubi. A review of wavelets in biomedical applications. Proceedings of the IEEE, 84(4):626-638, 4 1996. 16

[VRCP02] A. Vuckovic, V. Radivojevic, A. C. N. Chen e D. Popovic. Automatic recognition of alertness and drowsiness from EEG by an artificial neural network. Medical Engineering $\&$ Physics, 24(5):349-360, 2002. 18

[Wal91] Gregory K. Wallace. The JPEG still picture compression standard. Commun. ACM, 34(4):30-44, 4 1991. 13, 37

[Wel84] T. A. Welch. A technique for high-performance data compression. IEEE Computer, $17(6): 8-19,1984.5$

[WZTX01] Yang Wang, Yi-Sheng Zhu, N. V. Thakor e Yu-Hong Xu. A short-time multifractal approach for arrhythmia detection based on fuzzy neural network. IEEE Transactions on Biomedical Engineering, 48(9):989-995, sept. 2001. 1

[Xip12] Xiph.Org Foundation. Vorbis I specification, 2012. 35

[ZCK00] Y. Zigel, A. Cohen e A. Katz. ECG signal compression using analysis by synthesis coding. IEEE Transactions on Biomedical Engineering, 47(10):1308-1316, 2000. 18 